NATO UNCLASSIFIED

NORTH ATLANTIC TREATY ORGANIZATION

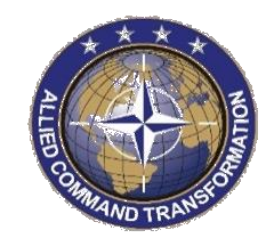

Supreme Allied Commander, Europe B-7010 SHAPE

Supreme Allied Commander, Transformation Belgium

Norfolk, Virginia 23551-2490

United States of America

\title{
$\mathrm{Bi}-\mathrm{SC}$ \\ EDUCATION \\ AND \\ INDIVIDUAL TRAINING \\ DIRECTIVE (E\&ITD) 075-007
}

\section{September 2015}

\section{Instructions for Onward Dissemination}

This Bi-strategic command directive bears the classification 'NATO UNCLASSIFIED'. The holder of the document is authorized to disseminate it further to parties concerned or influenced by the Education and Individual Training (E\&IT) directive if it is considered to be in NATO's interest. However, the document may ONLY be released to Armenia, Austria, Azerbaijan, Belarus, Bosnia and Herzegovina, Finland, Georgia, Ireland, Kazakhstan, Kyrghyz Republic, Malta, Moldova, Montenegro, Serbia, Sweden, Switzerland, Tajikistan, The former Yugoslav Republic of Macedonia, Turkmenistan, Ukraine, Uzbekistan, and members of $\mathrm{MD}$, members of $\mathrm{ICI}$, members of PatG and EU. This document may NOT be released to the general public, to include posting it on a publically-accessible website, without written permission. 
NATO UNCLASSIFIED

This page is intentionally left blank. 


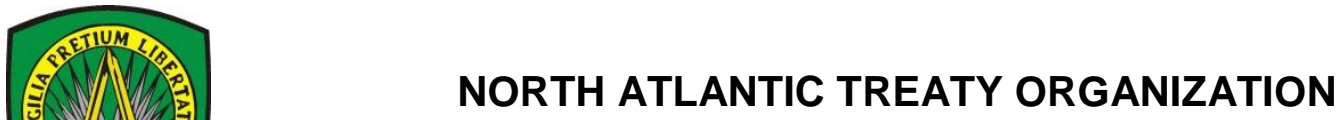

NORTH ATLANTIC TREATY ORGANIZATION

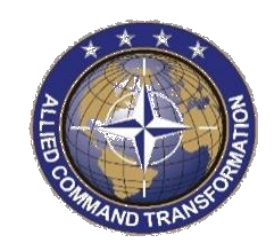

Supreme Allied Commander, Europe B-7010 SHAPE Belgium
Supreme Allied Commander, Transformation Norfolk, Virginia 23551-2490 United States of America

$\begin{array}{llll}\text { SHAPE: } & \text { SH/PLANS/J7/PLL/JC/15-309689/1 } & \text { Tel: } & +32-(0) 65-44-3736 \text { (SHAPE) } \\ \text { HQ SACT: } & \text { 5000/TPX-0210/TT-150592/Ser: NU0058 } & \text { Tel: } & +1-(757)-747-3602 \text { (HQ SACT) } \\ & & \text { Fax: } & +32-(0) 65-44-3545 \text { (SHAPE) } \\ \text { Date: } & 10 \text { September } 2015 & \text { Fax: } & +1-(757)-747-3242 \text { (HQ SACT) }\end{array}$

\section{BI-STRATEGIC COMMAND DIRECTIVE 075-007}

\section{EDUCATION AND INDIVIDUAL TRAINING DIRECTIVE}

REFERENCES: A. MC 0458/3 (Final), NATO Education, Training, Exercise and Evaluation (ETEE) Policy, dated 03 September 2014.

B. SHJ7/TTX/PF-206310, Bi-SCD 75-7, NATO Education and Individual Training Directive, dated 27 May 2009.

C. $\quad 5000 / T S C$ TPX 0140/Ser: NU0450, Amendments to Bi SC Dir 75-2 and Dir 75-7, dated 29 July 2010.

D. 5000/TSC TXX 0040/Ser: NU0225, Alignment of NATO's Education and Training with International Educational Standards, dated 03 May 2012.

E. 5000/TSC TPX0310/Ser: NU0427, NATO Education and Individual Training Directive, dated 13 September 2012.

F. SACT 5000/TPX0310/Ser: NU0119, Education and Individual Training Direction and Guidance No 1, dated 08 March 2012.

G. $\quad$ 5000/TCS 0150/TT-10234/Ser: NU, Education and Training Programme Management - Courses Accreditation - Direction and Guidance No 2, dated January 2014 (DRAFT).

1. Status. This directive is produced in response to Reference A and supersedes BiStrategic Command Directive 075-007, dated 27 May 2009 (Reference B). This directive also replaces other draft versions released as interim measures and the related direction and guidance provided within References C to G.

2. Purpose. This directive details the responsibilities, planning and procedures supporting the definition, delivery and related management of NATO E\&IT.

3. Applicability. This directive is applicable to all Education and Training Facilities (ETFs) operated by, and all E\&IT activities conducted by, NATO, Allied and partner nations supporting the preparation of the NCS, the NFS and individuals assigned to current and future NATO-led operations, including the NATO Response Force (NRF), to meet the NATO LOA. 
Bi-SCD 075-007

\section{NATO UNCLASSIFIED}

4. Publication Updates. Updates will be approved by COS SHAPE and COS HQ SACT.

5. Proponent. The lead proponent for this directive is HQ SACT, DCOS Joint Force Trainer.

FOR THE SUPREME ALLIED COMMANDERS, EUROPE AND TRANSFORMATION:
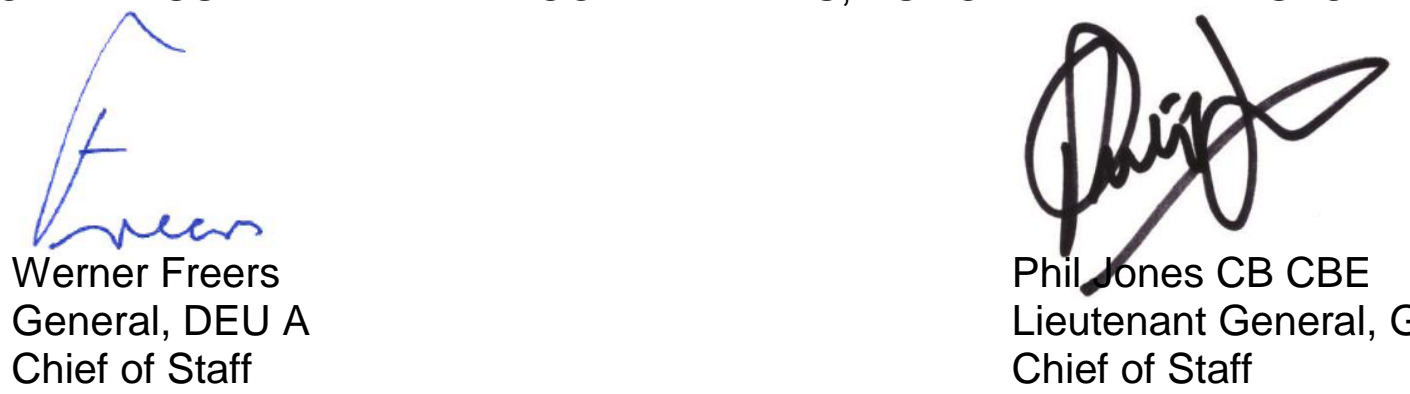

Lieutenant General, GBR A

Chief of Staff

DISTRIBUTION:

External -

Action:

List VIII NATO Accredited Centres of Excellence

List IX Partnership Training and Education Centres

List X NATO Command Structure - Operational Structure

List XI NATO Education and Training Facilities

Information:

List III National Liaison Representatives/others

List V PFP Staff Element

List VI PFP National Liaison Representatives

List VII NATO Agencies

List XV NATO HQ

Internal -

Action:

List II ACT Commands/Other Agencies

List XII Other Entities

Information:

List I HQ SACT Staff 
Bi-SCD 075-007

\section{NATO UNCLASSIFIED}

\section{RECOMMENDATIONS FOR CHANGES TO THE BI-SCD 075-007 EDUCATION AND INDIVIDUAL TRAINING DIRECTIVE (E\&ITD)}

The comment format below is used to record and report any recommendations/changes to this E\&ITD. Users are requested to submit recommendations/comments to the appropriate POC: ACO users to SHAPE J7 and all other users to HQ SACT/JFT.

(Enter HQs/Office/Name/Contact details)

Comments Provided by:

Date:

\begin{tabular}{|c|c|l|l|l|}
\hline Serial & $\begin{array}{c}\text { Chapter/ } \\
\text { Annex }\end{array}$ & Para & Comment & Rationale \\
\hline 001 & & & & \\
\hline 002 & & & & \\
\hline 003 & & & & \\
\hline 004 & & & & \\
\hline 005 & & & & \\
\hline 006 & & & & \\
\hline 007 & & & & \\
\hline 008 & & & & \\
\hline 009 & & & & \\
\hline 010 & & & & \\
\hline 011 & & & & \\
\hline 012 & & & & \\
\hline
\end{tabular}


Bi-SCD 075-007

NATO UNCLASSIFIED

Record of Changes and Updates

\begin{tabular}{|l|l|l|l|l|}
\hline Date & $\begin{array}{c}\text { Chapter/ } \\
\text { Annex }\end{array}$ & Para & \multicolumn{1}{|c|}{ Change } & Remarks \\
\hline & & & & \\
\hline & & & & \\
\hline & & & & \\
\hline & & & & \\
\hline & & & & \\
\hline & & & & \\
\hline & & & & \\
\hline & & & & \\
\hline & & & & \\
\hline & & & & \\
\hline
\end{tabular}


Bi-SCD 075-007

\section{TABLE OF CONTENTS}

Background

Policy Foundation

Aim

Scope

Application

Global Programming.

Disciplines

Governance

Requirements

NATO Training Management System

Certification of Courses

Funding and Ressources

NATO-Provided Course

Education and Individual Training with Partners and NNEs

Introduction

Quality Management System

Continuous Improvement Process

Responsbilities in Quality Management

Institutional Accreditation

Institutional Accreditation Process

Monitoring and Informing

Institutional Re-accreditation

Accreditation of Commercial Entities 22

Third Party Accreditation and Credit Recognition 22

SACT Recognition 
Introduction

Situating the Systems Approach to Training 25

Applying the Systems Approach to Training 26

Roles and Responsbilities within the Systems Approach to Training 27

Support to Current Operations - Rapid Analysis and Design 29

Education, Individual Training and the Systems Approach to Training $\quad 30$

CHAPTER 5 - SAT: ANALYSIS PHASE 31

Introduction 31

Step 1: Establish a TNA WG 33

Step 2: Analyse Tasks 34

Step 3: Write Performance Objectives 36

Step 4: Refine Target Audience $\quad 37$

Step 5: Formulate Guidance $\quad 37$

Step 6: Document the Results 40

CHAPTER 6 - SAT: DESIGN PHASE $\quad 41$

Introduction $\quad 42$

Step 7: Define Learner Characteristics 42

Step 8: Conduct Instructional Analysis $\quad 42$

Step 9: Write Enabling/Learning Objectives 44

Step 10: Prepare an Assessment Plan 47

Step 11: Define Instructional Strategies $\quad 48$

Step 12: Specify Content and Guidance $\quad 50$

CHAPTER 7 - SAT: DEVELOPMENT PHASE 52

Introduction $\quad 52$

Procure/Produce Instructional Materials $\quad 53$

Procure/Produce Assessment Instruments 53

Develop an Optimum Schedule/Timetable 55

Prepare Instructional Staff/Faculty 56

Conduct Trials $\quad 57$ 
Bi-SCD 075-007

Introduction

Integrate an E\&IT Solution

Conduct of E\&IT

Introduction 65

Conduct Post Course Review $\quad 65$

Conduct Institutional Review $\quad 70$

\section{ANNEXES}

A. Abbreviations.

B. Glossary.

C. Additional Support to NATO E\&IT: NATO School Oberammergau Course List.

D. Quality Management System Standards.

E. NATO Quality Standards.

F. NATO System Approach to Training.

G. Performance Proficiency Levels and Key Words.

H. Task Statement Tracking Matrix.

I. Task Analysis.

J. Performance Objectives.

K. Course Control Document - I: Control Form.

L. Course Control Document - II: Course Proposal.

M. Learning Domains.

N. Enabling/Learning Objective - Example.

O. Depth of Knowledge - Performance Proficiency Matrix.

P. Methods of Instruction.

Q. Method Selection Matrix.

R. Course Control Document - III: Programme of Classes.

S. Course Monitoring.

T. Test Item Analysis. 


\section{CHAPTER 1 - INTRODUCTION}

\section{BACKGROUND}

1-1. NATO Education and Training (E\&T) activities are core functions for preparing the NATO Command Structure (NCS) and NATO Force Structure (NFS) for current and future missions in accordance with the Alliance's level of ambition (LOA) ${ }^{1}$. NATO conducts E\&T to ensure headquarters and forces are ready, effective and interoperable. NATO E\&T also strengthens relations with Partner nations and non-NATO entities (NNEs) ${ }^{2}$ and this fortifies cooperative security. NATO E\&T activities provide a visible deterrence and can be an effective assurance measure. NATO E\&T ultimately demonstrates the strength and resolve of the Alliance.

1-2. Within NATO, preparing individuals, headquarters and forces is a continuum with the responsibilities shared between the alliance and each nation. The preparation of the individual contributes directly to collective effectiveness. Within NATO there is a holistic approach to E\&T and this is illustrated in the NATO Training Spectrum, Figure 1-1. The individual focus within the NATO Training Spectrum consists of two elements ${ }^{3}$ :

a. Education.

b. Individual Training.

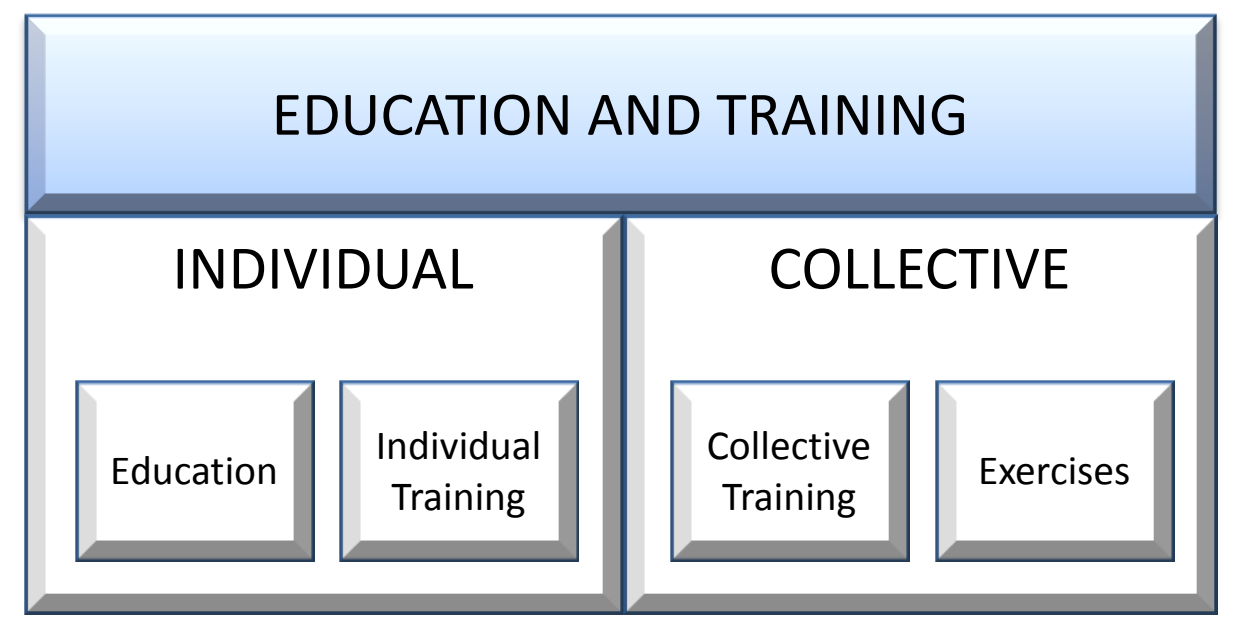

Figure 1-1 NATO Training Spectrum

1-3. Together, Education and Individual Training (E\&IT) within NATO is comprised of the activities that develop the skills, knowledge and other attributes required in the performance of

\footnotetext{
${ }^{1}$ As per MC 0458/3 (para 23), nations are responsible for the education and training of their personnel and forces allocated to NATO. The use of common funding for E\&IT is addressed further beginning in Chapter 2, para 2-11. ${ }_{2}$ As defined in MC 0458/3 (footnote 3), NNE includes International Organizations (IO), Governmental Organizations (GO) of non-NATO nations, Non-Governmental Organizations (NGO), Non-NATO Multinational forces, Host Nations (when the Host Nation is not a NATO nation), Contractors on operations, exercises and transformational activities as well as Non-NATO countries that do not meet the definition for "NATO partner".

${ }^{3}$ The terms "Education" and "Individual Training" were defined within MC 0458/3. A glossary is provided in Annex B.
} 
assigned duties and upon which information can be correctly interpreted and sound judgement applied $^{4,5}$.

\title{
POLICY FOUNDATION
}

1-4. The Military Committee (MC) establishes the policy framework which governs NATO E\&T. The Bi-Strategic Commands (Bi-SCs) subsequently interpret the policy and produce unified direction. The hierarchy of the E\&T policy and directives within NATO which have influenced this directive are illustrated in Figure 1-2.

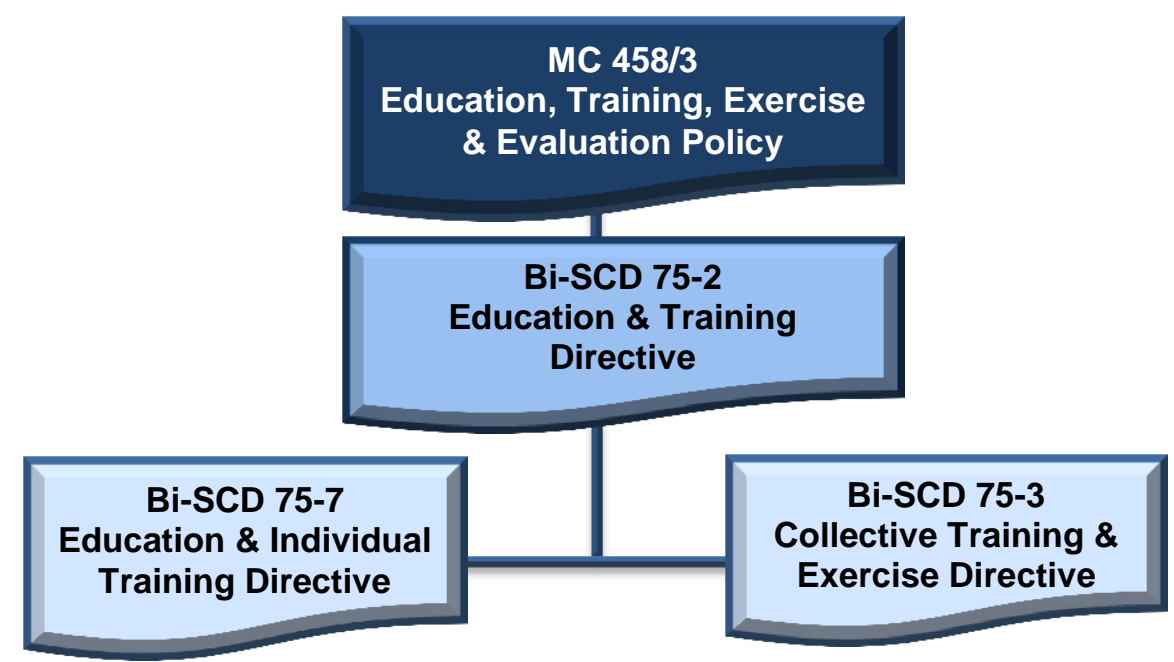

Figure 1-2 NATO's E\&T Policy and Directives

\begin{abstract}
AIM
1-5. The aim of this directive is to define the processes and products supporting NATO E\&IT and situate this within NATO Global Programming as described in MC 0458/3.
\end{abstract}

\section{SCOPE}

1-6. This directive details the processes and products supporting the development, implementation, maintenance and overall management of NATO E\&IT solutions ${ }^{6}$.

\section{APPLICATION}

1-7. This directive is applicable to all Education and Training Facilities (ETFs) operated by, and all E\&IT activities conducted by, NATO, Allied and partner nations supporting the preparation of the NCS, the NFS and individuals assigned to current and future NATO-led operations, including the NATO Response Force (NRF), to meet the NATO LOA ${ }^{7}$. ETFs primarily include NATO Education and Training Facilities (NETFs) and applicable NATOAccredited Centres of Excellence (COEs) as well as recognized Partnership Training and

\footnotetext{
${ }^{4}$ NATO Glossary of Individual Training and Education Terms (Version 7), NATO Training Group - Task Group on Individual Training \& Education Task Group, October 2013.

${ }^{5}$ Within Chapter 4, beginning in para 4-15, the rationale for combining E\&IT and the related delineation of responsibilities between the alliance and each nation is explained.

${ }^{6}$ To support the complete implementation of Global Programming and this directive, several courses have been developed and details are provided in Annex C.

${ }^{7}$ The ETF scope is defined in MC 0458/3 para 7. ETFs are controlled by, or otherwise report to, NATO, a NATO nation, a NATO recognized partner nation or any combination thereof.
} 
Education Centres (PTECs). In addition, and as necessary, ETFs may also include Multinational/National Training Institutions (NTIs) from NATO nations and other education and training facilities from partner nations and NNEs that are in compliance with NATO procedures and standards, and serve as complementary assets that also offer direct support to NATO through the delivery of NATO recognized E\&IT solutions. ${ }^{8}$

${ }^{8}$ MC 0458/3 (Annex B) provides a list of NETFs, NATO Accredited COEs and recognized PTECs; however, HQ SACT/ Joint Force Trainer maintains the most current list of ETFs supporting NATO E\&T. 


\section{CHAPTER 2 - EDUCATION \& INDIVIDUAL TRAINING MANAGEMENT}

\section{GLOBAL PROGRAMMING}

2-1. NATO E\&IT is managed through Global Programming. The aim of Global Programming, as it relates to E\&IT, is to ensure the right E\&IT is provided to the right personnel at the right time and in the right location in the most economical manner possible.

\section{DISCIPLINES}

2-2. Global Programming relies upon disciplines to categorize, capture and manage the requirements that become the basis for E\&T solutions. A discipline is a NATO approved body of knowledge and skills that outlines an existing or evolving E\&T requirement. The NATO discipline structure is relatively stable while the requirements captured within the individual disciplines evolve and change over time to meet NATO's political and military needs. The list of disciplines is approved annually by the MC.

\section{GOVERNANCE}

2-3. HQ SACT, through the Joint Force Trainer (JFT), manages Global Programming and the associated discipline structure. For each discipline there will be a Requirement Authority (RA) and a Department Head (DH) supporting the centralized coordination and decentralized execution of related activities. This governance structure is detailed in MC 0458/3 and the RA/DH roles are summarized within Annex B. NATO will rely on a variety of ETFs, as specified in para 1-7, to provide NATO E\&IT solutions. Control of these organizations rests with different authorities, but the responsibility for seeking a NATO-unified effort is HQ SACT.

\section{REQUIREMENTS}

2-4. NATO E\&IT solutions are determined through a requirements-driven approach. The following determine an E\&IT requirement:

a. Performance Requirements. Performance requirements are used to define what an individual will be prepared to do and to what level. An individual NATO-specific performance requirement is the expression of the gap between an individual working in a NATO environment and an individual educated and trained to work in a similar national environment. Performance requirements are derived from the tasks performed by individuals as part of their principle duties during operations or while occupying specific NFS/NCS positions. NATO Job Descriptions (JDs) generally capture performance requirements and this contributes to defining E\&IT solutions. Performance requirements may also stem from SACEUR's Annual Guidance on Education, Training, Exercise and Evaluation (SAGE). Training Needs Analysis (TNA) within the Global Programming - Development Methodology converts NATO performance requirements, which are consolidated within a Training Requirements Analysis (TRA) Report, into E\&IT solutions. The detailed procedural guidance to support this activity is provided in Chapters 5 through 9 of this directive.

b. Production Requirements. A Production Requirement concerns quantity, it is the number of personnel to be trained to meet specific performance requirements within a defined time period. Production requirements are essential to determine the priority of effort as well as the timeframe and location for conducting E\&IT. The Individual Training and Education Programme (ITEP) consists of planning and coordination forums as well 
as a Training Management Support system, the electronic-ITEP (e-ITEP), to manage production requirements as part of the Global Programming - Production Planning Process. The ITEP also provides tools to ensure E\&IT solutions are in place to address the NATO E\&IT requirements that have been identified across the whole NATO discipline structure.

\section{NATO Training Management System}

2-5. The e-ITEP is a web-based platform that provides the E\&IT component of NATO's Training Management System ${ }^{9}$. The e-ITEP is primarily intended to support E\&IT production management. The e-ITEP is constructed to manage in-year production, project future year E\&IT production requirements and also provide trend analysis data based on activity from previous years. The e-ITEP shares data with NATO's Automated Personnel Management System (APMS). The intent for the e-ITEP is to capture NATO's E\&IT production requirements, through the APMS links, and compare this with E\&IT opportunities scheduled within the e-ITEP. The result is that the e-ITEP can project and match the demand for E\&IT with the available solutions. The e-ITEP production plan is premised on valid and reliable NATO Peacetime Establishment/Crisis Establishment (PE/CE) management data and this is enabled through the APMS ${ }^{10}$. The e-ITEP also includes broader functionality to support the management of NATO E\&IT, including:

a. Education and Training Opportunity Catalogue (ETOC). The ETOC is NATO's E\&IT solution management system; it is a repository of course information including the essential documents that support NATO certified courses. The ETOC is the system which permits courses offered to NATO to be aligned with a discipline and subsequently certified. The ETOC is an open system which permits ETFs covered within the scope of this directive to offer their courses to ETOC users, providing insight into available opportunities.

b. Individual Training Plan (ITP). The e-ITEP supports an ITP by aligning E\&IT solutions with associated JDs through PE/CE position numbers. Within the e-ITEP, individuals enter their NATO position number and the ITP will generate the essential and desirable qualifications for the associated billet/post.

c. Advanced Distributed Learning (ADL). The e-ITEP contains a Learning Management System (LMS) to support the delivery e-Learning courses. The system is integrated with the courses identified in the ITP.

d. Course Schedules. Leveraging the information entered into the ETOC, details of planned courses can be reviewed.

\footnotetext{
${ }^{9}$ The e-ITEP is accessible at: https://e-itep.act.nato.int. Technical support is available at: eitephelp@act.nato.int.

${ }^{10}$ The NATO Defence Manpower Committee oversees the APMS. The APMS pulls course data from e-ITEP. The e-ITEP relies on individuals to use the APMS to select courses and update PE/CE JDs. The JDs provide the e-ITEP with the overall notional demand for NATO courses.
} 


\section{CERTIFICATION OF COURSES ${ }^{11}$}

2-6. Courses uploaded into the ETOC by ETFs are eligible for NATO certification. The certification of courses by NATO is dependent on HQ SACT/JFT institutional accreditation and the alignment of a course with NATO's E\&IT requirements. HQ SACT/JFT assigns the course certification category and relies upon the advice of a DH to determine if a proposed course is a match with NATO E\&IT requirements ${ }^{12}$. The $\mathrm{DH}$ assessment is essential to categorizing courses and is used, in part, to determine if a proposed E\&IT solution is eligible for common funding as a NATO-provided course.

2-7. There are three categories of course certification:

a. $\quad$ Approved. The proposed course meets a NATO E\&IT requirement and the ETF providing the solution is an institution accredited by HQ SACT/JFT.

b. Selected. The proposed course meets a NATO E\&IT requirement; however, the ETF providing the solution is not institutionally accredited by HQ SACT/JFT.

c. Listed. The proposed course does not necessarily align with a NATO E\&IT requirement ${ }^{13}$.

2-8. The approved, selected and listed courses are published within the ETOC. Exceptions to the certification of courses are administered and adjudicated by DCOS JFT based on the best interests of NATO.

2-9. Course certification is a continuous process. Courses are initially assessed during a TRA to determine whether their content aligns, and potentially satisfies, a NATO E\&IT performance requirement. The results of the TRA are captured in the TRA report. Courses may also be reviewed following TRA activity and an update is provided during the proceedings of an Annual Discipline Conference (ADC). Courses will be assessed using appropriate control documents which have been uploaded within the ETOC and contain the required course information ${ }^{14}$. Approved and Selected courses must remain responsive to NATO E\&IT requirements and the Course Control Documents (CCDs) must also remain accessible in the NATO ETOC. Approved and Selected courses are reviewed during the ADC to confirm their continued relevance. The results of the reviews are captured within a Discipline Alignment Plan (DAP).

2-10. Course certification is awarded based on an E\&IT solution being delivered by a specific ETF. The certification of a course is not transferable between institutions unless endorsed by the DH and the ETFs involved are unconditionally accredited by HQ SACT/JFT.

\footnotetext{
${ }_{11}^{11} \mathrm{HQ} \mathrm{SACT}$ is responsible for the content and certification of courses as per MC 0458/3, para $25 \mathrm{a}$. vii.

12 The DH is expected to use the documentation produced during the TNA to assess the fit between a NATO E\&IT requirement and the proposed E\&IT solution and thereby avoid visits to individual ETFs. Visits to ETFs that are institutionally accredited by HQ SACT should only occur in exceptional circumstances. Engagement and coordination with HQ SACT is required for visits to ETFs outside the DHs command and control when the visit involves assessing the solution/requirement fit or other similar quality assurance activity.

${ }^{13}$ Listed courses may meet national E\&IT requirements and often support broader capacity building objectives.

${ }^{14}$ Chapters 5 and 6 identify the detailed course information required in order to assess the alignment between a proposed/existing E\&IT solution (a course) and a NATO E\&IT requirement. Technical support is available at: eitephelp@act.nato.int.
} 


\section{FUNDING AND RESOURCES}

2-11. Overarching Principles. The NATO Resource Policy and Planning Board (RPPB) provides direction which impacts how common funding may be used to support NATO E\&IT activities and this includes funding for NATO-provided courses. The following overarching principles guide RPPB decision making concerning the use of common funding for E\&IT ${ }^{15}$ :

a. "Over \& Above". NATO common funding eligibility will focus on the fulfilment of requirements which are over and above those which can reasonably be expected to be made available from national resources ${ }^{16}$.

b. Separate requirements from resourcing. There is a need to maintain a clear separation between requirement identification, eligibility, and affordability. Resourcing should not limit the identification and definition of new requirements. Where there is a genuine need, E\&IT solutions will be sought.

c. Justification of military requirements in line with Alliance objectives and priorities. For E\&IT, a clear link must be established which connects E\&IT requirements with NATO objectives and priorities ${ }^{17}$.

d. Each nation is responsible for filling military posts that it has accepted with fully qualified and trained personnel who meet the requirements detailed within the NATO JDs. Consequently, nations agree that the training related to essential qualifications detailed in the JD should be nationally funded.

e. NATO-specific E\&IT required by military personnel provided to NATO bodies is a NATO responsibility. NATO common funding will provided funds to cover such training costs for military and civilian personnel. This can include investment requirements from the NATO Security Investment Programme (NSIP), generally for facilities and equipment identified as a military requirement in a capability package.

2-12. Course Fees and Exceptions. With only a few exceptions, the institutions supporting NATO E\&IT are largely customer-funded and further resourced through established recurring national and multinational funding contributions ${ }^{18,19}$. In the area of E\&IT, ETFs may rely on course fees provided by the requesting/sponsoring organization to resource the design, development, delivery and maintenance of existing E\&IT solutions. Exceptions may be made in support of NATO Partnership programmes and to address immediate operational requirements (IOR), in particular E\&IT for pre-deployment and in-theatre needs.

\footnotetext{
${ }^{15}$ Reference: PO(2014)0805. Education, Training, Exercises and Evaluation Overarching Policy for NATO Common Funding, dated 15 December 2014. NOTE: Resource Policy and Planning Board direction is subject to periodic revision.

${ }^{16}$ As per reference at footnote 15: NATO-specific E\&IT required by military personnel provided to NATO bodies is a NATO responsibility.

${ }_{17}$ The link between E\&T requirements and the objectives and priorities of the Alliance are established through a North Atlantic Council (NAC) approved Strategic Training Plan (STP).

${ }^{18}$ NATO Defence College has an allocation of NATO PE positions and support funding and is responsive to the MC.

${ }_{19}^{19}$ Within the NCS, resources are allocated towards orientation and initial staff indoctrination programmes. These programmes are unit specific and are not generally captured as part of broader NATO E\&IT requirements.
} 
2-13. New Capabilities. In situations where new capabilities are being introduced initial funding for related equipment as well as initial development of the required E\&IT, solutions may be provided through NATO common funding. These initiatives primarily stem from the new capabilities developed through capability packages and the NATO Defence Planning Process (NDPP). Once introduced the steady-state E\&IT resourcing will remain consistent with the overarching funding principles outlined above. A Voluntary National Contribution Fund (VNCF) may also be used to initially build NATO capabilities.

2-14. Subject Matter Experts (SMEs) for Course Delivery. Travel costs for NATO nation SMEs originating from outside the NCS required for the delivery of NATO-provided courses are eligible for common funding. This is limited to a total of two individuals per scheduled course iteration. HQ SACT oversees the approval process in accordance with the criteria the RPPB provides. The approval of the funding remains subject to NATO affordability.

\section{NATO-PROVIDED COURSE}

2-15. A NATO-provided course is an E\&IT solution that is programmed and delivered to meet the specific needs of NATO and is certified by HQ SACT/JFT as approved within the ETOC ${ }^{20}$. To be certified as an approved NATO course within the ETOC, the course must:

a. Satisfy a NATO E\&IT requirement that is identified by a SACEUR appointed RA.

b. Be delivered by an ETF that has successfully completed the HQ SACT/JFT Quality Assurance institutional accreditation.

\section{EDUCATION AND INDIVIDUAL TRAINING WITH PARTNERS AND NON-NATO ENTITIES}

2-16. E\&IT is a key element of NATO's military cooperation with partners and with selected NNEs ${ }^{21}$. Partners and appropriate NNEs are therefore encouraged to participate in, observe or otherwise contribute to relevant NATO E\&IT activities. Partner and NNE involvement in NATO selected and approved courses may be subject to MC endorsement and NAC approval. Courses delivered by ETFs which are not considered to be provided for NATO do not require MC endorsement and NAC approval. ${ }^{22}$

2-17. For Partners specifically, E\&IT activities are normally embedded in Country Specific Plans and Roadmaps. These documents contain NATO's partner-specific cooperation objectives and priorities. Many courses that are published in the ETOC support NATO's area of cooperation Partners. Partner nation participation in a NATO E\&IT activity is administered through the Partnership Cooperation Menu (PCM) and is supported by the Partnership Realtime Information, Management and Exchange (ePRIME) system. Subject to Bi-SC Military Partnership Directorate (MPD) coordinator approval, the selected and approved courses in the ETOC, including those offered by partners, are eligible for an ACT reference number in ePRIME. The MPD also determines the eligibility of the ETOC listed courses for an ACT

\footnotetext{
${ }^{20}$ In order to prevent misinterpretations a NATO-provided course refers to a specific course iteration that is programmed by an ETF at a specific place and time for NATO. A NATO-provided course should be clearly distinguished from similar activities and the NATO-provided course should be explicit within in planning documents and programmes of work.

${ }^{21}$ As defined previously in footnote 2, NNE includes Non-NATO countries that do not otherwise meet the definition for "NATO partner".

${ }_{22}$ It is expected that such courses would adhere to the proper use of NATO/SACT Recognition as outlined in para 3-18 and 3-19.
} 
reference number. Eligibility is based on NATO's partnership objectives and priorities. MPD may also seek support from HQ SACT/JFT, to provide MPD with an assessment of the individual course in the ETOC. Bi-SC Commanders' Guidance - Military Co-operation (Bi-SCD 087-002) provides further details supporting the use of the PCM and ePRIME.

2-18. Certain NATO E\&IT activities may be of interest and opened to appropriate NNEs. This will require an ePRIME Proposing Body, ${ }^{23}$ or any involved (or sponsoring) Allied nation, to submit a timely and justified request through their respective chain of command in order to keep HQ SACT/JFT informed and, when necessary, in order to seek MC endorsement and NAC approval ${ }^{24}$. All requests for NNEs to participate in a NATO-provided course must include a clear rationale for NNE involvement. Requests should be received at least 120 days prior to the start of the event in order for a proper review and the necessary approvals to be obtained.

\footnotetext{
${ }^{23}$ NNEs are not subject to, or captured within, the PCM process. The reference to ePRIME Proposing Body is intended to capture a NATO body or agency which is likely to nominate an NNE to participate in an E\&IT activity.

${ }^{24} \mathrm{MC}$ endorsement and NAC approval is NOT required for NNE participation in activities conducted by a NATO Accredited COE, as per clarifications provided in DGMIS-BUS-0095-2015 dated 02 July 2015 and IMSTAM (C\&RS)-0020-2015 dated 17 March 2015. Endorsement/approval is also NOT required for NNE participation in recognized Partnership Training and Education Centre (PTEC) activities (as per DGIMS-BUS-0115-2105 dated 10 August 2015); however, HQ SACT/JFT is to remain informed of all potential NNE involvement with NATOprovided courses at a NATO Accredited COE or recognized PTEC.
} 


\section{CHAPTER 3 - QUALITY MANAGEMENT}

\section{INTRODUCTION}

3-1. A wide variety of ETFs offer E\&IT solutions to NATO ${ }^{25}$. The intent of this chapter is to detail the mechanisms and processes implemented by NATO to assure the quality of E\&IT provided by ETFs that offer solutions which align with the NATO E\&IT requirements identified by a SACEUR appointed $\mathrm{RA}^{26}$.

3-2. It is important to ensure that the planned and systemic approach to building, maintaining and improving the execution of E\&IT activities is in alignment with required standards ${ }^{27}$. Compliance with these standards provides confidence that the definition and delivery of E\&IT continues to be aligned to support NATO requirements ${ }^{28}$. HQ SACT/JFT conducts institutional accreditation in order to provide confidence to the Alliance that recognized ETFs supporting NATO utilize an effective Quality Management System (QMS). Institutional accreditation is also harmonized with the certification of individual courses, as described in the chapter 2.

\section{QUALITY MANAGEMENT SYSTEM (QMS)}

3-3. An established QMS within an ETF provides confidence in the definition and delivery of quality E\&IT solutions. A QMS incorporates the required continuous improvement mechanisms to address change and emerging challenges. A QMS has four dimensions each with its own purpose, depth and scope derived from quality related practice. The quality dimensions and their specific application in NATO E\&IT are illustrated in Figure 3-1. In broader terms, the four dimensions of a QMS are as follows:

a. Inspection. Inspection is implemented mainly for identifying and correcting errors before they may cause problems.

b. Quality Control (QC). QC is a systematic approach to identifying and rectifying problems at each step of the process.

c. Quality Assurance (QA). QA widens the responsibility for quality to include other functions beyond the main/direct activities (e.g., the impact of support functions). The focus is the overall quality of the output and is aimed at preventing errors, mistakes and defects.

d. Quality Management (QM). QM is a way of thinking and working with emphasis on:

(1) Meeting the needs and expectations of customers.

\footnotetext{
${ }^{25}$ The scope of ETFs to be considered is provided in para 1-7 with further detail provided in footnote 7 .

${ }^{26}$ For NATO, quality E\&IT is effective, efficient and affordable. This chapter addresses the E\&IT standards and mechanisms identified in MC 458/3, in particular paragraphs 14, 25 a. iii. and 38.

${ }^{27}$ The standards presented here are influenced by the $3^{\text {rd }}$ edition of the International Education Standards which were produced by the European Network for Quality Assurance in Higher Education in 2009; however, they are adapted to suit NATO's needs by HQ SACT/JFT.

${ }^{28}$ The planned and systemic approach to managing NATO E\&IT is achieved through a two stage approach guiding the definition and delivery of E\&IT solutions. Within this directive the two stages are subsequently broken out as the Analysis, Design, Development, Implementation and Evaluation phases of the NATO Systems Approach to Training. Details are provided in chapters 4-9.
} 


\section{NATO UNCLASSIFIED}

(2) Covering all parts of an organization.

(3) Involving every person in the organization.

(4) Examining all aspects related to quality.

(5) Aiming at "right the first time" by designing-in quality rather than inspecting for it afterwards.

(6) Developing systems and procedures which support quality and continuous improvement.

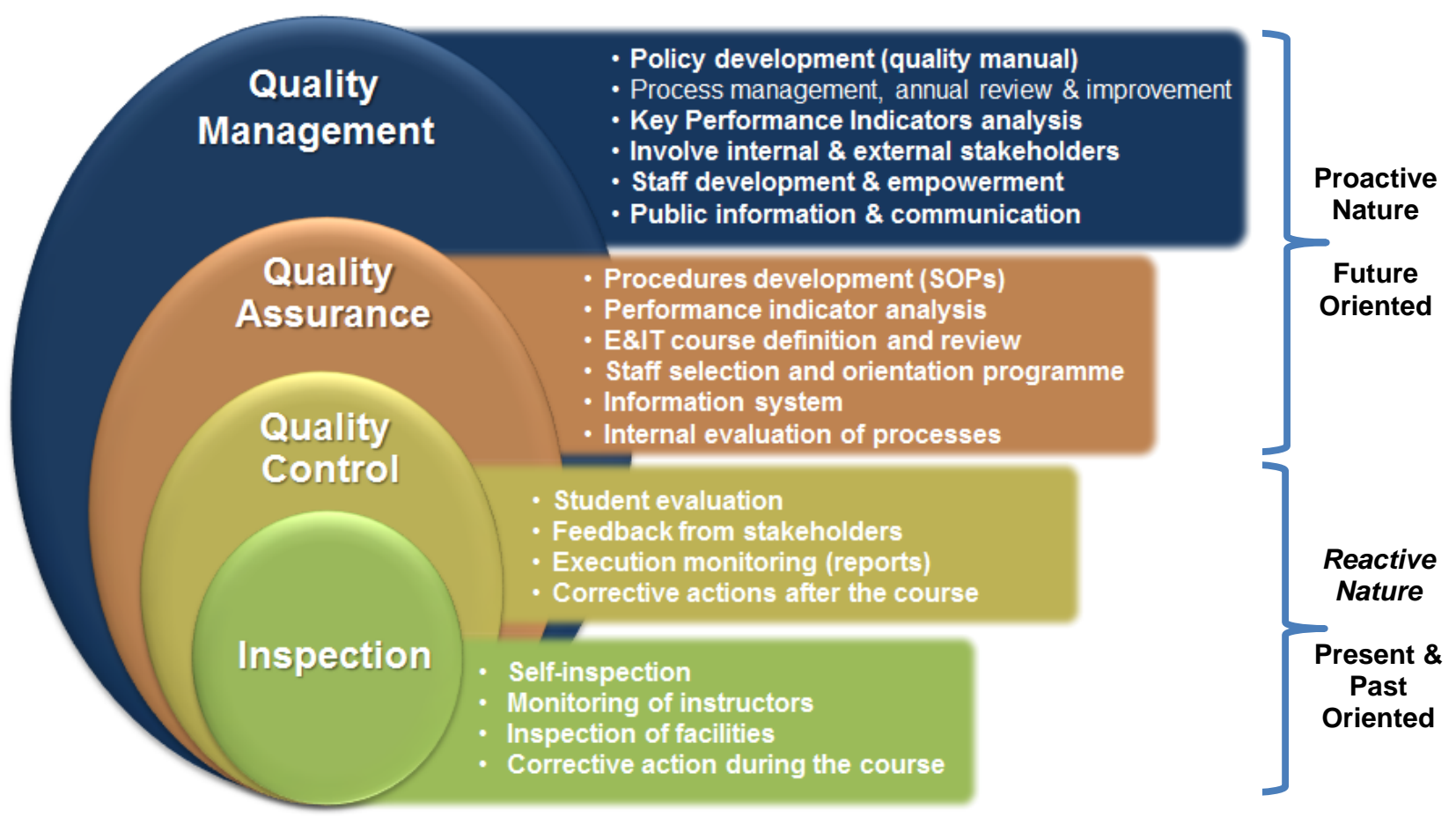

Figure 3-1 Quality Dimensions Applied to NATO E\&IT

3-4. A QMS is a complete set of quality standards, procedures and responsibilities. The QMS within an ETF defines and covers all facets of the operation, from identifying and meeting the needs of the stakeholders to planning, implementing, monitoring and reviewing the E\&IT, together with all the relevant activities regarding these functions. The QMS regulates the organizational structure, the responsibilities, the processes, the procedures and the resources of the institution. The documentation that usually comes with a QMS describes the quality policy, the system, the objectives, the organizational structure, the responsibilities, the jobs/functions and outlines procedures in detail.

\section{CONTINUOUS IMPROVEMENT PROCESS}

3-5. A Continuous Improvement Process (CIP) is an essential element of $\mathrm{QM}$ and is embedded within a QMS. A CIP has to be in place within an ETF to assure that it will consistently address NATO E\&IT requirements. HQ SACT/JFT conducts ETF institutional accreditation to complement an ETF's CIP. 
3-6. For ETFs subject to NATO institutional accreditation, the CIP consists of internal and external loops, as illustrated in Figure 3-2. Both loops are executed continuously. The frequency of the internal loop depends on the ETFs normal planning and execution cycle. ETFs are expected to gather relevant information, analyse it, make judgements concerning results and in the final step, if necessary, make changes to improve their processes and procedures. The external Continuous Improvement $(\mathrm{Cl})$ loop includes an initial ETF institutional accreditation and this leads to an evaluation report which provides an ETF with recommendations to improve internal processes and procedures, as required. There is an additional external feedback loop which is provided through an annual QA Report produced by the ETF. HQ SACT/JFT compiles the annual returns from accredited ETFs and generates a consolidated QA Summary. The summary highlights findings and best practices and this is distributed annually to ETFs.

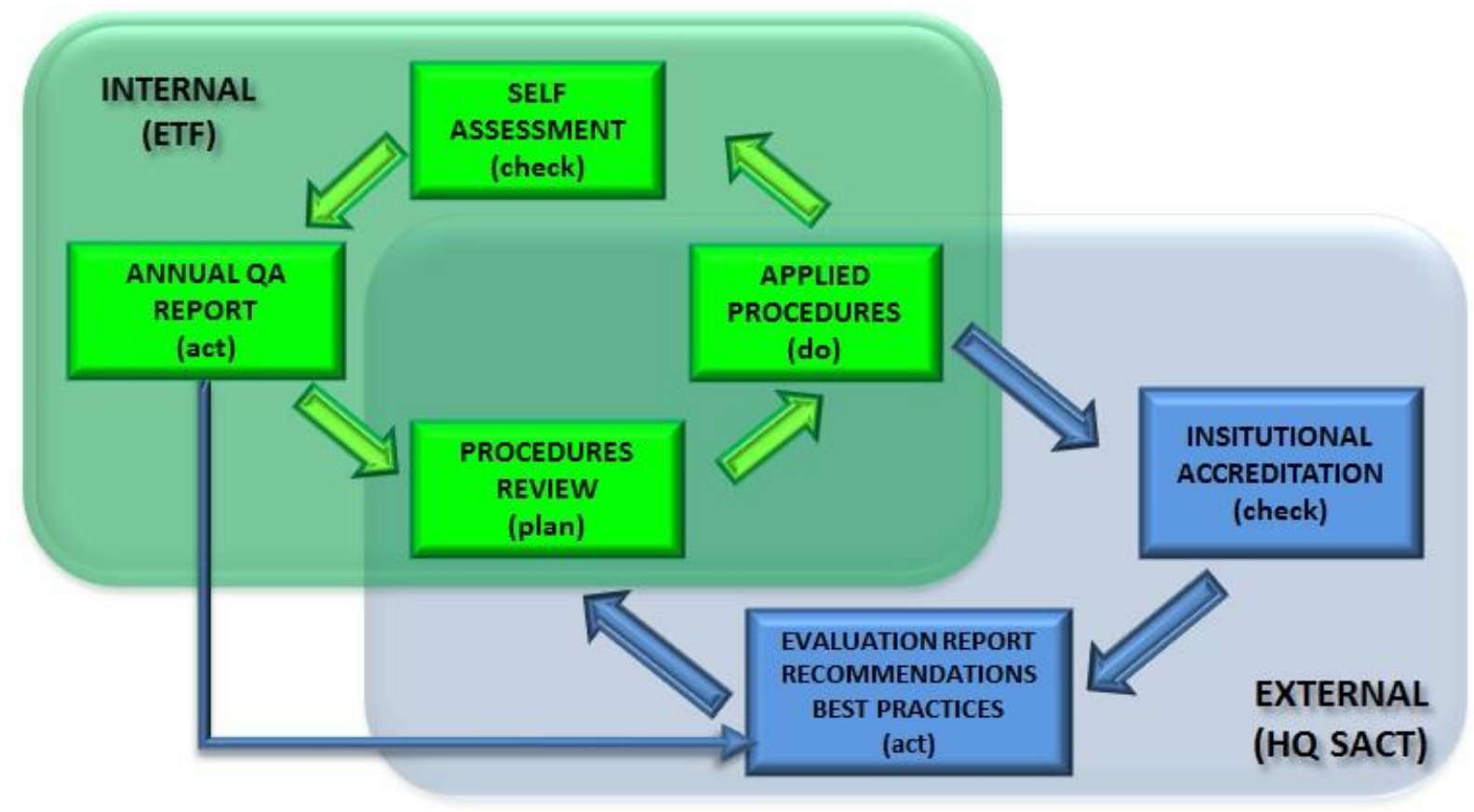

Figure 3-2 Process of Continuous Improvement

\section{RESPONSIBILITIES IN QUALITY MANAGEMENT}

3-7. The primary responsibility for providing quality E\&IT for NATO rests with the commanders/commandants/directors of the respective ETFs supporting NATO. It is important to acknowledge and emphasize there are valuable contributions made by other major stakeholders that can influence the ETFs QMS. Operational Commanders contribute by providing updates on evolving requirements based on the latest developments in the operational environment as well as by providing feedback to ETFs concerning the graduates they receive. Each individual involved with providing E\&IT (the trainers) along with those receiving it (the trainees) contributes to the quality and continuous improvement of E\&IT.

3-8. HQ SACT is responsible for:

a. The management, execution and accreditation of E\&IT.

b. Developing and maintaining Doctrine and Quality Standards for NATO E\&IT. 
c. Ensuring that the E\&IT in support of NATO is in compliance with NATO standards.

d. The certification of courses.

3-9. Accredited ETFs are responsible for:

a. Establishing, maintaining and reviewing their QMS and adhering to the standards described in Annex D.

b. Submitting to HQ SACT/JFT an annual QA Report.

\section{INSTITUTIONAL ACCREDITATION}

3-10. Institutional accreditation requires an ETF to demonstrate the existence of an effective QMS as well as to provide evidence of their contribution to NATO. HQ SACT/JFT assembles and leads a QA Team of Experts (ToE) and relies on their recommendations to accredit ETFs. The institutional accreditation process is based on NATO Quality Standards which are focused on three broad areas, as detailed in Annex E. The QMS is based on a set of seven standards detailed in Annex D.

\section{INSTITUTIONAL ACCREDITATION PROCESS}

3-11. The main steps for the institutional accreditation process are identified in Figure 3-3 and the steps are:
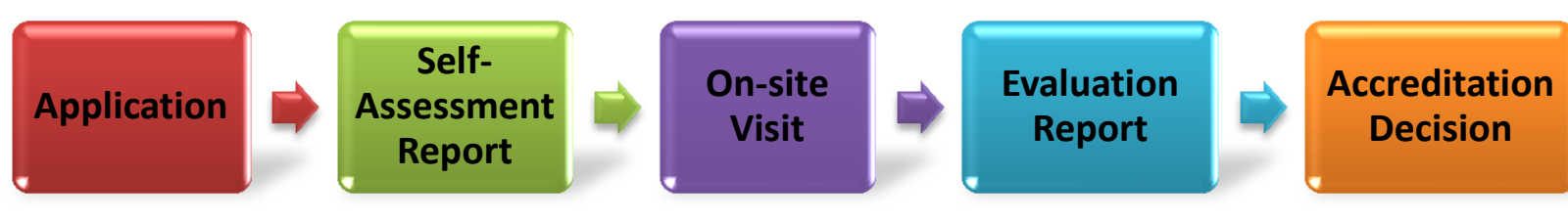

Figure 3-3 Institutional Accreditation process

a. Application. Participation in the accreditation process is on a voluntary basis. ETFs providing NATO E\&IT should apply for accreditation when they have developed and effectively implemented their QMS. HQ SACT/JFT will provide an application template on request. The application will be formally submitted to HQ SACT/JFT and to the QA ToE (jttqa@act.nato.int).

b. Self-assessment. Report. After the acknowledgement of the formal application, the ETF submits to HQ SACT/JFT an evidence-based self-assessment report which provides qualitative and quantitative information and further analysis concerning the ETF's activities. HQ SACT/JFT will provide additional guidance to an ETF for preparing the report, if requested. The self-assessment report is to be submitted to $H Q$ SACT/JFT a minimum of one month prior to the on-site visit. $H Q$ SACT/JFT will ask for additional documentation, as necessary, in order to complete the evaluation.

c. On-site Visit. The actual time for the visit will be coordinated and agreed between the ETF and HQ SACT/JFT, and it is based on ETF readiness and availability. During the visit, the QA ToEs will assess the QMS and the internal CIP as well as 
associated activities contributing to the provision of efficient, effective and affordable E\&IT solutions. This assessment is completed through open discussions and interviews with relevant staff members as well as by reviewing relevant documents and examining the facilities. The on-site visit will be tailored to the uniqueness of each ETF. The schedule of events will be coordinated and agreed at least one month before the on-site visit.

d. Evaluation Report. The QA ToE will prepare a draft report based on the on-site evaluation. The report is intended to support the ETFs further development through external feedback and expert advice ${ }^{29}$. The evaluation will be based on conformity analysis of each criterion against the pre-established NATO quality standards. There will be three possible ratings; however, where outstanding results are identified a "best practice" will be acknowledged. The ETF will have the opportunity to comment on the findings within the draft evaluation report before it is finalized. The three possible results are as follows:

(1) Meets the Standard.

(2) Partially Meets the Standard.

(3) Does not Meet the Standard. In this case the ETF will be provided with recommendations to resolve and improve.

e. DCOS JFT Accreditation Decision. DCOS JFT will base the final decision on the QA ToE recommendation and evaluation report. The following decisions are possible:

(1) Unconditional Accreditation. An accreditation remains valid for six years ${ }^{30}$.

(2) Conditional Accreditation. An accreditation which is valid for one year. A valid conditional accreditation can be converted to unconditional at any point six months after the release of the DCOS JFT decision, provided the ETF can demonstrate that the areas requiring improvement are resolved and appropriate evidence is provided.

(3) Not Accredited. The ETF will be provided with guidance to resolve and improve specific areas. Resolving the concerns permits the ETF to achieve an accreditation.

\section{MONITORING AND INFORMING}

3-12. Following successful institutional accreditation, HQ SACT/JFT monitors each accredited ETF throughout the validity period through an annual QA Report. The annual QA Report is

\footnotetext{
${ }^{29}$ An evaluation report provides an ETF with recommendations to improve internal processes and procedures. The costs incurred to accomplish these recommendations must be borne by the ETF and not NATO.

${ }^{30} \mathrm{An}$ accreditation remains valid as long as the Institution continues to conduct NATO-provided courses in support of NATO requirements. HQ SACT JFT retains the right to withdraw accreditation if an institution no longer continues to make a contribution to NATO and satisfy the NATO Quality Standards provided at Annex E.
} 
based on a template structure provided by HQ SACT/JFT and it is due the end of January each year. The annual QA Report demonstrates a continuing commitment to quality and is essential to sustaining the ETF institutional accreditation status.

3-13. Based on the annual QA Reports provided by accredited ETFs, DCOS JFT will issue an annual QA Summary which includes best practices collected from ETFs, common problems and proposed solutions. The summary will be distributed to the community of interest.

\section{INSTITUTIONAL RE-ACCREDITATION}

3-14. Re-accreditation will be conducted following the same steps described earlier in para 3-11.

\section{ACCREDITATION OF COMMERCIAL ENTITIES}

3-15. NATO institutional accreditation is intended for ETFs, as defined in para 1-7. Commercial entities and industry in general, including privately operated firms, consulting companies, professional and academic institutions and "for-profit" entities, are not within the scope of NATO institutional accreditation unless authorized by the appropriate framework. Entities which enter into services contracts with NATO will have the terms and conditions of these arrangements explicitly detailed in the contract and, where appropriate, this will include E\&IT quality management considerations.

\section{THIRD PARTY ACCREDITATION AND CREDIT RECOGNITION}

3-16. ETFs that are institutionally accredited by an external organization or another third party, other than HQ SACT/JFT, are still required to apply and go through the NATO accreditation process in order to achieve NATO ETF institutional accreditation. ETFs are not mandated to go through the NATO ETF institutional accreditation process - it is voluntary.

3-17. NATO E\&IT courses may receive recognition and potentially transfer credits towards an alternative qualification or credential which is conveyed by a body outside of NATO, including: a professional certification, a certificate, a diploma and/or a degree. This additional credit recognition through professional and academic institutions is a desirable secondary effect for NATO E\&IT which can provide a valuable incentive to encourage further learning and personal development. ETFs that have completed institutional accreditation are encouraged to summarize their academic partnership activities and achievements within their annual QA Report.

\section{SACT RECOGNITION}

3-18. In recognition of achieving and continuing to maintain ETF institutional accreditation, ETFs are permitted to promote their achievements and may, combined with their own logo/letterhead, use the following notation: "NATO Accredited Education and Training Facility". The ACT logo can be used on ETF products, related to NATO-provided courses, but only in a combination with the logo of the accredited ETF. It is understood that the notation and/or use of the ACT logo does not imply any authority to represent NATO or ACT.

3-19. HQ SACT recognition is authorized for NATO-provided courses and the associated course completion certificates for NATO-provided courses may bear an electronic facsimile endorsement (signature) of the SACT. While other courses may be similar, and may even be based on NATO doctrine, only NATO-provided courses are to be associated with SACT 


\section{Bi-SCD 075-007}

\section{NATO UNCLASSIFIED}

recognition. SACT recognition must not be associated with education related seminars, workshops or other similar forums. Exceptions to the use of SACT recognition for E\&IT are resolved through the DCOS JFT. Accredited ETFs are expected to be vigilant and avoid ambiguity or confusion between NATO-provided courses and those which are national or are for other purposes. ETFs are expected to summarize their use of SACT Recognition within their annual QA Report. 


\section{CHAPTER 4 - FROM E\&IT REQUIREMENTS TO E\&IT SOLUTIONS}

\section{INTRODUCTION}

4-1. HQ SACT/JFT is responsible for the overall implementation and management of Global Programming and this includes the Development Methodology which is used to transition from requirements to solutions. HQ SACT/JFT relies upon various stakeholders, both within the NCS and externally to it, to ensure essential NATO E\&IT solutions are defined and delivered to satisfy NATO requirements. This chapter is focused on E\&IT solutions and introduces NATO TNA as part of the Global Programming - Development Methodology. Through TNA there is a transition from E\&IT requirements to the definition and delivery of E\&IT solutions. This chapter describes the stakeholder relationships involved with TNA and in particular the roles and responsibilities of the appointed $\mathrm{RA}$ and $\mathrm{DH}$ for a discipline as well as the relationship with ETF E\&IT solution providers.

4-2. TNA activity within Global Programming follows the approval of a discipline based STP and the production of a TRA Report. Within NATO, TNA concerns the provision of individual and collective E\&T solutions. For E\&IT this encompasses the application of the NATO Systems Approach to Training (SAT) ${ }^{31}$. The focus of the NATO SAT is E\&IT, in particular what an individual is trained to do and the level of proficiency that is to be achieved. The NATO SAT constitutes a cycle and evaluation is a fundamental element that brings about the reassessment of initial requirements and the continuous improvement and refinement of E\&IT solutions. The Exercise Process, as detailed in Bi-SCD 075-003, is used during TNA to address solutions for Collective Training and Exercises. The NATO SAT and the NATO Exercise Process are nested within TNA of the Global Programming - Development Methodology, as illustrated in Figure 4-1.

\footnotetext{
${ }^{31}$ The NATO Systems Approach to Training (SAT) is as an iterative and interactive sequence of activity leading from the definition of a need for education and individual training through to defining, developing and implementing effective and efficient learning solutions to satisfy the need.
} 


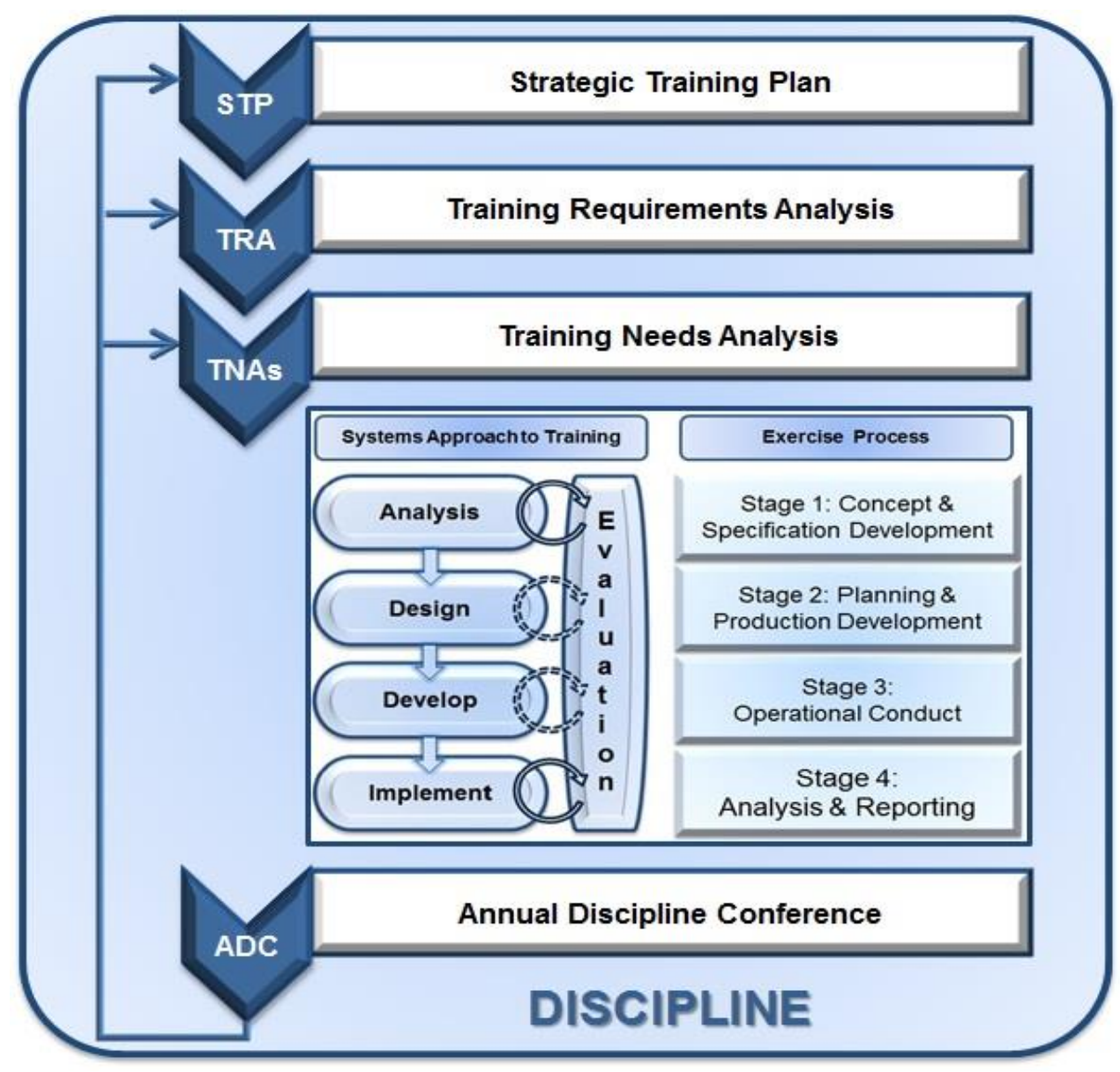

Figure 4-1 Global Programming - Development Methodology

\section{SITUATING THE SYSTEMS APPROACH TO TRAINING}

4-3. The STP and the TRA Report verify performance gaps and scope the initial E\&T requirement. The result forms a discipline based requirements package ${ }^{32}$. A TRA Report may result with several TNA Working Groups (WGs) to formulate the solutions to address the E\&IT gaps. TNA WGs focus on the solutions to address the E\&IT gaps unique to a discipline. E\&IT solutions are achieved through the SAT and new solutions are defined (through SAT) when a TRA Report identifies a gap and no suitable solutions appear to currently exist. E\&IT solutions that support NATO operations or serve areas of common interests with NATO partners may also be generated through $\mathrm{SAT}^{33}$.

4-4. TNA and the SAT processes are integrated within the broader Development Methodology supporting Global Programming. This integrated approach ensures the overall need for E\&T is aligned with Alliance objectives and that prior to developing E\&IT solutions there is a clear link established with the principle duties and tasks within NFS/NCS JDs and, where feasible, with collective tasks and exercise objectives ${ }^{34}$. The STP and the TRA Report

\footnotetext{
${ }^{32}$ A Performance Gap is the difference between actual and desired/required performance.

${ }^{33}$ Mission specific E\&IT requirements, based on potential performance gaps are identified by mission commanders. When Immediate Operational Requirements are identified the SAT process is initiated.

${ }^{34}$ ACO Force Standards and the NATO Task List (Bi-SCD 080-090, dated 16 November 2007) provide a basis for collective tasks and activities.
} 
serve as the initial scoping activity intended to first assess, and then capture, an overall need for E\&T and this leads to the definition and delivery of individual and collective E\&T solutions.

4-5. The ADC is an opportunity to review all E\&T activities associated with a discipline to ensure E\&T solutions remain aligned with E\&T requirements ${ }^{35}$. The review is led by the $D H$ and involves the ETFs, the RA as well as HQ SACT/JFT representation. The timing of the $A D C$ is based on the needs of the RA and the assigned DH. One DAP is generated annually, as a minimum, for HQ SACT approval summarizing the status of the E\&T for each discipline ${ }^{36}$. The DAPs provide HQ SACT with the detail necessary to provide proper management oversight of NATO E\&T.

\section{APPLYING THE NATO SYSTEMS APPROACH TO TRAINING}

4-6. Defining and delivering effective, efficient and affordable E\&IT solutions to satisfy NATO performance gaps is achieved through the NATO SAT. The NATO SAT consists of five distinct phases and includes a feedback loop at the conclusion of each phase, as per Figure 4-2. The NATO SAT is normally engaged when an E\&IT requirement is identified through a TRA and no suitable solutions are in place to address the requirement. Each of the SAT phases is supported with a discrete series of steps and activities. An overview of the NATO SAT steps and activities is provided in Annex F. The DH defines NATO E\&IT solutions and the results must be approved by HQ SACT/JFT in order to become recognized and NATO certified. ETFs serve a vital role supporting the $\mathrm{DH}$ and are responsible for the actual delivery of NATO E\&IT solutions. Recognizing the uniqueness of NATOs E\&T governance structure and, in particular, the reliance on numerous entities outside the NCS, the NATO SAT is intended to be flexible and adaptive. The five phases of NATO SAT are summarized here and detailed guidance is provided in the subsequent chapters ${ }^{37}$ :

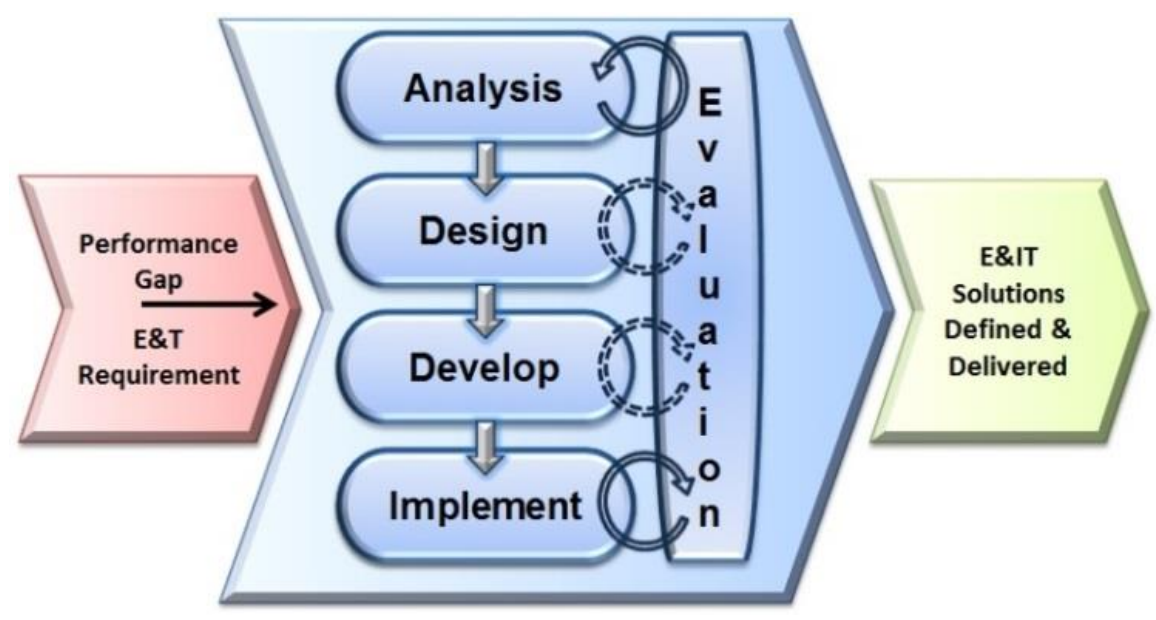

Figure 4-2 NATO Systems Approach to Training

a. Analysis Phase. The purpose of the Analysis Phase is to generate clear and precise Performance Objectives (POs). POs capture the intended outcome of NATO

\footnotetext{
${ }^{35}$ An ADC may also include a review of the integration of discipline related requirements as part of Collective Training and Exercises.

${ }^{36}$ The details of the ADC, the DAP as well as STP and TRA are in Bi-SCD 075-002.

${ }^{37}$ The NATO SAT process will identify the expected contents of the products defining NATO E\&IT solutions. A process to develop E\&IT solutions is outlined in Chapters 5-9. This is a logical and systematic approach to achieve the required products and it is offered as guidance. In many situations suitable E\&IT solutions for NATO requirements already exist.
} 
E\&IT and this is ideally expressed in terms of essential on-job performance consistent with the Principle Duties for NCS/NFS positions as well as NATO operations and the performance requirements which stem from SAGE. The Analysis Phase results with the production of a CCD which outlines a broad training strategy and the intent for a proposed E\&IT solution ${ }^{38}$. The Analysis Phase is described in detail in Chapter 5.

b. Design Phase. The purpose of the Design Phase is to create, or otherwise select, an E\&IT solution which will enable individuals to achieve specified POs. The Design Phase results with the production of a further CCD which defines in detail the instructional strategy supporting an E\&IT solution. The instructional strategy includes what content will be delivered, how the content will be delivered and, most important, how learning will be monitored and assessed. The Design Phase is described in detail in Chapter 6.

c. Development (Develop) Phase. The purpose of the Development Phase is to produce, or otherwise procure, the materials or services that are essential to support the delivery of an E\&IT solution. The Development Phase results with the production of courseware which is defined during the Design Phase and is described in the CCDs. Details concerning the Development Phase are described in Chapter 7.

d. Implementation (Implement) Phase. The purpose of the Implementation Phase is to put into operation the management, support and administrative functions necessary to successfully conduct E\&IT solutions. Conducting E\&IT solutions requires planning, preparation, execution as well as the close out of the activities which are specific for a course. The Implementation Phase results with the production of qualified graduates. The Implementation Phase is described in Chapter 8.

e. Evaluation Phase. The purpose of the Evaluation Phase is to assess the efficiency, effectiveness and affordability of an E\&IT solution once it is implemented and determine how it can be improved in the future. The Evaluation Phase formally closes the NATO SAT feedback loop and determines whether a specific E\&IT solution has satisfied the POs which were defined during the Analysis Phase. The Evaluation Phase results with improved E\&IT solutions and provides an important input to a discipline related ADC. ETFs that are institutionally accredited by HQ SACT/JFT embed a CIP, which includes post course and institutional reviews as part of a QMS. The Evaluation Phase is described in Chapter 9.

\section{ROLES AND RESPONSIBILITIES WITHIN THE SYSTEMS APPROACH TO TRAINING}

4-7. HQ SACT/JFT formalizes the specifics of the RA and DH relationships taking into consideration the unique intricacies of the associated discipline; details concerning these relationships begin to form within a STP. NATO is responsible for satisfying the E\&IT

\footnotetext{
${ }^{38}$ This directive refers to Course Control Documents (CCD) as output products that are used to define NATO E\&IT solutions. CCDs are generated through the NATO SAT processes. Equivalent output products for the NATO SAT Analysis and Design Phases may already exist in alternative formats within ETFs. The products may be referred to by various names, including: Training Plan, Programme of Learning, Course Curriculum, Programme of Instruction, and Course Syllabus among other names. The alternative formats and names may be desired (or required) in accordance with local or national preferences. This directive provides templates (in Annexes K, L and R) and also identifies the elements to be included in the documents in the chapters (5 and 6) that follow.
} 
requirements that are unique or otherwise specific to NATO, however, the Alliance relies heavily upon ETFs outside of the NCS to deliver the E\&IT solutions. HQ SACT/JFT conducts institutional accreditation in order to provide confidence to the Alliance that recognized ETFs supporting NATO utilize an effective QMS. The NATO SAT model is a central element to the accredited ETFs overall approach to quality management.

4-8. Through the NATO SAT the RA, the DH and ETFs harmonize efforts and contribute to the definition and delivery of effective, efficient, and affordable E\&IT solutions to meet NATO's specific E\&IT requirements. Specific assignments within each of the phases of the NATO SAT are summarized in Table 4-1 and this takes into consideration the autonomy of ETFs supporting NATO E\&IT as well as the role of the RA and DH.

\begin{tabular}{|c|c|c|c|c|c|c|c|}
\hline \multicolumn{8}{|c|}{$\begin{array}{c}\text { NATO } \\
\text { Systems Approach to Training (SAT) } \\
\text { Assignments Matrix }\end{array}$} \\
\hline \multirow{2}{*}{ Stage } & \multirow{2}{*}{ SAT Phases } & \multicolumn{4}{|c|}{ Stakeholders } & \multirow{2}{*}{ SAT Products ${ }^{2}$} & \multirow{2}{*}{ Approval } \\
\hline & & RA & DH & ETF & OPR $^{\top}$ & & \\
\hline \multirow{2}{*}{ 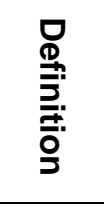 } & Analysis & C & $A \& R$ & C & C & $\begin{array}{l}\text { Course Control } \\
\text { Document I \& II }\end{array}$ & JFT \\
\hline & Design & C & $A$ & $\mathrm{R}$ & $\mathrm{R}$ & $\begin{array}{l}\text { Course Control } \\
\text { Document III }\end{array}$ & JFT \\
\hline \multirow{3}{*}{ 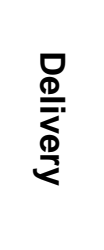 } & Development & 1 & $A$ & $\mathrm{R} / \mathrm{C}$ & $C / R$ & Courseware & ETF \\
\hline & Implement & 1 & 1 & $A \& R$ & $\mathrm{R}$ & $\begin{array}{l}\text { Qualified } \\
\text { Graduates }\end{array}$ & ETF \\
\hline & Evaluation & 1 & I & $A \& R$ & $\mathrm{R}$ & $\begin{array}{l}\text { Improved E\&IT } \\
\text { Solutions }\end{array}$ & ETF \\
\hline \multicolumn{8}{|c|}{$\begin{array}{l}\text { Assignments: } \\
\text { Responsible: Executes the task/activity in support of NATO. } \\
\text { Accountable: Ensures the task and related work is completed for NATO. } \\
\text { Consulted: Input is sought during the activity before it reaches final approval. } \\
\text { Informed: Receives updates as activities progress. }\end{array}$} \\
\hline \multicolumn{8}{|c|}{$\begin{array}{l}\text { 1. An external Course Officer of Primary Responsibility (OPR) is required when an ETF does not have } \\
\text { internal expertise or the capacity to dedicate to the delivery of a specific NATO E\&IT solution. An } \\
\text { external Course OPR may support several of the responsibilities within SAT depending on the } \\
\text { capacity of the ETF and the level of available DH support. The level of Course OPR support is } \\
\text { determined prior to activating a course within the ETOC. }\end{array}$} \\
\hline \multicolumn{8}{|c|}{$\begin{array}{l}\text { 2. Course Control Documents (CCDs), detailed in Chapters } 5 \text { and } 6 \text {, are products that define NATO } \\
\text { E\&IT solutions. ETFs may have already generated output products to address CCD II and III. }\end{array}$} \\
\hline
\end{tabular}

Table 4-1 NATO Systems Approach to Training (SAT) Assignments Matrix

4-9. The appointed DH supports HQ SACT/JFT in translating NATO requirements into E\&IT solutions. The DH, coordinates with ETFs, and supports HQ SACT/JFT through the definition and development of E\&IT solutions. The DH relies on ETFs and the level of effort to coordinate will vary depending on the complexity of the discipline. The $\mathrm{DH}$ is not necessarily responsible for the conduct or delivery of E\&IT solutions. ETFs are responsible for E\&IT delivery. The DH is accountable for the definition and development of E\&IT solutions and these responsibilities are captured within an official appointment letter which is negotiated with HQ SACT/JFT. 
4-10. As an E\&IT solution is defined and formalized the DH may seek HQ SACT/JFT support to identify and appoint a Course Officer of Primary Responsibility (OPR). Course OPRs are external to the ETF and normally come from within the NCS. Course OPRs support E\&IT definition and delivery, in cases where the DH does not have the capacity to support an ETF. The Course OPR must have sufficient expertise to ensure the assigned E\&IT solution continues to reflect NATO policies, concepts, doctrine and procedures and thereby remains up-to-date and relevant. The Course OPR assignment is a principle duty and is to be captured within the applicable NATO NCS/NFS JD.

4-11. A DH may need to coordinate with several ETFs in order to satisfy the full scope of E\&IT requirements supporting a discipline. The DH remains accountable to HQ SACT; however, in some situations a designated ETF may initiate TNA activity, in particular the production of CCDs defining an E\&IT solution, with the support of the $\mathrm{DH}$. Ultimately, the $\mathrm{DH}$ must endorse any proposed E\&IT solution and reconcile this with the TRA Report.

4-12. HQ SACT will support DH coordination efforts by ensuring the associated tasks and the added work to support NATO's E\&IT is appropriately documented and tasked, be it through a specific Programme of Work or, when necessary, through another recognized planning and tasking framework ${ }^{39}$. HQ SACT/JFT also assigns a Discipline POC to support the maintenance and day-to-day oversight of a discipline and may become further engaged, as required, in order to ensure a DH has the required support to effectively coordinate with ETFs.

\section{SUPPORT TO CURRENT OPERATIONS - RAPID ANALYSIS AND DESIGN}

4-13. Current operations have the highest priority with regard to support from NATO's E\&T resources. Emerging security threats as well as the advent of new concepts and doctrine may have an impact on NATO operations and readiness. NATO may also be required to train host nation or local forces in support of operations. Responsive and agile E\&IT is required to meet these challenges and solutions must be developed in rapid fashion. HQ SACT will lead this effort in close coordination with SHAPE.

4-14. Rapid Analysis and Design (RAD) responds to the urgent need to address operational performance gaps. RAD will accelerate the Global Programming - Development Methodology and compresses the TNA - NATO SAT process resulting in the swift production of E\&IT solutions. RAD will be implemented by HQ SACT in order to address immediate operational requirements identified by SACEUR. Once this need is identified the first step to RAD is led by HQ SACT, with SHAPE support. The initial step involves a clear identification and definition of the performance gap. RAD requires the identification of the area of deficiency and specifying the tasks to be performed. The direct input of the requesting agency is essential. Identified tasks are immediately translated into POs. Once the POs are defined, the E\&T expertise within the Global Programming - Governance Structure, the $\mathrm{DH}$, is leveraged. If DHs do not have adequate solutions in place, a Team of Experts is formed and the activities within the SAT Design Phase commence.

\footnotetext{
${ }^{39}$ Depending on the institution there will be different planning frameworks, e.g., MCM 236-03, MC Concept for NATO Centres of Excellence, 04 Dec 2003.
} 


\section{EDUCATION, INDIVIDUAL TRAINING AND THE SYSTEMS APPROACH TO TRAINING}

4-15. The NATO SAT applies to education as well as individual training. These are not mutually exclusive events or constructs. Elements of education and individual training are often blended in application to create a solution that will achieve desired learning objectives and specific performance outcomes. A NATO course is the descriptor commonly used to identify a solution to a NATO E\&IT requirement. A NATO course involves planned, sequenced and structured learning activities based on pre-defined objectives for a clearly identified (target) audience. Depending on application and context, E\&IT solutions may be further categorized for ease of management. Examples include: Functional Systems Training, PreDeployment Training, In-Theatre Training, Contractor Provided Training as well as Foundation Training among other descriptors. Regardless of the category, the attributes for a NATO course remain consistent with the description provided. The context of the event along with the related objectives and activities will determine if E\&IT is a NATO or national responsibility.

4-16. Key Leader Training (KLT) is a specific category of E\&T events which prepares leaders to respond appropriately within a specific context, such as within a NATO Exercise or operation. Leaders are required to interpret information, often provided by experts within a specific functional area (or discipline), in order to make decisions and determine an appropriate course of action. KLT consists of specific learning objectives which define the context specific base of knowledge that may be necessary to make decisions during a NATO Exercise or operation. In this context, KLT is a NATO responsibility.

4-17. Unlike $\mathrm{KLT}$, Professional Military Education (PME) has a longer term time horizon and a career focus as opposed to a concentration on the near term context (1-3 years) or specific duties and job requirements. PME cultivates military leadership by conveying a broad body of professional knowledge and developing the habits of mind along a career continuum. The focal point is intellectual agility including: critical thinking, rational thought and ethical decision making. PME is based on learning objectives which may be formulated through SAT to prepare military service members to lead and to manoeuvre within uncertain situations and resolve ill-defined problems. With only a few exceptions, which generally stem from political guidance, PME and related career development programmes are a national responsibility.

4-18. PME generally increases in intensity and depth of knowledge and skill with career progression and increasing rank. Encouraging specific development programmes for Officer and NCOs from within the Alliance and Partner nations supports achievement of a common standard. In so doing, this prepares military service members to face the challenges of operating in a multi-national, interoperable, NATO environment. NATO has endorsed requirements supporting PME programmes. Nations are expected to contribute personnel for $\mathrm{PE} / \mathrm{CE}$ posts who have the necessary PME commensurate with the responsibilities and expectations of the rank, as identified on the applicable PE/CE JD, and this includes the required language proficiency.

4-19. Key Leader Engagement events, conferences, professional seminars and related forums are frequently conducted within NATO to keep a broad audience aware of evolving issues and their implications. These forums are important and educational in nature; however, they often fall outside the definition for a NATO course. 


\section{CHAPTER 5 - SAT: ANALYSIS PHASE}

\section{INTRODUCTION}

5-1. Purpose. The purpose of the Analysis Phase is to generate clear and precise Performance Objectives (POs). POs capture a performance gap and identify the intended outcome of NATO E\&IT. POs are expressed in terms of the required job performance proficiency to be achieved ${ }^{40}$. During the process of capturing a performance gap the Analysis Phase results with answers to the following:
a. Why train?
b. Who must be trained?
c. What must be trained, to what level and under what conditions?

5-2. Product. CCDs are produced at the conclusion of the Analysis Phase. These documents are uploaded into the ETOC and guide the design, development, implementation and evaluation of an E\&IT solution. The documents establish the agreement among stakeholders concerning the intent of an E\&IT solution and provide the justification, background and detail concerning the need for the E\&IT solution.

5-3. Methodology. The Analysis Phase relies on a TNA Working Group (WG) to systematically analyse the performance statements in a TRA in order to identify, select and organize the specific tasks that require $E \& I T^{41}$. The WG requires inputs from a community of interest including command staffs (in particular the RA), end-users, subject matter experts (SMEs), and E\&T specialists. Expertise from outside the NCS may also be required. The success of the TNA WG relies upon the discretion, experience and expertise of the assembled members and their respective abilities to make reasoned judgements throughout the Analysis Phase. The TNA WG provides the required guidance to design an E\&IT solution during the next phase of the NATO SAT.

5-4. Process. The following steps are undertaken during the Analysis Phase:
a. $\quad$ Step 1: $\quad$ Establish a TNA WG.
b. Step 2: $\quad$ Analyse Tasks.
c. Step 3: Write Performance Objectives.
d. Step 4: Refine Target Audience.
e. $\quad$ Step 5: $\quad$ Formulate Guidance.

\footnotetext{
40 POs may also be referred to as Behavioural or Terminal Objectives. The content is similar to Training Objectives for an NATO exercise. POs focus on individual performance while exercise Training Objectives are focused on collective (team) performance.

${ }^{41}$ The TRA Report provides the basis for Performance Objectives. The TRA Report provides a list of tasks and these are expressed as Performance Statements. During the TNA WG these statements are examined and developed further in order to ensure precision, provide clarity and proper scope primarily related to the Principle Duties for specific NCS/NFS jobs.
} 
f. Step 6: Document Results.

\section{STEP 1: ESTABLISH A TNA WG}

5-5. The TNA WG is normally formed by the DH after the approved TRA Report is released. A TRA Report should provide a complete picture of the performance requirement. Following the initial review, the TNA WG will reach a decision point and select the appropriate way forward. During Step 1 the TNA WG will:

a. Confirm the Target Audience. The intent is to identify rank levels and the PE positions, including the organizational/command level for the positions within the NATO structure (Political/Strategic, Operational and Tactical), that may require E\&IT. This step provides an initial description and should be documented as a point of reference for the follow on TNA WG activities. The description is refined as the E\&IT requirement becomes more clearly understood and will be particularly useful during the SAT Design Phase. Consider:

(1) What is the expected level of experience as well as prior E\&T of the target audience?

(2) Is the intended target audience drawn from a similar military branch, occupation background or area of specialization (e.g., Medical, Logistics, Combat Arms, Communications and Information Systems, Finance)?

(3) What are the expectations of Commander's regarding the proficiency of graduates?

(4) What level of autonomy is expected on the job (e.g., function with minimal guidance or supervision)?

(5) How many NATO personnel require this E\&IT on an annual basis? ${ }^{42}$

b. Confirm the TRA Performance/Task Statements. The TRA Report should capture all the performance/task statements requiring E\&IT. The intent is to review the TRA Report and verify this is the case. Where necessary the list of statements may be modified or further supported with additional performance/task statements and related sub-tasks. The TNA WG considers:

(1) Does the list of performance/task statements within the TRA Report capture the complete performance requirement for the previously identified target audience?

(2) Does each task statement capture a job performance action (a verb) and a clear result?

(3) Is the intended level of proficiency identified and understood ${ }^{43}$ ?

\footnotetext{
42 The e-ITEP links to job description data in an effort to provide an estimate of the potential demand for E\&IT; however, a systematic process for associating and linking the essential and desirable E\&T with NCS/NFS JDs continues to evolve.

${ }^{43}$ Proficiency levels and key word indicators are provided in Annex G.
} 
c. Select a Course of Action. At this point, the TNA WG determines if a Task Analysis is required. If the TRA appears to have captured the complete E\&IT requirement it is possible to move to Step 3 . If further analysis is required, the TRA performance/task statements should be documented and the proficiency level for each statement identified and coded using a Tracking Matrix. Documenting the performance/task statements will assist the $\mathrm{DH}$ in maintaining discipline alignment. Documenting the statements also provides an audit trail confirming the source of the task and this ensures the TRA Report performance/task statements remain linked, and accounted for, relative to other E\&IT solutions. If new task statements are required, they should also identify the command level (Political/Strategic, Operational and Tactical) and the desired proficiency ${ }^{44}$. A description of the proficiency levels to support the development of task statements is provided in Annex G. The Task Statement Tracking Matrix is a locally generated form, an example is provided in Annex $\mathrm{H}$. Ideally, all statements will:

(1) State a specific action using a key word and an object. A list of key words is provided in Annex G.

(2) Have a definite beginning and end.

(3) Be clearly definable, ideally observable and measurable.

(4) Have a specific purpose.

(5) Be an action that is performed in a relatively short period of time.

d. Refine the Task List. Ensure all the essential performance statements are identified and that they accurately define the expectations of the target audience in terms of what they are expected to do. Any new task statements that are added to this list should be assigned a distinct tracking number in order to capture them later as part of a list of proposed TRA amendments. TRA changes are also reviewed by the $\mathrm{DH}$ and RA and may be an item for discussion during the ADC.

\footnotetext{
${ }^{44}$ Similar tasks may be performed at the political, strategic, operational and tactical levels. During task analysis distinguishing the difference between the tasks performed at the different levels (Political, Strategic, Operational and Tactical) will be essential. When documenting the performance statements the use of colour is one method to distinguish the statements across the different levels.
} 


\section{STEP 2: ANALYSE TASKS}

5-6. At this point, the performance/task statements developed during the previous step are examined and organized to illustrate relationships relative to a job and a broad duty area. A task analysis provides a structured and sequenced diagram of performance statements including specific tasks, subtasks and supporting task elements. Additional performance statements may be added in order to continue to provide clarity and illustrate the dependency and, if necessary, interdependencies of elements. The resulting diagram clearly illustrates the performance statements and this consists of tasks, sub-tasks and task elements (discrete actions) which most likely require some form of E\&IT in order to be able to achieve desired performance. The result of a task analysis is illustrated in Figure 5-1. The task analysis process consists of the following steps:

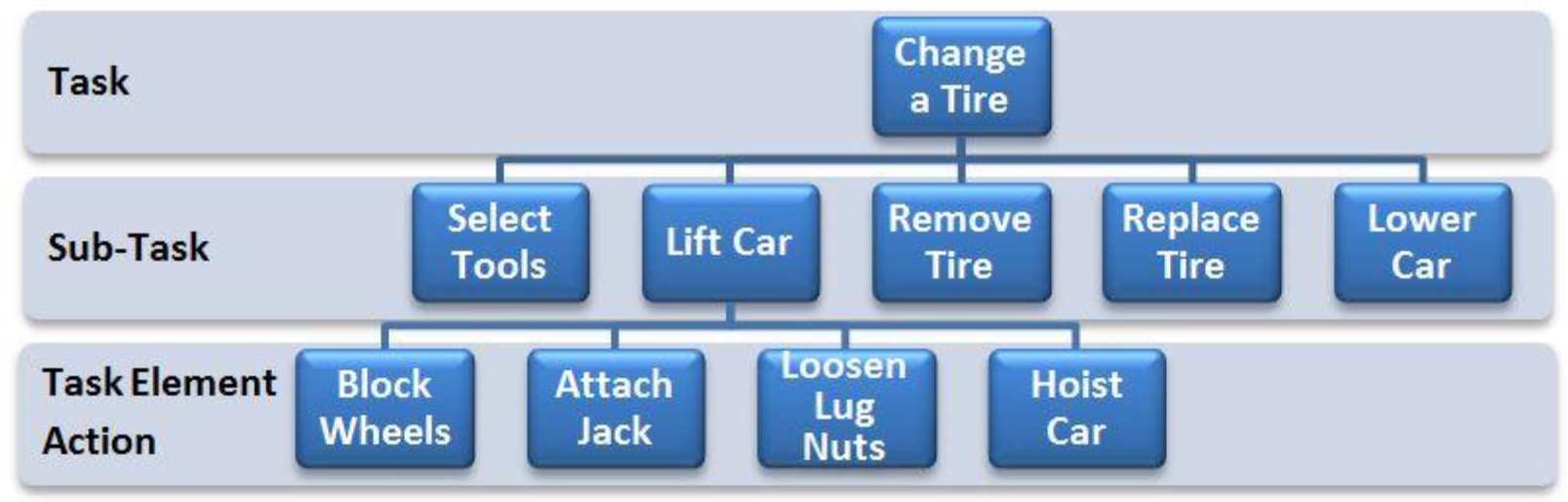

Figure 5-1 Simplified Task Analysis

a. Select the Tasks that Require E\&IT. Some task statements generated to capture the complete picture of the performance requirement may not require E\&IT in order to achieve the desired level of competence. Many tasks are often best learned on the job. At this point the acknowledged SMEs will review each statement generated and determine if formalized instruction is necessary. At the end of this process there will be a list of tasks which will likely require E\&IT in some form. The "no train" statements may still be beneficial in the next step; however, at this point those which do not require E\&IT can be identified. When selecting tasks to be included in E\&IT, the complexity and the associated underlying cognitive activity should be considered. A decision guide to assist with selecting tasks for E\&IT is provided in Figure 5-2. These considerations are based on the difficulty, importance and frequency of task performance (DIF Analysis). Ultimately, judgement will still be required and the following should be considered: 


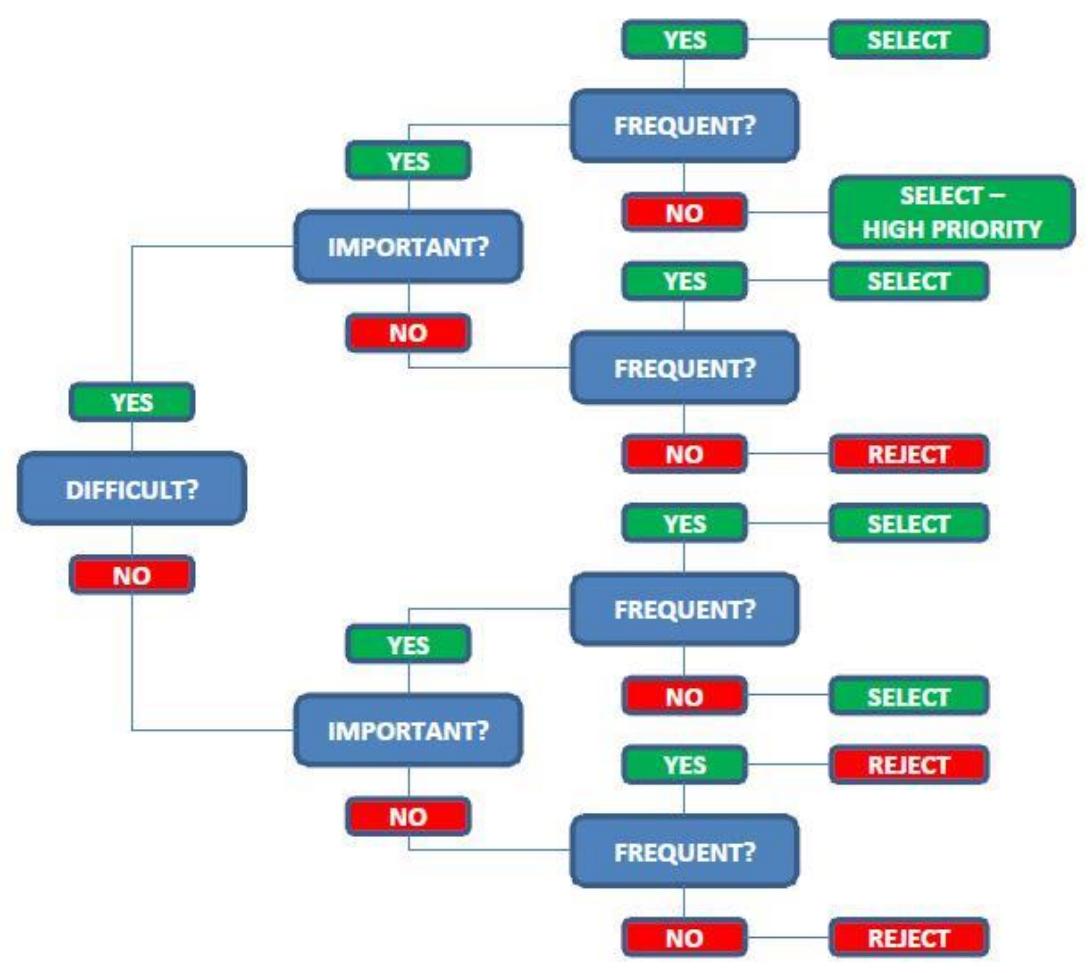

Figure 5-2 DIF Analysis

(1) Is the target audience already able to perform the task?

(2) What is the consequence or impact of an error?

(3) What is the consequence from not training this task?

(4) Could the task be better covered by pre-requisite instruction (via eLearning)?

(5) What is the time between completion of E\&IT and task performance? The longer the timeframe the more likely that there will be a decay of skills?

(6) Could a job performance aid or self-study packet be used in place of a course?

(7) Is the task better suited to On-Job-Training (OJT)?

b. Structure Tasks. This is the process of organizing tasks and sub-tasks in an order and sequence based on a relationship that captures performance. The performance may in turn be an action which is physical (overt and observable) or more cognitive in nature. The task analysis process is dynamic. A task analysis should highlight and identify dependency and a logical sequence. In some cases an interdependency of common skills may become apparent. There are automated support tools to assist with the activity and there are alternative forms to a task analysis. Regardless of approach, SME input is essential. The task analysis is intended to provide the structure to guide the writing of POs. A diagram of structured task statements may illustrate hierarchical and procedural relationships, such as Figure 5-3 
or it may be more overlapping with interconnected dependencies such as in a concept map, illustrated in Figure 5-4. With procedures there is a definite start and end. There may also be decision points and subordinate processes that illustrate a critical path. Task analysis examples are provided in Annex I.

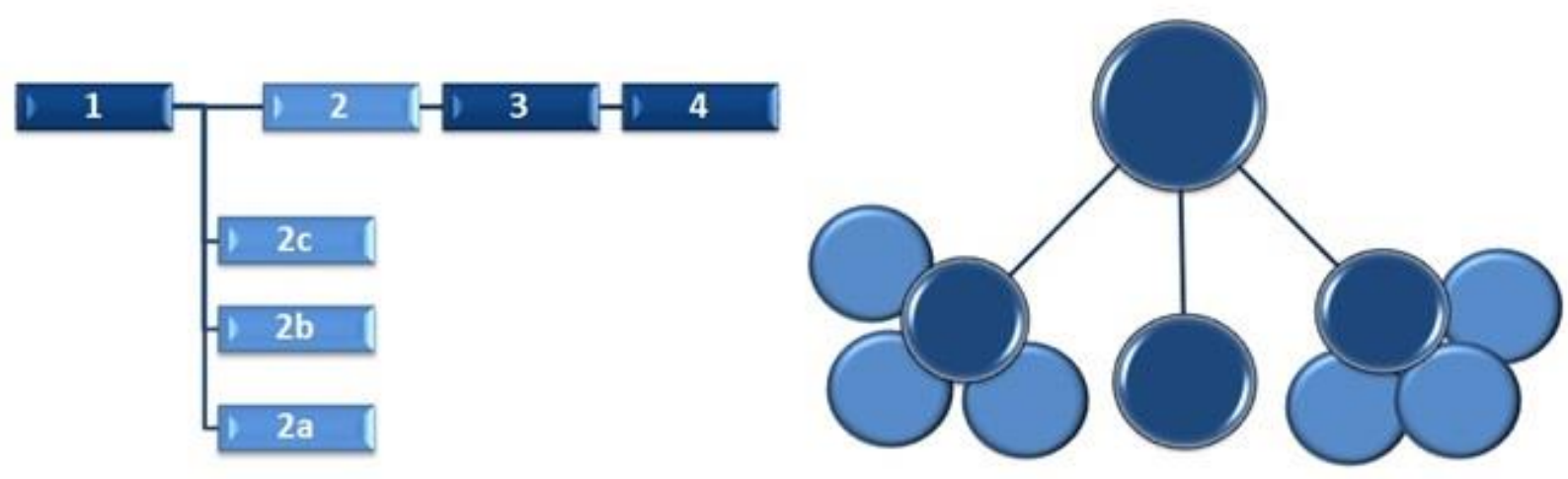

Figure 5-3 Hierarchical and procedural

Figure 5-4 Concept Map/Web Diagram

\section{STEP 3: WRITE PERFORMANCE OBJECTIVES (PO) ${ }^{45}$}

5-7. POs specify, in precise terms, what an individual must be able to do in terms of job performance. Once the performance/task statements are refined, structured and sequenced, including the additional tasks, sub-tasks and other supporting elements (or discrete actions), they are logically grouped and consolidated into POs. A PO often represents a broad duty area and the PO includes a clear performance statement to represent this consolidation. In addition, a PO includes the conditions under which the performance is to be carried out and a standard which defines the proficiency level to which individuals are expected to achieve. Not all tasks, sub-tasks and task elements identified during the previous step will necessarily appear in the POs but they can help formulate the conditions and standards statements. Specific standards of performance may already be defined within existing documentation. PO standard statements should be linked to the references when possible. POs become the basis for RA and DH agreement regarding the specific outcome to be achieved as a result of an E\&IT solution. Further guidance for writing POs, including example POs, is provided in Annex J. The elements of a PO are as follows:

a. Performance Statement. A clear, concise and precise statement representing a logical and complete part of the job function which is observable and measurable. The performance statement forms the first element of the PO. Performance statements are derived from the task statements identified during task analysis. A PO performance statement often represents a group of related tasks and activity. For example: "write a memorandum", "write a military letter", and "document minutes of a meeting" are all tasks which could be combined into: "prepare military correspondence". The determining factors in grouping and combining tasks are the similarity and complexity of the skills required to perform each task.

\footnotetext{
45 POs become the basis for external evaluation and determine if what was learned during a course has transferred to the job context. Additional detail concerning the link with external evaluation is provided in Chapter 9.
} 
b. Conditions. Conditions provide context and describe the situation, under which the performance must be completed. Conditions affect how the job or function is done. These are based on the actual workplace or other presumed area of operation. This answers: when, where, and with what the tasks will be performed.

c. Standards. Standards describe how and how well the performance must be completed. The greater the specificity provided, the more valuable the contribution to the development of E\&IT solutions. Clear, detailed and specific standard statements provide the scope and focus for E\&IT; they also facilitate accurate assessment. In all instances, the proficiency level required is based on actual job performance requirements. Standards generally specify a product, a process or a combination of the two and include measures of completeness, soundness of judgement, accuracy, and/or speed.

\section{STEP 4: REFINE TARGET AUDIENCE}

5-8. This step also provides an opportunity for a quality check and is a verification of the intended audience. At this point, the intent is to ensure the POs, as defined, address the needs at the differing levels of the NATO organizational structure (Political, Strategic, Operational and Tactical). The performance statement, the first element of a PO, may apply at the different levels; however, the conditions and standards may differentiate the performance based on the required proficiency and context. This review will determine if it is necessary to capture different POs based on the level within the NATO organizational/command structure and this will determine if there is a need for multiple E\&IT solutions to address the needs of the different target audiences. In most cases training individuals together across the different organizational levels leads to a unity of effort. Finally, this step confirms required language proficiency, pre-requisite assumptions (education and/or specific occupation background/experience required) and anticipated rank levels.

\section{STEP 5: FORMULATE GUIDANCE}

5-9. With a clear picture of what the result of an E\&IT solution is expected to achieve and the intended audience, it is now possible to provide additional guidance for the Design Phase activities which will follow. During this step the TNA WG will review Training Strategy options and provide a preliminary estimate concerning how the E\&IT requirement will likely be resolved. This includes:

a. An identification of the proposed learning environment.

b. An estimate of the duration for a course.

c. Potential for alternative interventions including use of OJT, seminars and/or job aids.

d. An annual production estimate - the anticipated annual demand based on an estimate of the number of personnel to be trained.

e. Funding options. An identification of potential funding sources for developing new E\&IT solutions, especially for emerging requirements, including common funding as well as other periodic Voluntary National Contribution Funding opportunities. 
5-10. For most situations the learning environment falls into one of three delivery options:

a. Residential Delivery. This is mainly instructor led instruction and involves bringing students to a centralized location. A specific ETF may possess purpose-built facilities such as classrooms, labs and training areas.

b. Distributed Delivery ${ }^{46}$. This involves taking a course to the students. Distributed delivery may be categorized as:

(1) E-Learning/Advanced Distributed Learning (ADL). This means of delivery infers that the instruction uses electronic and/or information technologies combined with methods of instruction which do not require the student to be present at a specific site and as a result the learning occurs at a distance. The E\&IT solutions can involve the use of an array of communications and collaboration tools as well as virtual/online environments; they maybe selfdirected (individual) programmed instructional packages or utilize real-time instructor collaboration and support.

(2) Mobile Education and Training Teams (METT). E\&IT solutions which involve delivering courses in the workplace or at another alternative to the residential location.

c. Blended Delivery. A combination of the residential and distributed instruction options. The potential to reach large numbers seemingly anytime and anywhere while still leveraging the benefits of residential delivery makes the blended approach attractive.

5-11. Delivery tends to fall within the options listed; however, there are other political/strategic or practical factors which may influence the selection of an optimal Training Strategy, such $\mathrm{as}^{47}$ :

a. Outsource delivery to a nation, a public/private institution (e.g., civilian university); or

b. Contract in expertise. Augment instructor capacity by hiring specialized instructional services for a specified period of time.

\section{STEP 6: DOCUMENT THE RESULTS}

5-12. This step is used to capture the results of the Analysis Phase. A record of proceedings is suggested in order to document the TNA WG decisions and methodology. The record of decisions may be included as part of the package which contains the two documents described below. Alternative formats for the Analysis Phase deliverables are acceptable. The intent is to ensure specific elements are addressed within the products. The two products are:

\footnotetext{
${ }^{46}$ Correspondence courses are another form of distributed delivery; however, technology enabled on-line or distance learning delivery, which is captured within ADL/e-Learning, has for the most part superseded "low-tech" delivery.

${ }^{47}$ OJT, internships and apprenticeships are alternative and highly effective experiential strategies for developing competence; however, these approaches have limited application in support of NATO E\&T.
} 
a. Course Control Document I - Control Form. The Control Form is a coversheet to a proposal for a new (or pre-existing) NATO E\&IT solution. The coversheet is specific to a course. The Control Form serves as the basis of agreement for moving forward and formalizing an E\&IT solution with a specific ETF. All NATO selected and approved E\&IT solutions, including those which are already developed and in place, require a Control Form. The Control Form will identify the specific stakeholders concerned with managing a discipline and concerned with the definition and delivery of E\&IT solutions. The sign offs acknowledge work is being undertaken and in some situations it infers obligations which should be annotated in respective NATO JDs (example: an External Course OPR appointment). The Control Form may also include various sign offs internal to the ETF. An example Control Form is provided in Annex K:

(1) ETF Course OPR. Identifies who is responsible for an existing or proposed E\&IT solution within the ETF. The Course OPR could be the TNA WG Chair or have a different title (e.g., Course Director).

(2) Quality Control. The internal controls and sign offs within the chain of command of the ETF which will lead to institutionalising an E\&IT solution.

(3) Command. ETF leadership. Formalizes the intent and commitment of the institution to move forward with a proposed NATO E\&IT solution.

(4) Other - External Course OPR. The External Course OPR is included if the ETF delivering the E\&IT solution required NCS support. HQ SACT/JFT will coordinate with the RA if the External Course OPR is not known.

(5) Department Head. Acknowledges the proposed E\&IT solution is in alignment with a discipline TRA Report ${ }^{48}$.

b. Course Control Document II - Course Proposal. The Course Proposal provides the foundation for a new E\&IT solution and includes enough detail to identify where and how the solution fits within the discipline landscape. The Course Proposal form is in Annex L. The Course Proposal includes the following:

(1) Requirement for a Course. The rationale for a specific E\&IT solution and this includes the background and history which served as the basis for creating a course.

(2) Aim. Provides the overall intent of the E\&IT.

(3) Performance Objectives. Details the intended job performance outcomes to be addressed through an E\&IT solution. Each PO includes a performance statement, the conditions and standard to be achieved. POs also specify the proficiency level and may include other additional details to support the design of E\&IT solutions.

\footnotetext{
${ }^{48} \mathrm{The} \mathrm{DH}$ is in the lead for the TNA; however, a specific ETF may execute the task on behalf of a DH. Once the Control Form is uploaded within the ETOC HQ SACT staff will verify with the DH if the DH endorsement is not provided.
} 
(4) Target Audience. This is a confirmation of the intended audience specifying who is eligible to enrol on the course, including the rank level, language proficiency and security clearance. The description may also include experience level, military occupation(s) or possibly a military specific branch affiliation which the E\&IT solution is intended for.

(5) Training Strategy. A brief description concerning how the E\&IT requirement will likely be resolved, including an estimate of the duration for a course or other alternative intervention.

5-13. The Analysis Phase concludes with a clear definition of the E\&IT requirements and provides guidance for designing E\&IT solutions. The Designated ETF submits the DH endorsed CCDs to HQ SACT/JFT through the ETOC to initiate the course certification process $^{49}$.

${ }^{49}$ Step 6 captures the essential and specific elements required for the certification of courses. See Certification of Courses (Chapter 2) for details pertaining to the review of existing courses which are uploaded into the ETOC.

Additional support with ETOC is available through: eitephelp@act.nato.int 


\section{CHAPTER 6 - SAT: DESIGN PHASE}

\section{INTRODUCTION}

6-1. Purpose. The purpose of the Design Phase is to create or, if a current solution exists, select an E\&IT solution which will enable individuals to achieve the POs constructed in the Analysis Phase.

6-2. Product. At the conclusion of the Design Phase, an instructional strategy is generated which includes what content will be delivered, how the content will be delivered and, most important, how learning will be monitored and assessed. For new courses this strategy is outlined in the Course Control Document III - Programme of Classes and this is to be uploaded into the $\mathrm{ETOC}^{50}$.

6-3. Methodology. The ETF generates the Course Control Document III - Programme of Classes and relies upon the support, creativity and expertise of a Design Team. The Design Team includes instructional staff (course director and faculty) and other content area experts as well as the support of an instructional design specialist to complete the NATO SAT definition stage. The final structure of content as well as the selection of methods and media is heavily influenced by the philosophical views of the Design Team and in particular beliefs concerning instruction and how individuals learn.

6-4. Process. The following steps are undertaken during the Design Phase and this builds upon the six steps which were started during the Analysis Phase. While the provision of specific steps appears prescriptive, the SAT within NATO is intended to be flexible and adaptive. The process described below is a logical and systematic means to generate Course Control Document III - Programme of Classes:
a. Step 7: Define Learner Characteristics.
b. Step 8: Conduct Instructional Analysis.
c. Step 9: Write Enabling/Learning Objectives ${ }^{51}$.
d. Step 10: Prepare an Assessment Plan.
e. Step 11: Define Instructional Strategies.
f. Step 12: Specify Content and Guidance.

\footnotetext{
${ }^{50}$ See Footnote 38 for additional guidance concerning format and structures for courses and solutions which already exist and which may serve as a suitable alternative to CCD III.

51 The term Enabling/Learning Objectives (ELOs) acknowledges the subtle difference which may be in place within national E\&IT systems. Enabling/Learning Objectives may be referred to as, "Enabling Objectives" or "Learning Objectives". They are considered synonymous and serve the purpose of providing the incremental steps which enable the essential learning required to achieve a broader, job focused, Performance Objective.
} 


\section{STEP 7: DEFINE LEARNER CHARACTERISTICS}

6-5. For an E\&IT solution to be effective and efficient, it must build upon what the prospective students can already do and what they know as well as provide a meaningful learning experience which motivates. In this step the target audience, defined earlier in the Analysis Phase, is revisited; however, the focus is now towards how the generalized characteristics of the target audience may affect learning. Considerations such as the size and location of the target audience may affect decisions concerning how the E\&IT solution is delivered. The focus is usually on the following three areas:

a. Subject-matter Competence. Examining current subject-matter competence assists with identifying the start point for learning and it also identifies potential prior experience which could be leveraged during the conduct of E\&IT.

b. Preferred Training Strategy. The demographic data, including the prospective student location(s), can influence the selection of the instructional environment. Is the target audience spread over a wide area? Consider the target audience age group and education level as well as the general attitude towards the use of computers and online learning options.

c. Student Motivation, Attitudes and Aptitudes. These are characteristics that can influence the selection of instructional strategies. The answers to the following questions will influence whether a more direct or controlled approach is required:

(1) What is the motivation level of the students?

(2) Is this E\&IT required and does it have career implications?

(3) What is the general attitude towards learning?

(4) Does the target audience have common interests?

(5) What is their attitude towards the subject matter being taught?

(6) What is their language ability?

(7) What is their reading and writing ability (e.g., residential instruction) or if an indirect approach is appropriate (e.g., ADL/e-learning)?

\section{STEP 8: CONDUCT INSTRUCTIONAL ANALYSIS}

6-6. Instructional Analysis begins with an examination of the POs in order to identify all components and sub-components of the tasks that make up the PO, including supporting skills and knowledge elements as well as other attributes, such as attitudes. The components and the other elements may also be considered as individual nodes which will ultimately be connected to create a representative picture of the course content. The aim is to determine everything a student needs to learn. The components, sub-components and supporting elements will in turn be grouped into supporting objectives, and these will be place in a sequence suitable for learning. The Design Team generates the elements through discussion and brainstorming and they may also be extrapolated from reference material, including: doctrine, procedural manuals, directives, lessons learned and personal experience. Indicators of attitudes that affect a PO include safety and security considerations and dimensions of 
character and leadership (i.e. elements of judgement, ethical decision making and the care/concern for others).

6-7. During the Instructional Analysis, the skills and knowledge elements are broken out into their sub-components when it is anticipated that separate demonstrations (of skills and attitudes) or explanations (of knowledge or attitudes) will be useful. This deconstruction process follows along similar processes to that of a Task Analysis and stops when the identified elements are at the level of the target audience's entry level abilities (baseline skill/knowledge/attitudes). The intent is to identify the core content that students will need to internalize and master in order to achieve the POs identified during the Analysis Phase. An example of an Instructional Analysis is outlined in Figure 6-1.

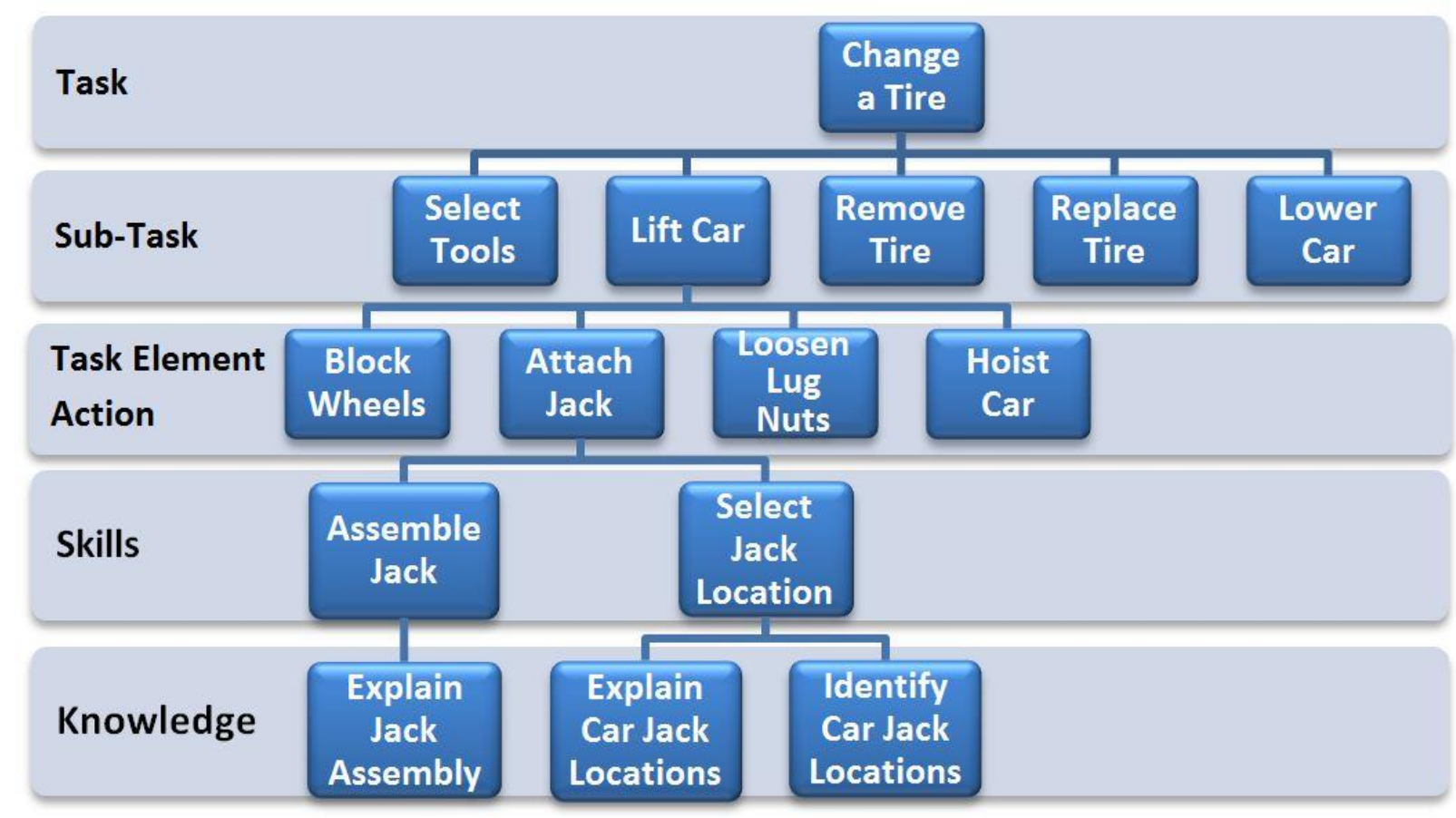

Figure 6-1 Instructional Analysis

6-8. The Instructional Analysis is complete once the main points (the teaching points) associated with the supporting (enabling) elements have been identified. Teaching points are the discrete steps, facts or concepts that will require a separate demonstration or explanation. 


\section{STEP 9: WRITE ENABLING/LEARNING OBJECTIVES (ELO) ${ }^{52}$}

6-9. ELOs identify a segment of instruction which constitutes a major step to enable PO achievement. ELOs define what the individual will learn and are the basis for providing evidence of student progress. In addition to writing the ELOs, this step also includes grouping and sequencing the supporting teaching points. ${ }^{53}$

6-10. ELOs often correspond to the major components (tasks and sub-tasks) identified when deconstructing POs during Step 8 - Instructional Analysis; however, an ELO may also be structured based on the supporting knowledge, skills, and attitude (KSA) elements. A well written ELO provides the basis for student assessment and this is generally the basis for the decision to develop an ELO. The ELOs will also guide the sequencing of instruction and other decisions which follow concerning an instructional strategy. The KSA elements, which support tasks, are categorized into specific learning domains and structured to reflect different levels of learning required during a course. KSA descriptors are summarized in Table 6-1 and additional detail concerning the application of the levels within the related learning domains is provided in Annex M.

\begin{tabular}{|c|l|l|}
\hline $\begin{array}{c}\text { Supporting } \\
\text { Element } \\
\text { (Domain) }\end{array}$ & \multicolumn{1}{c|}{ Definition } & \multicolumn{1}{c|}{ Examples } \\
\hline $\begin{array}{c}\text { Knowledge } \\
\text { (Cognitive) }\end{array}$ & $\begin{array}{l}\text { The theoretical and practical understanding of subject } \\
\text { matter required to perform work. It is the information } \\
\text { required to effectively accomplish a step, task, or job. This } \\
\text { involves the cognitive processing of information (storing, } \\
\text { recalling and interpreting) and its subsequent application, }\end{array}$ & $\begin{array}{l}\text { - explain the format of } \\
\text { the operations order; } \\
\text { and } \\
\text { describe the steps for } \\
\text { clearing a building. }\end{array}$ \\
\hline $\begin{array}{c}\text { Skill } \\
\text { (Psychomotor) }\end{array}$ & $\begin{array}{l}\text { An organized and coordinated pattern of mental and/or } \\
\text { physical activity that becomes refined through repetition and } \\
\text { practice. }\end{array}$ & $\begin{array}{l}\text { clear a building. } \\
\text { organize inventory. }\end{array}$ \\
\hline $\begin{array}{c}\text { Attitude } \\
\text { (Affective) }\end{array}$ & $\begin{array}{l}\text { An opinion or conviction which underlies or motivates } \\
\text { behaviour. A pre-disposition to behave in certain ways and }\end{array}$ \\
$\begin{array}{l}\text { generally believed to be developed over time and largely } \\
\text { shaped by an environment. Attitude is composed of } \\
\text { cognitive (belief), affective (emotional), and behavioural } \\
\text { (action) components. }\end{array}$ & $\begin{array}{l}\text { - safety consciousness. } \\
\text { cultural sensitivity. } \\
\text { ethical conduct. }\end{array}$ \\
\hline
\end{tabular}

Table 6-1 Abilities: skills, knowledge and attitude

6-11. ELOs may also take shape as a result of clustering related supporting skill and knowledge components which are common across a PO or POs. This most commonly occurs when it is necessary to create a base of shared knowledge or foundational skills which would otherwise be common across several ELOs. It may be necessary to go through several iterations during the Instructional Analysis to establish a satisfactory structure and ultimately define the ELOs and content for the E\&IT solution.

6-12. ELOs, like POs, are composed of three essential parts: a performance statement, conditions statement, and a standard. The difference between the two types of objectives is the focus; the PO is intended to articulate job performance whereas ELOs are situated within

\footnotetext{
${ }^{52}$ An Enabling/Learning Objective may also be referred to as a "Learning Objectives" or "Enabling Objectives".

${ }^{53}$ Teaching points become the content for an E\&IT solution. Given the iterative nature of this activity capturing the teaching points during this step will provide greater clarity and assist with the grouping and sequencing ELOs.
} 
the learning context and describe what an individual will have learned following instruction. An example of an ELO is provided in Annex N. The elements of an ELO are as follows:

a. Performance Statement. A clear, concise and precise statement representing a logical and complete segment of what is to be learned in order to achieve a PO. This statement provides an indication of the learning domain and the level of learning to be achieved.

b. Conditions. Conditions statements describe the context in which learning will occur. This answers: when, where, and with what the learning will occur.

c. Standards. Standards define the criteria for acceptable performance by a student within the E\&IT environment. Standards may be stated in terms of a performance sequence, completeness, accuracy, time and/or other qualitative characteristics. The standard identifies the depth and level of learning the students must achieve when they perform under the specified conditions. Without a standard, it is difficult to determine when students have achieved the required level of learning. When appropriate, the standards may also include the criteria for attitudinal indicators/traits (e.g., safety consciousness) given it is rare for an ELO to be constructed which specifically addresses attitudes without some element of skill and knowledge.

6-13. Once the ELOs have been identified and defined the supporting teaching points can be grouped and sequenced with the ELOs. The ELOs and the teaching points guide the remaining Design Phase activity, including the identification of the activities required to achieve the intended levels of learning. Teaching points become the core content for the E\&IT solution. The teaching points generally fall within one of five content categories and the categories affect the sequencing of the teaching points and the selection of an instructional method. The five content categories are:

a. Facts. Specific and unique data or information. This includes the basic elements students must know in order to be acquainted with a discipline and this includes definitions and terminology.

b. Concepts. A classification of items, words, or ideas. The interrelationship among the basic elements within a larger structure enables them to function together.

c. Processes. A flow of events, actions or activities that detail how things work as opposed to how to do things. There are normally two types: business processes (or work flows) and technical processes that describe how things work in equipment or nature.

d. Procedures. A series of step-by-step actions and decisions that range in levels of complexity and result in the achievement of a task. There are two types of procedural actions and these are linear and branched.

e. Principles. Guidelines, rules, and parameters that govern outcomes, decisions. This includes what should be done as well as what should not be done. Principles allow one to make predictions and draw implications. Given an effect, one can infer the cause of phenomena. Principles are the basic building blocks of causal and theoretical models. 
6-14. Instructional Analysis provided a visual representation to support the grouping and associating of the teaching points. Once the ELOs are defined linking the teaching points becomes fairly straightforward. The teaching points should be structured into logical units and organized into a sequence that will guide learning. A complete picture of the hierarchy of objectives and teaching points is provided in Figure 6-2. The following are suggested teaching point structures:

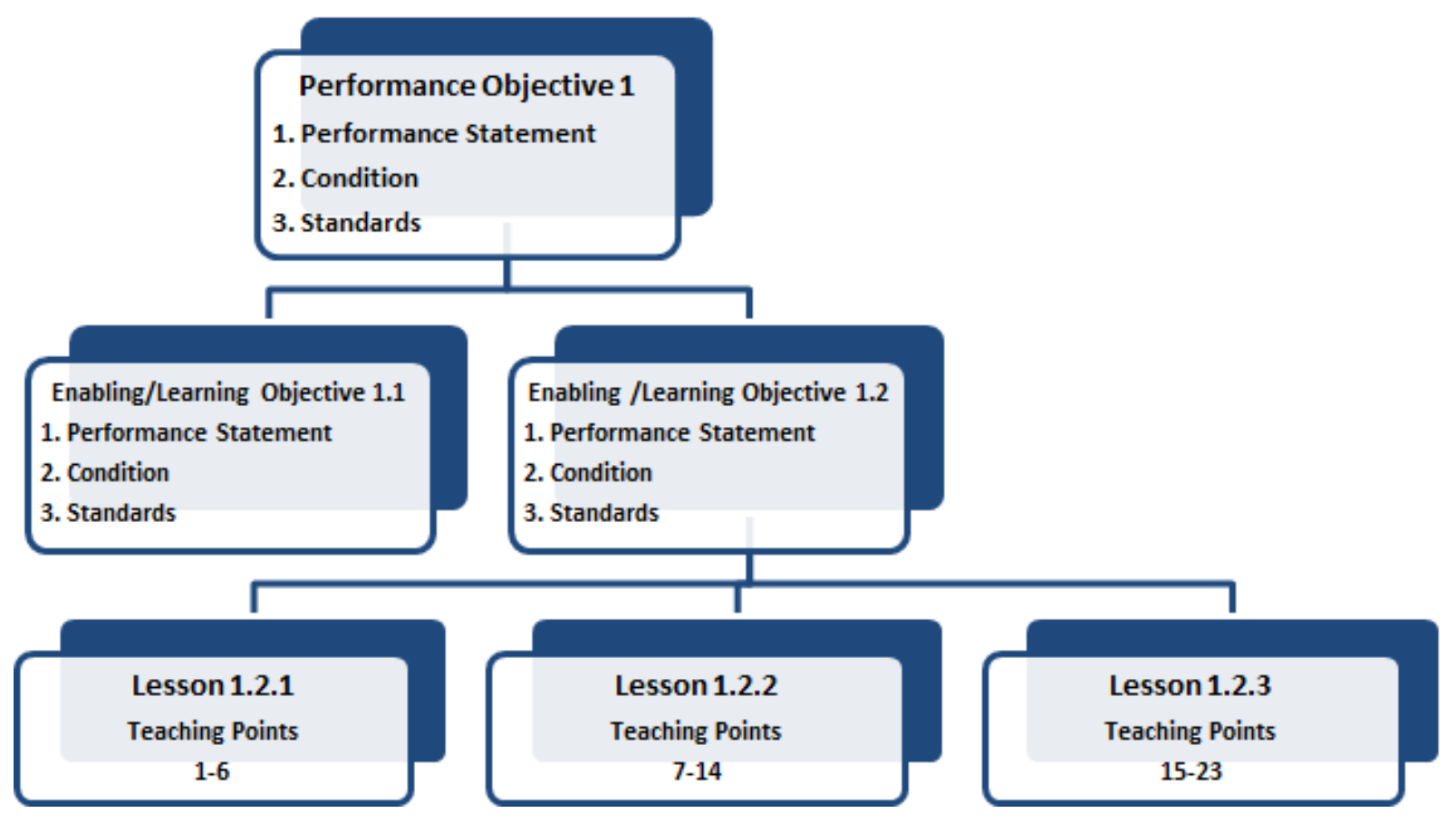

Figure 6-2 Hierarchy of objectives

a. Whole to Part. Present the result or product first, and then present the process for each step.

b. Part to Whole. Present the process or steps first, then the final result or product.

c. Simple-to-Complex. Present concepts that the target audience may be familiar with or that are less complicated, then build on these concepts by presenting newer or more difficult ones.

d. Complex-to-Simple. Actions are sequenced in terms of decreasing complexity; each associated with the larger complex structure of which it is a part.

e. Chronological. Present concepts or ideas in the order they occur over time, such as with historical events.

f. Sequential. Present procedures or steps in the order they are performed on the job.

g. Cause and Effect. Actions are sequenced to demonstrate cause and affect relationships. This sequencing is appropriate for relationships that individuals must commit to long-term memory. 
h. Critical Order. Actions are sequenced in the order of relative importance, whether from the least important to the most or vice versa. Teaching points favouring this technique are those that generally require important actions. Example: "Clear the weapon" would be sequenced prior to: "Disassemble the weapon".

6-15. A complete ELO will identify a type of learning (e.g., skill versus knowledge) and define the level of learning to be achieved through an E\&IT solution. Levels of learning are expressed in terms of a Depth of Knowledge (DoK) and skill ${ }^{54}$. DoK is aligned with the job performance proficiency levels that were outlined previously in Annex G. A matrix illustrating the alignment of DoK and job performance proficiency levels is provided in Annex O. This matrix is used during future steps to make design decisions and may also be useful when assessing the fit between an NATO E\&IT requirement and existing E\&IT solutions.

\section{STEP 10: PREPARE AN ASSESSMENT PLAN}

6-16. The Assessment Plan builds from the ELOs and establishes the overall strategy for student evaluation. The Assessment Plan specifies how achievement of the POs will be assessed and how the student progress will be monitored. Student progress is based on the assessment of the ELOs. The Assessment Plan for a specific E\&IT solution will also take into consideration broader Standard Operating Procedures (SOPs) and related instructions within the ETF (e.g. policies for plagiarism, attendance, progress review/appeals, and personal conduct).

6-17. The Assessment Plan should be performance oriented and, to the maximum extent possible, emphasize practical testing in order to determine achievement. Practical tests require the student to apply skills and knowledge and perform in realistic settings. Theory tests can be an effective supplement to practical tests. Theory tests are generally in written form (e.g., short answer) and employ sampling; Sampling involves selecting representative elements from a larger field of knowledge. Oral interaction/examination may also be an effective means of student assessment.

6-18. An Assessment Plan provides a guide for the construction of assessment instruments during the Development Phase. The considerations for the Assessment Plan are captured and explained in Table 6-2.

\footnotetext{
${ }^{54}$ Depth of Knowledge (DoK) refers to the level of skill and knowledge to be learned as a result of an E\&IT solution. DoK is intended to be an inclusive term covering all three learning domains. The DoK levels are aligned with job performance proficiency levels.
} 


\begin{tabular}{|l|l|l|l|l|l|}
\hline \multicolumn{1}{|c|}{ Element } & \multicolumn{1}{|c|}{ Purpose } & \multicolumn{1}{c|}{ How } & When & Resources & $\begin{array}{l}\text { Coordination } \\
\text { Instructions }\end{array}$ \\
\hline $\begin{array}{l}\text { Identifies } \\
\text { what is to be } \\
\text { assessed } \\
\text { relative to the } \\
\text { PO /ELO } \\
\text { structures. }\end{array}$ & $\begin{array}{l}\text { What is } \\
\text { being } \\
\text { assessed in } \\
\text { terms of } \\
\text { content and } \\
\text { the level of } \\
\text { proficiency? } \\
\text { ls this } \\
\text { formative or } \\
\text { summative } \\
\text { assessment? }\end{array}$ & $\begin{array}{l}\text { How will this } \\
\text { be assessed: } \\
\text { practical test, } \\
\text { group project } \\
\text { or a syndicate } \\
\text { exercise, } \\
\text { assignment, a } \\
\text { theory/written } \\
\text { test, and/or } \\
\text { student } \\
\text { presentation? }\end{array}$ & $\begin{array}{l}\text { When in the } \\
\text { sequence of } \\
\text { ELOs and the } \\
\text { overall } \\
\text { schedule } \\
\text { should this } \\
\text { happen? }\end{array}$ & $\begin{array}{l}\text { Identify the } \\
\text { specific } \\
\text { resources } \\
\text { required? }\end{array}$ & $\begin{array}{l}\text { Determines what } \\
\text { is considered } \\
\text { success and the } \\
\text { impact of not } \\
\text { being } \\
\text { successful. }\end{array}$ \\
\end{tabular}

Table 6-2 Assessment Plan Template

\section{STEP 11: DEFINE INSTRUCTIONAL STRATEGIES}

6-19. Overview. The instructional strategy is the combination of instructional methods, media and the environment within which they are used to conduct instruction; the interconnections are illustrated in Figure 6-3. During this step the three elements are examined in order to determine how the content will be delivered and how the optimal conditions for learning are created $^{55}$. One of the more familiar examples of an instructional strategy is a lecture (method), led by an instructor with supporting material (the medium/media) in a classroom (environment). The key to good design comes in the form of meaningful activities more so than content, and in particular:

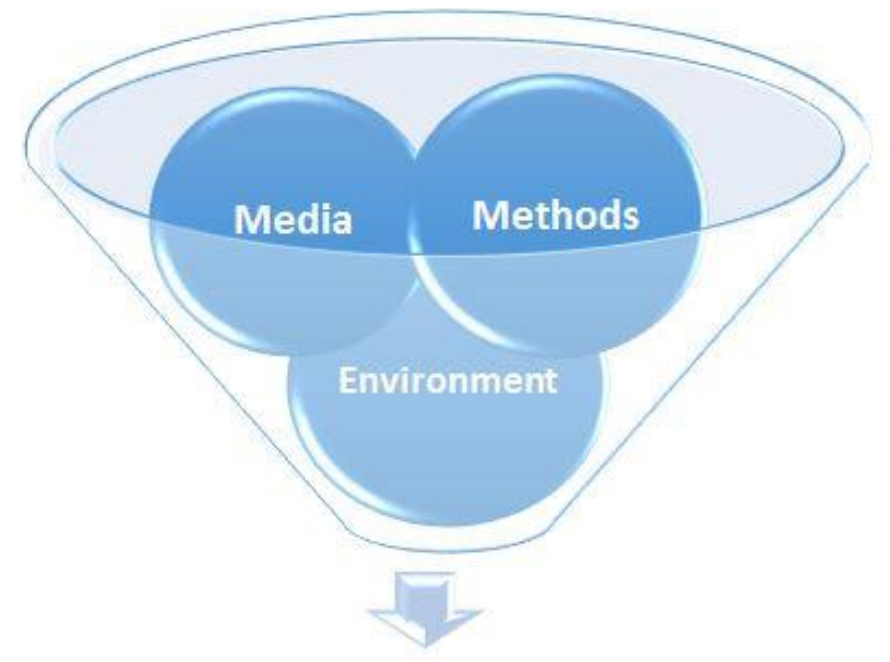

Instructional Strategy

Figure 6-3 Instructional Strategy Elements

\footnotetext{
${ }^{55}$ Clarification: Instructional strategy vice learning strategy. Instructional strategy is a preferred term given it defines the environment where learning takes place including the activities, events and media; these are the conditions external to the learner. Learning, on the other hand, is dependent on individuals and learning is an outcome, the result of instruction. A Design Team creates the conditions for learning through the structure, sequence and the planning of events; however, it doesn't "design learning" given this is an internal, individual process.
} 
a. Ensuring the instructional experience is realistic, relevant and ideally problemcentred.

b. Embedding opportunities for interaction, participation and active engagement during the learning process.

6-20. Verify the Environment. At the conclusion of the Analysis Phase, a broad Training Strategy is outlined within Course Control Document II. The Training Strategy proposes the environment and overall approach to achieve the POs. The Training Strategy is an expression of intent. At this point, the proposed environment is reviewed and the feasibility assessed ${ }^{56}$. When an ADL/e-Learning environment is proposed the selection of methods and media can often require greater sophistication, examination and planning. The ELOs and the assessment strategy defined earlier in the Design Phase (Steps 9 and 10) will remain integral to guiding instructional strategy decisions regardless of instruction being delivered on-line or through a more traditional residential course. HQ SACT/JFT provides further guidance to support the governance, development and use of ADL/e-Learning ${ }^{57,58}$.

6-21. Identify and Select Methods. The term method refers to a type of learning activity or instructional event, such as a practical demonstration, case study or guided discussion. There are a wide variety of instructional methods and many factors influence decision making. A description of suggested instructional methods and their application guidelines is provided in Annex $\mathrm{P}$. The aim is to identify methods that have a high probability of promoting learning and that support the transfer of what is learned back to the work/operational environment. Method selection is primarily influenced by the ELO. Other considerations include the course content and structure as well as the assessment plan and the philosophical considerations regarding the learning process. The philosophical considerations will influence the social dynamics and the level of control over the learning environment ${ }^{59}$. The grouping of teaching points as well as suitability for, and size of, the intended audience also influence method selection. A method selection matrix based on the ELO, and in particular the type and the intended level of learning to be achieved, is provided in Annex Q. The following considerations should be factored into the overall instructional strategy and method selection:

a. What will interest, engage and motivate students?

\footnotetext{
${ }^{56}$ Feasibility is confirmed by the institution providing the E\&IT solution. There are several factors which determine feasibility. The importance and relevance of the considerations are determined by the institution supporting the E\&IT solution and the associated chain of command. The considerations include organizational and student readiness, the business case as well as the appropriateness and suitability of the content.

${ }^{57}$ Guidelines for the procurement, development, implementation and evaluation of Advanced Distributed Learning. Version 1.0. NATO Training Group - Task Group for Individual Training and Education Developments (IT\& ED), December 2014. Additional training supporting the design, development and evaluation of ADL/eLearning courseware is available through NSO.

${ }^{58}$ See: ACT Directive 075-011 and the e-Learning Concept (Release 4) dated 28 January 2014. Prepared, maintained and distributed by HQ SACT/DCOS JFT. For technical advice: adl@act.nato.int

${ }^{59}$ Depending on the ELO it may be appropriate to provide students with opportunities to assume greater control and influence within the learning environment and provide opportunities for individuals to learn from each other. The characteristics of the target audience will determine the degree to which a learner centred approach would be appropriate. The characteristics of the target audience, reviewed at the start of the Design Phase (Step 7), capture subject matter competence and experience levels which could be leveraged during instruction. Leveraging student experiences encourages active engagement and assists with overcoming potential resistance and can have a positive effect for student motivation.
} 
b. Does the target audience have previously acquired skills/knowledge and/or other experiences which could be leveraged?

c. Are there opportunities for reflection embedded in the course overall? A well designed course provides opportunities for reflection, such as allocating time for a post exercise debrief. Reflection in the context of learning can be described as linking ideas and constructing meaning from experiences be they personal or otherwise. Individuals do not learn from direct experiences on their own. The learning results from reflecting on the experiences.

d. Are there operational scenarios, lessons learned, incident reports or stories which could be leveraged and used to promote higher levels of learning through more active engagement? This in turn could influence decisions to use specific imagery and video.

6-22. Identify and Select Media. Media are the delivery vehicles (the means, instrument, or material) used to provide the sensory stimulus to a student to heighten the potential for learning. Although the selection of instructional methods and media is discussed individually, they cannot be considered separately. Proper media ensures that information is presented to the students by the most effective and cost-efficient means possible. In an instructional situation, there is a message to be communicated. Video, web pages, diagrams and graphics, electronic slides and printed material are examples of media used to directly communicate or otherwise support the message to be delivered.

6-23. To be instructionally effective, a medium - or combination of media - must complement the method and ideally elicit a response. In general, terms the media selected should:
a. Provide a degree of realism and encourage practical application.
b. Provide feedback to the student.
c. Encourage interaction between students and the instructor, or the support system should there be no instructor in the loop.
d. Align with the assessment of students in accordance with the assessment plan.

\section{STEP 12: SPECIFY CONTENT AND GUIDANCE}

6-24. A clear description of the instructional strategy completes the Design Phase and concludes the definition stage within the NATO SAT. The details are documented in the Course Control Document III - Programme of Classes. At this point, a security classification can be confirmed. The Course Control Document III details are subsequently uploaded into the ETOC and this will lead to the activation of a NATO recognized E\&IT solution. This step will also capture the description of the intended audience, specifying who is eligible to enrol on the course. The results of the previous steps in the Design Phase are documented and the following additional detail is captured:

a. Time Allocation. An estimate of the time required to satisfy each of the ELOs based on the methods and media selected as well as the additional administration and support time to be captured in an individual course schedule/timetable. 
b. References. A list of the reference material in particular NATO doctrine, procedural manuals, directives and documented lessons learned which are applicable to a given ELO.

c. Resource Requirements. A list of the facilities, personnel, equipment and materials essential to successfully implement the overall instructional strategy as well as the materials which are required during individual events or lessons.

d. Limitations. A description of limitations which prevent the completion of a PO. These limitations often effect student evaluation and are a result of resource constraints or other limiting factors based on conditions and the desired standard to be achieved. Proficiency requires experience hence it is reasonable to assume the standard of a PO will require a period of on-job-experience in order to achieve the desired levels.

e. Remarks. Any additional comments that further clarify the intent of the design decisions.

6-25. The results of the Design Phase, and in particular the details in the Course Control Document III, are used by the DH to assess the alignment (the degree of fit) between the proposed E\&IT solution and NATO's E\&IT requirements ${ }^{60}$. Example formats for the Course Control Document III - Programme of Classes are provided in Annex R. Alternative formats are acceptable. The main concern is the content contained within the document.

${ }^{60}$ See Certification of Courses (Chapter 2) for details pertaining to the review of existing courses which are uploaded into the ETOC. 


\section{CHAPTER 7 - SAT: DEVELOPMENT PHASE}

\section{INTRODUCTION}

7-1. Purpose. The purpose of the Development Phase is to produce, or otherwise procure, the materials and/or services that are essential to support the delivery of an E\&IT solution and ultimately satisfy the objectives described in the CCDs.

7-2. Product. The Development Phase results with the production of courseware which is defined during the Design Phase and is described in the CCDs. The courseware products will vary in their complexity and sophistication based on the instructional strategy. Products can include student hand-outs, electronic presentations and master lesson plans through to more sophisticated programmed ADL/e-learning applications, training devices and simulators.

7-3. Methodology ${ }^{61}$. The execution of the Development Phase will vary based on the required products and the level of resident expertise. In some situations the Development Phase will require a specific management plan to provide the necessary controls and oversight. A project management plan is essential for Development Phase initiatives involving the procurement of specialized services for courseware production as well as the procurement of training aids, devices and equipment (e.g., procuring simulators, developing ADL solutions).

7-4. Process. There are five major milestones to be achieved during the Development Phase. The supporting activity will often occur concurrently, as opposed to a specific sequence of steps as described in earlier SAT phases. The Development Phase should; however, conclude with the conduct of trials. The following are the major milestones to be achieved in the Development Phase:
a. Procure/Produce Instructional Materials.
b. Procure/Produce Assessment Instruments.
c. Develop an Optimum Schedule/Timetable.
d. Prepare Instructional Staff/Faculty Plan.
e. Conduct Trials.

\footnotetext{
61 At this point the decisions made concerning the instructional strategy will influence the development methodology. The Development Phase for ADL/e-Learning solutions will rely on a different approach to the path taken for more traditional - residential courseware. E-Learning generally requires specialized design, development as well as programming expertise in order to produce more detailed design treatments and build the products to satisfy the ELOs defined during the NATO SAT Design Phase. The methodology is dynamic (not linear) and often relies on a prototyping approach. The additional considerations and supporting work products can include: style guides and scripted storyboards, which outline course navigation and flow, along with plans for student interaction, possible collaboration and communications. During ADL/e-Learning development visual elements and other embedded multi-media objects to be incorporated into courseware also may be specified. Additional training supporting the design, development and evaluation of ADL/e-Learning courseware is available through NSO.
} 


\section{PROCURE / PRODUCE INSTRUCTIONAL MATERIALS}

7-5. Instructional materials for residential delivery include the lesson plans, training aids (including real equipment) and other resources essential to guide and support learning. The materials also include the references as well as potential job aids, templates and checklists that, in addition to supporting the conduct of E\&IT, will also facilitate the transfer of learning to the workplace. Appropriate materials may be procured, or may already exist or be available from alternative sources, including other ETFs; however, more often a significant amount of inhouse effort will be required to fully develop an E\&IT solution. Excluding the procurement of major equipment, training devices and simulators, the main materials to be developed generally include:

a. Student Manuals and Handouts. These are the reference handbooks and support materials used and retained by the students, ideally in an electronic format. The contents vary but the intent is to support learning and encourage the transfer of learning to the workplace.

b. Instructor/Course Director Guides. These are the procedures and specific instructions for use by the instructor/faculty and Course Directors during the planning, preparation, execution as well as close out of specific E\&IT activities. The guide links to relevant institutional guidance, such as unit SOPs. The Instructor Guide may also include instructions for individual learning events and lessons, emphasizing coordinating instructions and potentially the key teaching points. When applicable, guidance concerning guest speakers/lecturers may be included in order to ensure proper coordination and that the objectives of the specific activity are achieved. An Instructor/Course Director Guide is intended to provide the definitive coordinating instructions essential to planning, preparation, execution and closeout of a course but should avoid duplicating existing SOPs. Instructor Guides are even more essential for ADL/e-Learning solutions. The use of electronic formats provides greater flexibility and adaptability.

c. Master Lesson Plans. Master lesson plans are generally used to provide detailed guidance and the required supporting materials (e.g., electronic presentations) in order to minimize the preparation time for the instructor cadre. The degree of detail varies based on institutional practices and preferences. Master Lesson Plans serve as detailed guides and, where appropriate, provide the opportunity for individual faculty/instructors to personalize.

\section{PROCURE / PRODUCE ASSESSMENT INSTRUMENTS}

7-6. The Assessment Plan, developed during the SAT Design Phase, identifies the assessment instruments to be constructed. The primary purpose for assessment is to determine if learning has occurred and the POs have been satisfied. Assessment also provides insight regarding student progress. These forms of assessment are often framed as formative assessment and summative assessment. The Assessment Plan will identify instruments and these generally fall into two broad categories:

a. Performance-Based. A performance-based assessment is a test that closely replicates a job context potentially using the same equipment, resources, setting, or circumstances that the individual would encounter. Performance based testing tends to increase the transfer of learning. Limitations of time, staff, and resources often constrain the degree of realism in practical, performance-based, testing. Normally, a 
performance checklist is used to record the level of achievement. The test will require specific instructions for both the instructor and the student. Presentations, demonstrations, a written assessment and/or report which reflect the job context are examples of a performance-based test.

b. Knowledge (Theory) Based. Knowledge-based assessment can be in an oral or written form. This method of assessment does not necessarily evaluate an individual's ability to perform the required job skills; however, it does provide an indication if the individual has the required foundation, the know-how, to perform. Although the emphasis is on practical testing, theory tests may be effective supplements to the performance based approach. The advantage of knowledge-based tests is the potential for a high degree of objectivity in scoring and the capability of measuring a large number of facts, concepts and principles in a relatively short time. Knowledge tests are typically constructed of the follow types of items:

(1) Multiple-choice,

(2) Matching,

(3) True-false,

(4) Essay,

(5) Short answer, and

(6) Completion (fill-in-the-blank)

c. There are many variations to knowledge-based tests which can provide authentic assessment, including:

(1) Out of Class (Take-home) Assignments. This less formalized form of assessment allows individuals to use references and other resources.

(2) Open-Book Tests. This type of assessment can reduce stress, but may decrease the student's motivation to study or internalize information.

(3) Paired/Group Testing. This allows students to work in pairs or at a syndicate/group level. This is a collaborative form of assessment.

(4) Individual Portfolios. This allows students to demonstrate how they have achieved the objectives through submission of work products.

7-7. Assessment instruments generally consist of three parts:

a. Administrative Instructions. The guidance necessary to establish required conditions for assessment to occur and this includes:

(1) Instructions for an Administrator. This outlines what is required prior to conducting student assessment (the set-up) and the instructions to be followed during the assessment event as well as the administrative routine afterwards. 
(2) Instructions for the Student. These instructions set expectations concerning behaviour during the assessment process and inform student of what to expect during the test situation, and what must be done to succeed.

(3) Instructors for the Proxy or Scorer. These instructions outline how to score the test, interpret results and make a judgement which will determine the result.

b. Assessment Instrument. The actual test or practical checklist which is used to gather data regarding student achievement.

c. Scoring Guide. The guidance or instrument (answer key) used to interpret results and make the judgement concerning student achievement and success.

\section{DEVELOP AN OPTIMUM SCHEDULE / TIMETABLE}

7-8. The optimum schedule is a plan of instructional activities intended to achieve the best possible learning conditions. The sequence of instruction is important to the success of any E\&IT solution. Schedules will also have to factor in administrative requirements and other standard briefings including security briefs as part of the institutional routine. The ADL/eLearning solutions will also have to factor in student availability across multiple time zones in addition to potential maintenance interruptions which may block access to the online Learning Management System (LMS). A well-planned schedule has the following characteristics:

a. $\quad$ Progression. The schedule brings students to the required standard through a logical sequence of events and activities, this requires pre-requisite knowledge prior to skills development and, where it is applicable, a step by step flow based on the performance sequence.

b. Variety. Wherever possible, without being at cross-purposes, POs and ELOs should be presented in a variety of sequences and using a variety in instructional methods in order to maintain interest and avoid fatigue.

c. Tempo. The tempo of instruction should build through periods of intense activity and be followed by periods of relative relaxation while taking into consideration a balance of the natural energy rhythms impacting Fatigue and Effectiveness as well as opportunities for reflection.

d. Efficiency. An efficient schedule is one which makes optimum use of facilities, resources and opportunities in both the support and the delivery of an E\&IT solution. An example would be leveraging a guest speaker across multiple courses simultaneously as well as having a leading expert address different courses during a single visit to an ETF.

e. Flexibility. The provision of spare periods addresses unforeseen circumstances. Without this reserve a course may run into difficulty. The addition of one spare training day for every thirty scheduled training days is reasonable planning estimate. 
7-9. There are additional factors to be considered when sequencing activities for optimum effect. The influence of these additional factors will vary depending on the broader intent of the E\&IT solution; however, in general, the considerations are as follows:

a. Saturation. The point reached when the rate of instruction is such that what is to be learned is neither internalized nor retained.

b. Fatigue and Effectiveness. Scheduling activity in accordance with the natural physical, mental and behavioural rhythms which can affect the body. Known as the circadian rhythms, these are changes that generally follow a 24-hour cycle, responding primarily to light and darkness and the influence of energy levels and wakefulness. Suggested guidelines to address fatigue and effectiveness are as follows:

(1) Schedule the more mentally challenging work in the morning.

(2) Schedule the more interesting work, along with opportunities for active engagement, in the afternoon.

\section{PREPARE INSTRUCTIONAL STAFF / FACULTY}

7-10. Preparing the instructor staff/faculty addresses organizational readiness and is part of the essential steps for preparing for implementation. Staff will generally need to be familiarized with the necessary coordination and administrative routines (booking accommodations, resource management and funding routine) while instructors must be able to deliver the E\&IT solution effectively, be it online or within a more traditional setting once it is developed. While instructor expertise is often dependent upon individual skill level and experience, formalizing an instructor development plan closes the readiness gap and establishes the conditions for success. The following guidance is provided; however, the specifics will need to be adapted to suit each ETF:

a. Confirm instructors have the subject matter expertise.

b. Arrange opportunities to develop individual presentation and instructional skills as well as how to manage the instructional setting.

c. Provide new instructors with initial indoctrination and a transition period in order to understand the administrative functions of an instructor as well as understand how best to function within the instructional environment. Where appropriate, provide opportunities for observing the instructional environment prior to delivering E\&IT for the first time.

d. Provide instructors sufficient time to personally prepare their own detailed lesson plans for a course.

e. Encourage reflection by having instructors self-assess their performance and continuing to have opportunities to observe others.

f. Monitor instructors, providing constructive feedback concerning instructor delivery techniques and how to improve learning conditions. Monitoring involves formalized periods of observation. 
g. Review other feedback. Encourage instructors to receive feedback from peers and review the responses provided by students during a course.

7-11. Instructor preparation is part of a broader faculty and staff development framework. This process is initiated each time new personnel join an ETF. For the instructor cadre this is an on-going process throughout the period of employment and there are three main elements to support this:

a. Initial Orientation. This begins prior to arrival with a welcome package and continues through to a unit specific orientation programme which may potentially include familiarization training to support local procedures, work flow and unique web/software applications.

b. Initial Skills Development. This promotes integration within the ETF and includes instructor development courses as well as any additional E\&IT that is required in accordance with a job description. During this phase there are opportunities to observe and integrate within the instructor cadre and formalized observation periods instructor supervisor monitoring sessions.

c. Continuity Training. Implementing additional professional development in support of a continuous learning culture and in order to maintain expertise. This is supported by formalized observation periods and potentially the opportunity to conduct peer observations.

\section{CONDUCT TRIALS}

7-12. Trials are conducted in order to identify design flaws and other deficiencies or problems with the planned instruction so that revisions and improvements can be made. Trials are conducted prior to institutionalizing a course and making significant investments in major equipment, simulators or other training devices to support an E\&IT solution. Trials will also serve to refine further the resource requirements as well as the time required for conducting instruction. Trials consist of repetitive cycles of development, testing, and revision until evidence shows that the E\&IT solution is effective. As the trials continue the necessary changes are made until the courseware is complete and ready for implementation. The level and number of reviews will depend on several factors including:
a. Sophistication of the instruction/courseware.
b. Consequence of error resulting from poor or incorrect instruction.
c. The remaining investment necessary to finalize an E\&IT solution.

7-13. Trials may be conducted on three levels and this reflects the transition from initial (pre-) production internal testing through to external pilot-testing with members of the target audience. The trials to be considered during the Development Phase are:

a. Internal Reviews. The purpose is primarily to identify content inaccuracies, instructional design weaknesses and potential resource shortfalls. Internal reviews are conducted throughout the Development Phase. SMEs make sure the content being provided is technically accurate and the depth of coverage is adequate. Curriculum developers ensure that the material follows sound instructional principles and that the 
methods and activities are well defined and appropriate to the content for the specified target audience. During internal review the following can be resolved:

(1) Lack of agreement between the ELOs and course content.

(2) Inaccuracies in content and subject matter. There are many ways to review the subject matter for accuracy, completeness, and quality. The bottom line is to cross-check the content with the data sources and references including NATO technical orders, regulations, directives, and checklists.

(3) Incomplete or weaknesses in materials including the details and instructions supporting scenarios, case studies, practical exercises as well as media elements including visual mock-ups, storyboards and scripts.

(4) Incomplete or weaknesses in assessment instruments including the validity, reliability, objectivity, comprehensiveness of the assessment instruments and the details in the instructions.

b. Individual and Small-Group Try-outs. The purpose is to confirm decisions made during the Design Phase and verify the quality of the instructional materials. During the individual and small-group try-outs the curriculum developer tests the materials based on small segments or specific learning "events" as they are developed with a sample of the intended audience. The try-outs serve to confirm assumptions made about the intended audience, in particular the prerequisite knowledge, time allocations and clarity of assignment and instructions.

c. Pilot Serial (Field Trial). The purpose is to assess the effectiveness of the developed course and assess the quality of lesson guidance and course material. The pilot serial is conducted like a regular serial/iteration; however, the course is monitored closely by appropriate staff and additional data is gathered; feedback from instructors and students is essential. The number of field trails is based on need and is influenced by the results of an initial trial and the complexity of the instruction. Observations from a field trial can be very broad and include:

(1) Incomplete or weaknesses in the schedule/timetable including a lack of continuity in the transition of instructional events and activity including the accuracy of the time allocations.

(2) Inadequate methods or weaknesses in how content is conveyed.

(3) Inadequate detail in the content.

(4) Clarity of instructions for the instructors as well as supporting course activities/events and student assessment.

(5) Confusion with test items.

(6) Verify the class size is appropriate.

(7) Clarity with the administration procedures and support coordination within the institution. 


\section{CHAPTER 8 - SAT: IMPLEMENTATION PHASE}

\section{INTRODUCTION}

8-1. Purpose. The purpose of the Implementation Phase is to put into operation the management, support and administrative functions necessary to successfully conduct E\&IT solutions.

8-2. Product. The Implementation Phase results with the production of qualified graduates.

8-3. Methodology. The Implementation Phase addresses the planning, preparation, execution as well as close out (after action) activities that support a specific course. Prior to conducting E\&IT the solution must be integrated into ETF operations and this is captured within the ETF's overall QMS.

8-4. Process. The following are the major milestones to be achieved during the Implementation Phase:
a. Integrate an E\&IT solution ${ }^{62}$.
b. Conduct E\&IT.

\section{INTEGRATE AN E\&IT SOLUTION}

8-5. The specific procedures for integrating an E\&IT solution within unit operations will vary from ETF to ETF. The integration of an E\&IT solution requires clear policy, procedures and work instructions which establish the routines within the ETF. The policy and procedures should define how a new, or revised, E\&IT solution is to be integrated with the core QMS processes within an ETF. This is intended to align and harmonize the management, administration and support functions with the overall main effort: the production of qualified graduates. In situations where an ETF may be multifaceted and have other roles (e.g., NATO $\mathrm{COE}$ ) the links between E\&T and the other functions should be captured and transparent (e.g., links between E\&IT delivery and doctrine development and / or lessons learned).

8-6. Management. Management, including personnel, resource and general management concerns the practice of directing and controlling all the processes effecting ETF operations. This begins with a well-communicated plan for the institution, which includes a commitment to quality that is based on a mission and vision which is aligned with NATO priorities and the expectations of major stakeholders. Key performance indicators are also identified and captured in order to report progress. Management activities address:

a. Recruiting, supervising, motivating and developing staff and faculty in accordance with clearly defined roles and responsibilities.

b. Controlling expenditures, managing budgets and contract management (as applicable).

\footnotetext{
62 Integrating a solution is captured here as part of the NATO SAT Implementation Phase; however, it is likely that many of the considerations and procedures were addressed as part of the Pilot Serial which was run during the Development Phase.
} 
c. Establishing E\&IT production targets, allocating resources and monitoring progress against targets.

d. Communicating effectively internally and external with stakeholders including through designated feedback systems.

e. Leveraging information systems and institutional knowledge management. Collect, analyse and efficiently use relevant information for the effective management and conduct of E\&IT and related activities.

f. Assessing, projecting and planning for future facility requirements, infrastructure, equipment and related maintenance as well as logistics support.

g. Planning and implementing organizational improvement projects including related initiatives to support staff and students in line with the overall mission.

h. Identifying and solving problems and managing change.

8-7. Administration. Administration is a very broad area and integration issues addresses three areas:

a. Course Administration. Defining the routine tasks which support personnel, and in particular students, which must be addressed as a course is integrated into operations. This involves policy and processes for student registration, course fee payments, generating student course lists, the arrival in-routine and processing, generating certificates, dispatching graduates (out-clearance) and records management (e.g., managing and archiving student and course related files).

b. Institutional Administration. This concerns the administrative instructions and activity which has a broader management impact, including the distribution of information internally as well as the information to be shared publicly, visit protocols and this includes support for guest speakers as well as, depending on the ETF, security and force protection measures.

c. E\&IT Management Administration. Through these administrative processes the support to unit operations are activated and often the data essential to tracking key performance indicators is generated. Depending on circumstance, E\&IT management administration addresses:

(1) Production Administration ${ }^{63}$. Ensuring the E\&IT solution is assigned appropriate course codes and integrated within the appropriate planning processes and training management systems (e.g., e-ITEP) in order to forecast demand, schedule courses, match bids with the available opportunities (or slots)

\footnotetext{
${ }^{63}$ As E\&IT solutions are integrated and become operationalized it will be essential to ensure applicable NATO $\mathrm{PE} / \mathrm{CE}$ JDs are updated to reflect the essential and desirable qualifications and, as applicable, the related course codes. The ADC will be one forum to track progress in this area.
} 
and, as required, de-conflict internally with an overall master schedule for the $\mathrm{ETF}^{64}$.

(2) Maintaining Documentation and Courseware. Maintaining a system of record for administering CCDs and course materials, including version controls and, when applicable, copyright permissions. At this point the Course Control Document III, uploaded during the Design Phase, is revised based on Pilot Serial feedback and DH input.

8-8. Support. Support addresses the essential functions, activities, and tasks necessary to sustain ETF operations and the conduct of E\&IT. The essential infrastructure assets and facilities including a training area, laboratories, classrooms, syndicate rooms, fitness facilities and other infrastructure are most likely in place along with the core logistics support functions including: supply, transportation, lodging and meals. As part of implementing a course the links must be established to the support processes in order to ensure it is in place when it comes time to conduct E\&IT. The resource and support requirements are often unique for each course and the materials, supplies, equipment and training aids are initially captured as E\&IT solutions are developed through the NATO SAT process.

\section{CONDUCT OF E\&IT}

8-9. The conduct of E\&IT requires a finished product to be in place and the course to be integrated within the management, administration and support functions of the ETFs QMS. Generating graduates through the execution of E\&IT is the centre of gravity; however, there are other activities which are part of a systematic approach. A Course Director is generally appointed, in accordance with specific Terms of Reference, to administer and manage a course from planning through to close out ${ }^{65}$. The activities supporting the conduct of E\&IT are captured in Figure 8-1, and these form an overall planning timeline which can vary from course to course and are often unique to a particular ETF. The following activities are considered as part of conducting E\&IT:
a. Course Planning.
b. Course Preparation.
c. Course Execution.
d. Course Close Out.

\footnotetext{
${ }^{64}$ Within NATO the administration activity ensures proper course codes and reference numbers are assigned. This permits the integration of information with other systems including the NATO Automated Personnel Management System for NATO job descriptions and with e-PRIME in order to support partner requirements.

${ }^{65}$ The Course Director may be a position or an appointment depending on the ETF and may also be known as a Senior Instructor, Lead Instructor and/or Course Manager.
} 


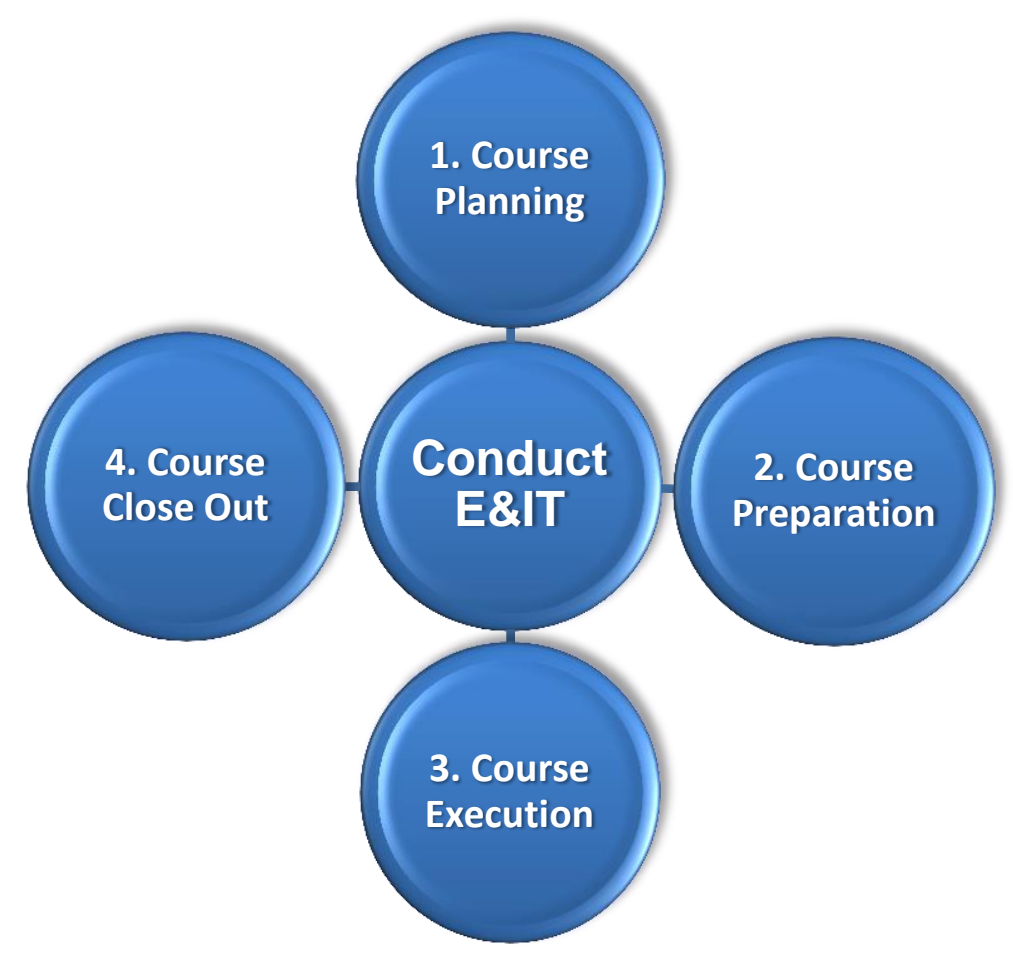

Figure 8-1 Conducting E\&IT

8-10. Course Planning. Course planning generally takes place 4-12 months prior to execution and occurs once the production planning process has defined the ETFs overall master schedule. Many of these considerations are addressed as part of administrative processes (e.g., matching bids with course vacancies); however, course specific issues concern:

a. Course Readiness. Ensuring the observations raised during the pilot serial, or a recent review of the course, are addressed.

b. Feasibility. Verifying the planned Instructional Strategy is feasibility. A course may be ready; however, other conditions may exist which compromise the planned mode of delivery, be it:
(1) Residential,
(2) Distributed (includes ADL/e-Learning and METT), or
(3) Blended.

c. Course Information. Confirm the accuracy of course information packages to be distributed to students and made available publically.

\section{d. Instructor Support}

(1) Verify there are adequate instructors to support execution in accordance with the planned schedule. 
(2) Initiate contact, invite and confirm guest speakers and other stakeholders (as required).

8-11. Course Preparation. Course preparation generally takes place 6-8 weeks prior to course execution and occurs once it is confirmed that a course will go forward as scheduled and that it will be delivered in accordance with mode identified previously during course planning. Course preparation primarily involves internal coordination:

a. Reconciling final bid selection. Confirms the course list and transportation as well as lodging are arranged.

b. $\quad$ Finalizing course supplies and distributing joining instructions and pre-course materials (as required).

c. Scheduling and coordinating course support (e.g., transportation, facility booking).

d. Finalizing the course schedule/timetable including the sequence of events, instructor assignments and programme instructor monitoring.

e. Distribute outlines, potentially previous presentations, to invited Guest Speakers and other SMEs supporting course execution. It is essential that those involved appreciate and understand the specific objectives and topics their contribution is intended to address.

f. For the distributed and blended delivery modes, this can also include shipping courseware to an alternate location (for an METT) as well as setting up a course sessions within an on-line LMS (for ADL/e-Learning).

8-12. Course Execution. Course execution concerns the actual running of a course and this begins with pre-course preparation, generally one week prior to the start of a course, and continues through to student graduation and the close out of a course. During execution, instruction is delivered and student assessment is conducted as planned. This activity is completed in accordance with ETF policies, directives and specific work instructions supporting the ETF's QMS. The ETF should have prescribed SOPs to address a wide range of issues and they generally regulate the daily routine (hours of operation), security protocols, student assessment procedures and possibly complaint resolution. The additional considerations for course execution, which may also have separate SOPs, include the following:

a. Collecting course/tuition fees (as applicable).

b. Finalizing set-up and preparation of the environment, be it a physical structure or online.

c. Completing pre-course preparations with instructional staff and ensuring debriefs ("hot washes") are conducted, as necessary, throughout the course in order to monitor course execution and address any concerns which may arise.

d. Preparing and debriefing Guest Speakers and other SMEs supporting course execution. Note: Guest Speakers/SME presentations should be reviewed in advance in 
order to ensure continuity and fit with the flow of instruction and adjustments made prior to delivery.

e. Finalizing and administering instructor and student feedback forms.

f. Monitoring instruction. Execute plans for observing and debriefing the instructional events in order to assess delivery techniques, adherence to the intent of the CCDs and lesson plans as well as the effectiveness of course design. Course design issues include time allocation and methods of instruction. The intent is to improve instruction.

8-13. Course Close Out. Course close out involves activities which commence at the conclusion of course execution and typically continue for one week afterwards finalizing any outstanding administrative and support issues. Course close out culminates with an immediate after action report (AAR) which summarizes impressions concerning the conduct of the course. Was the course aim achieved? The AAR captures issues that may have an impact on future courses related to course planning, preparation and execution. The issues identified may impact the quality of E\&IT solutions including administration and support concerns. The AAR also captures student demographic data and this is used to confirm the course is being delivered to the intended target audience. The AAR becomes an essential input into the Evaluation Phase. 


\section{CHAPTER 9 - SAT: EVALUATION PHASE}

\section{INTRODUCTION}

9-1. Purpose. The purpose of the Evaluation Phase is to assess the efficiency, effectiveness and affordability of an E\&IT solution and determine how it can be conducted better within an ETF which seeks to continuously improve.

9-2. Product. The Evaluation Phase results with improved E\&IT solutions.

9-3. Methodology. The NATO SAT Evaluation Phase consists of a systematic quality review process and feedback loops which supports continuous improvement ${ }^{66}$. ETFs that are institutionally accredited by HQ SACT/JFT embed end of course assessments along with other institutional review processes as part of a QMS. These processes formalize the Evaluation Phase and ensure that there is an opportunity for continuous improvement and innovation. The results of the Evaluation Phase provide an indication of the fit between E\&IT requirements and specific solutions; the results of the Evaluation Phase are a valuable input for the related $A D C$ in order to confirm continuing suitability.

9-4. Process. There are two distinct processes supporting the Evaluation Phase and they are:

a. $\quad$ "Post course reviews, which focus on judgements pertaining to a specific E\&IT solution. It is the process of gathering and analysing data from inside and outside the E\&IT environment in order to determine how well E\&IT was conducted and how well graduates are prepared for their job.

b. Institutional reviews, which focus on the institution and provides for a periodic review of quality management overall.

\section{CONDUCT POST COURSE REVIEW (PCR)}

9-5. The PCR is a structured and systematic process which involves collecting and analysing both quantitative and qualitative data in order to assess the quality (effectiveness, efficiency and affordability) of an E\&IT solution and improve results. There are two distinct elements to a PCR, as highlighted in Figure 9-1. The initial PCR involves an internal evaluation and this is a report that builds from the observations outlined in the AAR which is compiled immediately following each course. This report should identify the areas of a course that require improvement along with an action plan to bring about improvements. The results of an internal evaluation may influence the need for an external evaluation. External evaluation is a follow-up process which occurs after graduates have had a period of time to apply acquired skills within the job/operational context. The period of time varies based on the skills/knowledge acquired and the job context; however, it generally occurs within six months. The PCR process is adapted to fit within the QMS of an ETF ${ }^{67}$. The details concerning the two distinct elements are as follows:

\footnotetext{
${ }^{66}$ The NATO SAT Evaluation Phase includes secondary cycles of review which are integrated within the Design and Development Phases of the NATO SAT model and these are applied as new solutions are defined and delivered. See Figure 4-2.

${ }^{67}$ Example: The AAR and internal evaluation PCR may be combined. Regardless of approach, it is essential that the process is clearly defined.
} 


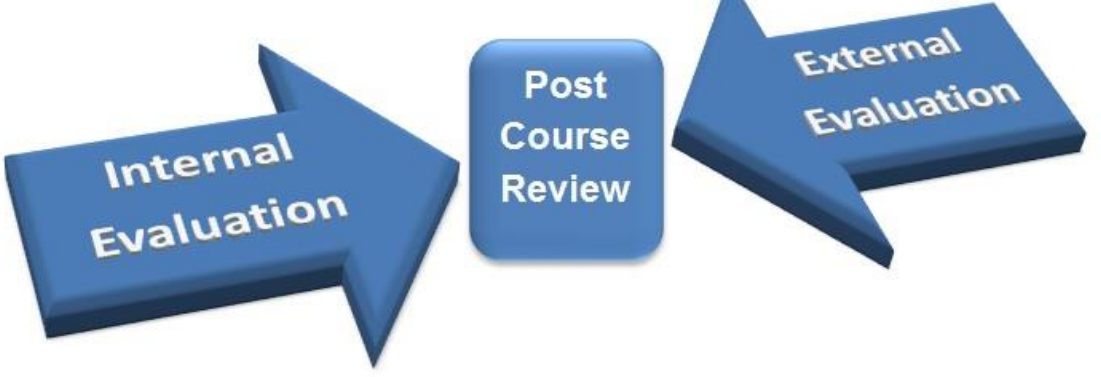

Figure 9-1 Post Course Review - Data Sources

a. Internal Evaluation. The internal evaluation PCR concentrates on feedback and E\&IT management administration data captured from within the ETF. The primary focus is to assess the reactions and perceptions to a recently conducted course and verification that learning has occurred ${ }^{68}$. There are many data sources which support internal evaluation and a sample is illustrated in Figure 9-2. The scope of internal evaluation can include course monitoring, which can assess overall course alignment as well as include instructor monitoring. Further details supporting course monitoring are provided in Annex S. Instructor feedback, and this can include observations provided by Guest Speakers, is another valuable data source. Instructor feedback can highlight administrative and logistic support issues in addition to other course conduct concerns impacting quality. Internal evaluation is an essential component of an effective ETF QMS and this will normally, at a minimum, address the following elements:

${ }^{68}$ As outlined in the Implementation Phase (Chapter 7), the conduct of E\&IT includes: Course Planning, Course Preparation, Course Execution as well as Course Close Out. 


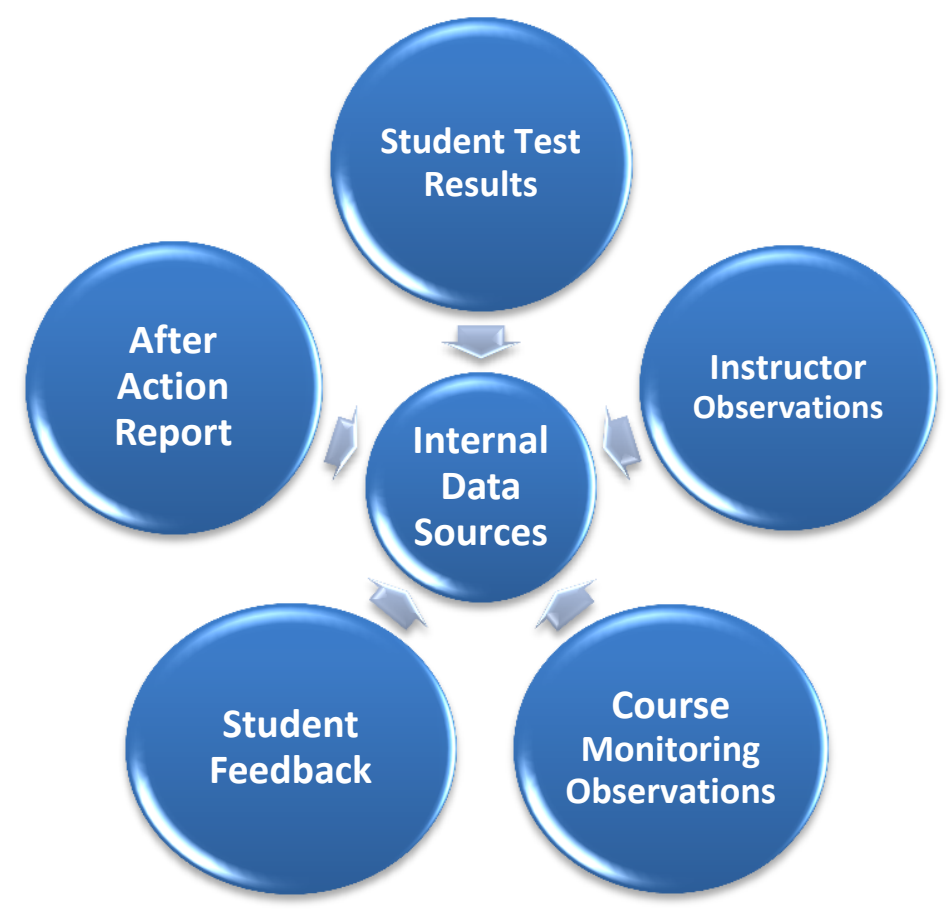

Figure 9-2 Post Course Review - Internal Data Sources

(1) Student Reaction. The reaction of students during a course can provide an indication of their motivation along with their overall level of satisfaction. This data can be used to make inferences regarding the design and delivery of instruction including the products of the SAT Development Phase. There is not one specific approach to take when gathering student feedback. The approach will depend on what is appropriate for the target audience and their experience level. Feedback can be sought at the conclusion of a course, once students have had the opportunity to reflect on the entire experience, or throughout the execution of a course. Feedback can also be captured using a combination of both approaches. Where appropriate, graduates can offer an assessment of the importance or value a course may contribute to their current or future job. In general, the input is sought during a course and occurs at the conclusion of a meaningful segment of instruction. For ease of analysis, specific quality indicators and a consistent ordinal rating scale is used. Indicators attempt verify if the desirable conditions for learning have been established given this can have an impact on student motivation. Example indicators to consider are:

(a) Time Allocation. Indicates if the amount of time allocated to this event was appropriate.

(b) Relevance. Indicates the degree to which the content is made applicable to the job.

(c) Confidence. Indicates the degree of confidence an individual has in applying what was learned (or presented) back at their job, should the opportunity present itself. 
(d) Adequacy. Indicates the level of detail and depth that the subject matter was covered.

(e) Clarity. Indicates how well and individual understood the subject matter. Were explanations clear?

(f) Quality of Materials. Indicates the quality of materials used during the session. Were the materials provided useful?

(g) Pacing. Indicates if the tempo and rate of the flow of instruction was appropriate.

b. Learning. This documents the quantitative (production) results of the course and confirms that learning has taken place. A course is considered effective to the extent that the students have successfully satisfied the POs. Summative assessments confirm that the POs have been satisfied. The assessment plan for a course is formulated during the NATO SAT Design Phase (Step 10) and this also maps out how learning progress is monitored (formative assessment). Results from both formative and summative assessments may be used to identify potential concerns with course design and development as well as how it was implemented. Results may also identify weaknesses in student selection (e.g., did students meet the pre-requisites?). The priorities for future course monitoring can be influenced by the results from formative and summative assessment. The reliability and validity of tests used during a course provides the foundation for effective evaluation of student performance and learning. Both the reliability and validity of a test should be verified in order to confirm the appropriateness of the test as an accurate measure of instructional effectiveness. Test items should undergo considerable scrutiny during the trials step within the SAT Development Phase. Additional test item analysis techniques can be applied following implementation and details are provided in Annex T. 
c. External Evaluation. The external - PCR concentrates on observations and feedback from the field of operations. The primary focus is to assess the degree to which what was learned during the course has transferred to on-the-job performance and achieved results. The results of an external evaluation feed back into the NATO SAT Analysis Phase, as highlighted in Figure 9-3. The data gathered is used to determine whether the initial E\&IT requirement has been satisfied through the E\&IT solution that was conducted during the SAT Implementation Phase. The E\&IT requirement is captured in the POs defined during the SAT Analysis Phase. External evaluation is carried out after graduates have completed a course and have had the opportunity to apply what they have learned within the job/operational context. The

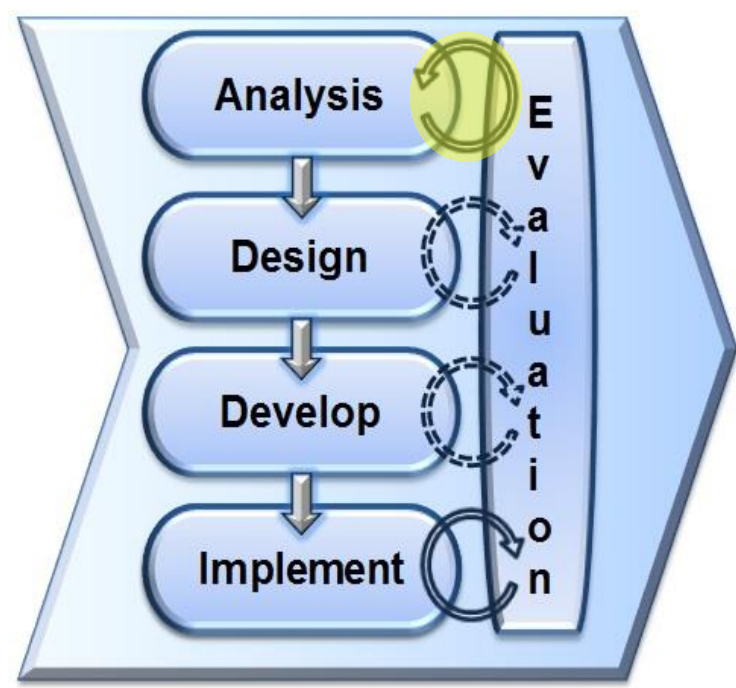

Figure 9-3 NATO SAT

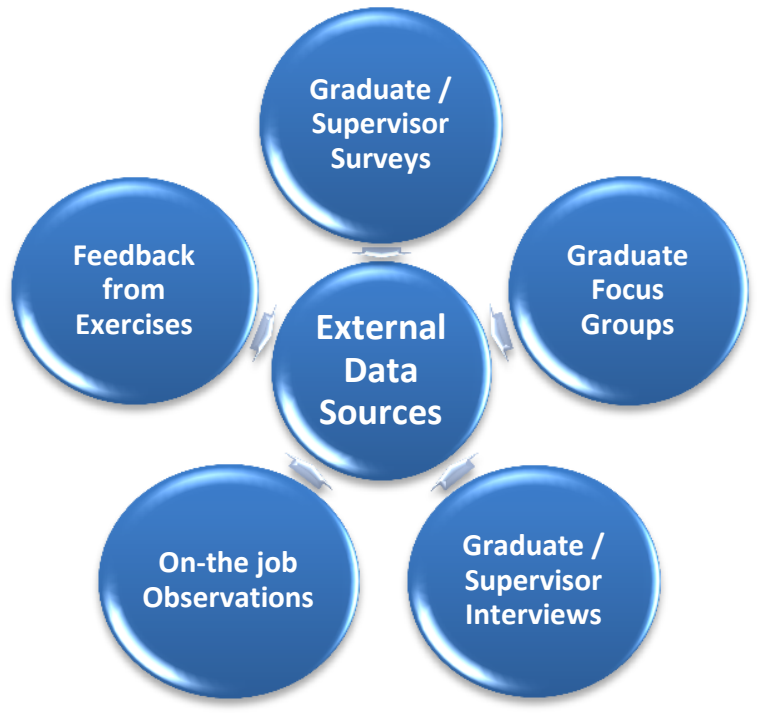

Figure 9-4 Post Course Review - External Data

subtle but significant nuance for effective external evaluations is to avoid having graduates reflect directly upon their course experiences - this feedback is best gathered during internal evaluations. The focus is on a graduate's ability to perform specific tasks. There are many data sources which may be selected to support external evaluation and a sample is illustrated in Figure 9-4. One of the more common, and efficient, data gathering methods is a survey. Through an external evaluation survey feedback is provided by the graduates and possibly their supervisors directly from the field. For advanced level courses, the feedback generally comes directly from graduates. Effective external evaluation data is based on the performance statements captured within a PO and feedback is provided pertaining to the relevance and application within the job context ${ }^{69}$. Each $\mathrm{PO}$ is reviewed by a survey respondent relative to a series of quality indicators. The data gathered is subsequently analysed in order to determine if the right person, is being trained the right things and to the required level ${ }^{70}$. Example indicators include:

(1) Importance. How important is the proper execution of the performance statement to the graduate's success on the job?

\footnotetext{
${ }^{69}$ It may be necessary to refine and add to the list of performance statements. A lot will depend on how well the POs were defined during the Analysis Phase.

${ }^{70}$ Results are shared internally as well as with the DH and RA at the ADC.
} 
(2) Relevance. Is the performance statement applicable to a graduate's job. Is this something they do or could do if the situation presents itself?

(3) Confidence. Is the graduate confident in their ability to execute the performance statement, should they be required to?

(4) Adequacy. Do graduates feel they are adequately prepared to execute the performance statement?

\section{CONDUCT INSTITUTIONAL REVIEW}

9-6. The Institutional Review is a self-assessment of overall organizational performance by leadership. The focus is an analysis of the institutions key performance indicators with the emphasis on the core E\&T mission. Institutional Review is an organizational internal check - a quality management instrument supporting a CIP. Depending upon the ETF, an Institutional Review should be conducted annually ${ }^{71}$. The review examines E\&IT relying on qualitative and quantitative data as well as, when applicable, financial performance. In general, the intent of the Institutional Review is to ensure institutional processes are aligned and determine the following:
a. Is the organization delivering the right courses to the right people?
b. Are the courses of desired quality (effective, efficient and affordable)?
c. Are courses sustainable and financially viable?
d. Are the results consistent with near term and longer term organizational plans?

9-7. The annual QA Report results from the Institutional Review and is an essential element of an accredited ETF's QMS. A review of courses is central to these proceedings and this will concurrently lead to an assessment of the ETFs:
a. Policy and procedures.
b. Staff/Faculty development.
c. Information systems and knowledge management.
d. Learning resources and student support.
e. Contributions to NATO.

\footnotetext{
${ }^{71}$ Chapter 3 provides further detail concerning quality management, CIP (internal/external checks) and the related ETF institutional accreditation process.
} 


\section{ABBREVIATIONS}

AAR
ACO
ACOS
ACT
ADC
ADL
ADDIE
APMS
Bi-SC
Bi-SCD
BRSG
C2
CCD
CE
CIP
CMC
COE
COUISe OPR
CT\&E
DCOS
DAP
DH
DIF
DOTMLPFI

E\&IT
E\&T
e-ITEP
e-Learning
ELO
e-PRIME
ETEE
ETF
ETOC
HQ
HQ SACT
IMS
IS
ISD
ITEP
JD
JFC

After Action Report

Allied Command Operations

Assistant Chief of Staff

Allied Command Transformation

Annual Discipline Conference

Advanced Distributed Learning

Analysis, Design, Development, Implementation and

Evaluation

Automated Personnel Management System

Bi-Strategic Command

Bi-Strategic Commands Directive

Bi-SC Requirements Steering Group

Command and Control

Course Control Document

Crisis Establishment

Continuous Improvement Process

Chairman of the Military Committee

Centre of Excellence

Course Officer of Primary Responsibility

Collective Training \& Exercises

Deputy Chief of Staff

Discipline Alignment Plan

Department Head

Difficulty - Importance - Frequency

Doctrine, Organization, (Education and) Training, Material, Leadership, Personnel, Facilities and Interoperability

Education and Individual Training

Education and Training

Electronic Individual Training and Education Programme

Electronic Learning

Enabling/Learning Objective

electronic Partnership Real-Time Information Management and Exchange System

Education, Training, Exercise and Evaluation

Education and Training Facility

Education and Training Opportunities Catalogue

Headquarters

Headquarters Supreme Allied Commander Transformation

International Military Staff

International Staff

Instructional System Design

Individual Training and Education Programme

Job Description

Joint Force Command 


\begin{tabular}{|c|c|}
\hline \multicolumn{2}{|r|}{ Joint Force Trainer } \\
\hline $\begin{array}{ll}\mathrm{RLT} \\
\mathrm{LI}\end{array}$ & $\begin{array}{l}\text { Key Leader Irainıng } \\
\text { Lessons Identified }\end{array}$ \\
\hline LIVEX & Live Exercise \\
\hline LL & Lessons Learned \\
\hline LMS & Learning Management System \\
\hline LOA & Level of Ambition \\
\hline MC & Military Committee \\
\hline METT & Mobile Education \& Training Team \\
\hline MoU & Memorandum of Understanding \\
\hline MPD & Military Partnership Directorate \\
\hline MTEP & Military Training and Exercise Programme \\
\hline NAC & North Atlantic Council \\
\hline NCS & NATO Command Structure \\
\hline NCO & Non-commissioned Officer \\
\hline NDPP & NATO Defence Planning Process \\
\hline NETF & NATO Education and Training Facility \\
\hline NFS & NATO Force Structure \\
\hline NITEC & NATO Individual Training and Education Conference \\
\hline NLR & National Liaison Representative (at HQ SACT) \\
\hline NNE & Non-NATO Entity \\
\hline NRF & NATO Response Force \\
\hline NSIP & NATO Security Investment Programme \\
\hline NTEC & NATO Training and Exercise Conference \\
\hline NTG TG IT\&ED & $\begin{array}{l}\text { NATO Training Group - Task Group Individual Training and } \\
\text { Education Developments }\end{array}$ \\
\hline NTI & (Multi)National Training Institution \\
\hline OCE & Officer Conducting the Exercise \\
\hline ODE & Officer Directing the Exercise \\
\hline OJT & On-Job-Training \\
\hline OPR & Officer of Primary Responsibility \\
\hline OSE & Officer Scheduling the Exercise \\
\hline PCR & Post Course Review \\
\hline PCM & Partnership Cooperation Menu \\
\hline PE & Peacetime Establishment \\
\hline PfP & Partnership for Peace \\
\hline PNLR & Partner National Liaison Representative at HQ SACT \\
\hline POC & Point Of Contact \\
\hline PO & Performance Objective \\
\hline PTEC & Partnership Training and Education Centre \\
\hline QA & Quality Assurance \\
\hline QC & Quality Control \\
\hline QM & Quality Management \\
\hline QMS & Quality Management System \\
\hline RAD & Rapid Analysis and Design \\
\hline RA & Requirements Authority \\
\hline RPPB & (NATO) Resource Policy and Planning Board \\
\hline SACEUR & Supreme Allied Commander Europe \\
\hline SACT & Supreme Allied Commander Transformation \\
\hline SAGE & SACEUR's Annual Guidance on Education, Training, \\
\hline & $\begin{array}{c}\text { A-2 } \\
\text { NATO UNCLASSIFIED }\end{array}$ \\
\hline
\end{tabular}


SAT

SHAPE

SME

SOP

SSC

STP

TA

TAA

ToE

TNA

TRA

TSC

WG
Exercise and Evaluation

Systems Approach to Training

Supreme Headquarters Allied Powers Europe

Subject Matter Expert

Standard Operating Procedure

Single Service Command

Strategic Training Plan

Target Audience

Target Audience Analysis

Team of Experts

Training Needs Analysis

Training Requirements Analysis

Training Synchronization Conference

Working Group 


\title{
GLOSSARY
}

\author{
ANNEX B TO \\ Bi-SCD 075-007 \\ DATED 10 SEP 15
}

Abilities - the capacity, or talent to perform skills (the cognitive/practical know how) and to apply knowledge in order to solve problems and fulfil tasks successfully. They are divided into cognitive abilities (logic, intuitive and creative thinking) and practical abilities (coordination and use of methods, material, tools and instruments).

Accreditation - the process resulting in rrecognition that an institution has met standards established by an external body/agency.

Advanced Distributed Learning (ADL) - an interactive, outcomes-focused approach to education, training, and performance-aiding that blends standards-based Distributed Learning. Within NATO, this means of delivery infers that the instruction uses electronic and/or information technologies combined with methods of instruction which do not require the student to be present at a specific site and as a result the learning occurs at a distance.

Affective Domain - a classification system for learning objectives focused on attitudes and values. The Affective Domain taxonomy specifies five levels to include: receive, respond, value, organization and characterization.

Aptitude - a natural ability to acquire and utilize specific skills and/or knowledge.

Aptitude Test - a measure of abilities that are assumed to be relevant to future performance in a specific type of skill or an area of achievement.

Assessment - The process of estimating the capabilities and performance of organizations, individuals, materiel or systems (AAP-06, 2014). Within education and individual training it is the process of measuring and documenting knowledge, skills, attitudes, and beliefs.

Assessment Strategy - defines an overarching approach to assessment for a course/segment and the supporting rationale for the approach. It must also include the consequences of failure of the course/segment.

Asynchronous Learning (Training) - is considered to be any learning event which is delivered after the original live event. Indicates a learning event where the interaction is delayed over time, such as a correspondence course or a threaded discussion, message board, used in online applications. (NTG TG IT\&ED)

Attitude - a deeply held opinion or conviction which underlies and motivates human behaviour and performance.

Benchmark - a standard against which an organization can assess its own performance. Such a standard may come from inside or outside the organization. Benchmarks are sometimes considered to represent "best/better practice". (NTG TG IT\&ED) 
Blended Learning - is considered to be an appropriate mix of traditional learning and ADL/e-learning methods and media.

Certification - the process of officially recognizing that organizations, individuals, materiel or systems meet defined standards or criteria. (AAP-06, 2014)

Cognitive Domain - a classification system for learning objectives focused on knowledge and thinking skills. The Cognitive Domain taxonomy specifies six levels to include: remembering, understanding/comprehension, application, analysis, synthesis and evaluation.

Collective Training - procedural drills and practical application of doctrine, plans and procedures to acquire and maintain collective tactical, operational and strategic capabilities.

Competence - ability to perform a particular skill or range of skills to a prescribed standard under prescribed conditions. (NTG TG IT\&ED)

Competency - a behavioural indicator of competence, this includes the set of knowledge, skills, abilities or other characteristics which may vary among individuals that contributes to effective performance. (NTG TG IT\&ED)

Content - the material provided during instructional programmes and this is primarily captured in teaching points, the singular element or step in a procedure for performing a job or task. Content will generally fall into one of five categories: facts, concepts, processes, procedures and principles.

Course - planned, sequenced and structured learning activities based on objectives, which stem from E\&IT requirements, for a clearly identified audience. See para 4-15 for further detail.

Course Control Documents (CCDs) - a set of documents used to define a NATO E\&IT solution based on an E\&IT requirement. Alternative formats include: Programme of Instruction, Qualification Standard, Training Plan, Curriculum and Syllabus.

Courseware - the instructional package/educational material comprising presentation materials, instructional aids, tests, textbooks, software, documentation and other media resources necessary for the student to achieve the course learning objectives supporting an E\&IT solution.

Criteria - a property or characteristic by which the quality of something (a product/result or individual/group performance) may be judged. Criteria are indicators of success that are linked to a standard. The development of criteria provides the evaluator with specific measures to indicate whether a standard has been achieved.

Curriculum - the combination of strategies and learning employed in an attempt to fulfil specific learning objectives of an educational institution or training unit. Also see syllabus. (NTG TG IT\&ED)

Depth of Knowledge (DoK) - refers to the level of learning to be achieved as a result of an E\&IT solution. DoK is an inclusive term addressing the Cognitive Domain 
(Knowledge elements) as well as the Psychomotor Domain (Skill elements) and, when appropriate, the Affective Domain (Attitude/Values elements).

Difficulty - Importance - Frequency Analysis (DIF Analysis) - is a method of analysing job information through the Difficulty, Importance and Frequency of tasks within the job, with the aim of enabling decisions to be made regarding the priority and/or necessity of the training. (NTG TG IT\&ED)

\section{Distributed Training (DT) - See Advanced Distributed Learning.}

Department Head (DH) - an appointment within NATOs Global Programming Governance Structure responsible for the translation of E\&T requirements into E\&T solutions and for the coordination of the solutions. Specific roles and responsibilities can include the following:

a. Collaborating and coordinating the definition and delivery of E\&T solutions with ETFs.

b. Leading the TNAs required to fill E\&T gaps identified in a TRA report.

c. Compiling an E\&T programme to meet E\&T requirements.

d. Assisting DCOS JFT with the assessment of proposed E\&T solutions.

e. Leading and conducting the ADC.

f. Developing and submitting once a year a DAP.

g. Participating in programming boards in order to align production requirements with programmed E\&T solutions.

h. Within means and capabilities, provide an analysis of related Lessons Identified, to include exercises and operations.

i. Within means and capabilities, support individual and collective NATOled training with SMEs and/or other advice at exercises and pre-deployment training events.

j. Within means and capabilities, support the NATO Officers Conducting the Exercise (OCEs) in the planning and conduct of collective training and exercises.

Discipline - a NATO approved body of knowledge and skills that outlines an existing, or evolving education and training need.

Education - education is the systematic instruction of individuals that will enhance their knowledge and skills, and develop competencies. Education provides a base of knowledge and intellectual skills upon which information can be correctly interpreted and sound judgement exercised. It is the developmental activity enabling individuals to make a reasonable response to an unpredictable situation (mindset). 
Education and Individual Training (E\&IT) - comprises the structured activities that develop the skills, knowledge and attributes required in the performance of assigned duties and upon which information can be correctly interpreted and sound judgement applied (and exercised).

\section{Education and Individual Training Solution - see Course.}

Education and Training Activity - see NATO Education and Training Activity.

\section{Education and Training Programme - see NATO Education and Training Programme.}

e-Learning (electronic learning) - refers to training, education, coaching and course content that is delivered digitally. It is normally delivered through a network or the Internet but it may also be delivered via CD-ROM. (NTG TG IT\&ED)

Enabling/Learning Objective (ELO) - is a principal unit of learning and constitutes a major step towards achieving the performance objective. Enabling objectives are subcomponents or sub-objectives of the performance objectives. They represent suitable scope appropriate for assessing progress.

Equivalency - is the recognition and acceptance by the appropriate NATO authority of non-NATO E\&IT and/or experience as a suitable alternative to satisfy a NATO E\&IT requirement.

Evaluation - the process of making judgements. A structured process of examining activities, capabilities and/or performances (potentially including related structures and processes) against defined standards or criteria (AAP-06 2014).

Exercises - an exercise is 'a military manoeuvre or simulated wartime operation involving planning, preparation, and execution. It is carried out for the purpose of training and evaluation. It may be a combined, joint, or single service exercise, depending on participating organizations (AAP-06 2014).

External Evaluation - a validation activity; specific to the NATO SAT Evaluation Phase, this is the process of gathering and analysing objective evidence (data) from outside the E\&IT environment in order to determine how well graduates are prepared for their jobs and satisfying job performance requirements.

Formative Evaluation - a range of formal and informal assessment procedures employed during the conduct of E\&IT (Course Execution) in order to monitor learning and improve instruction.

Individual Training and Education Programme (ITEP) - the programme and management process to match NATO and partner E\&IT requirements and opportunities, and provide E\&T solutions to fulfil NATO assigned missions in an effective, efficient and affordable way.

Individual Training - the development of skills and knowledge necessary to perform specific duties and tasks. Individual Training is learned response to predictable situations (skills). 
Informal Learning - is learning outside of structured and formalized learning events. This does not typically result in a formal qualification or certification.

Inspection - a Quality Management activity involving a formal examination or review of performance and outputs to determine adherence with regulations, assess effectiveness and to ensure fitness for purpose. Inspection is implemented mainly for screening out defects before they may cause problems and may identify areas for improvement.

Instruction - the process whereby learners are provided with the means to acquire knowledge, skills and attitudes. It provides the conditions to develop skills, knowledge and attitudes.

Instructional Analysis - a deconstruction process by which each Performance Objective is analysed to determine the supporting ELOs. Skills and knowledge elements are broken out into their sub-components when it is anticipated that separate demonstrations (of skills and attitudes) or explanations (of knowledge or attitudes) will be necessary during a course.

Instructional Strategy - the combination of media, methods and environment used in the conduct of E\&IT:

a. Environment - refers to where learning activities take place, e.g.; classroom, work-place, home.

b. Method - refers to the type of learning activity or instructional event.

c. Media - refers to the means of delivering instructional activities to the learner.

Internal Evaluation - specific to the SAT Evaluation Phase, uses both qualitative and quantitative data to assess the overall quality (the effectiveness, efficiency and affordability) of a course. Internal evaluation determines if the instruction provided has satisfied the intended objectives in relation to the resources expended. This is an essential activity within an ETF's Quality Management System.

Job Description (JD) - a delineation of the specific duties, responsibilities and qualification pertaining to a specific post. A JD generally includes a statement that defines the principle duties for a position and includes tasks, responsibilities and qualifications required for the job as well how it fits within the organization (AAP-06 2014).

Key Leader Training - aimed to familiarize selected command and staff officers, designated to fill specific $\mathrm{HQ}$ positions in a national or multinational environment, with the force mission and organization, updated situation, supporting plans, key reference documents, SOPs and $\mathrm{HQ}$ responsibilities in order to provide a common foundation on related issues. It has to focus on specific topics exposing the leaders to challenges they could face during a specific exercise or upcoming military operation. (Bi-SCD 075-003) 
Knowledge - facts, concepts, principles and other information acquired through experience or instruction; consists of a theoretical and/or practical understanding of a subject matter.

Knowledge Management - strategies and practices for exploitation and development of insights and experiences by all the individuals of an organization with a view to furthering the organization's objectives.

Learning - learning in the most basic form is the acquisition of knowledge, skills and attitudes and is confirmed through a change in behaviour. Learning is a process by which an individual assimilates and internalizes information, ideas and values thereby acquires knowledge and know-how as well as develop skills and overall abilities. Learning occurs through personal reflection, reconstruction, social interaction and practice. It may take place in formal, non-formal or informal settings. Learning may occur consciously as well as without conscious awareness. Learning is continuous and evolutionary, it does not happen all at once, but rather builds upon and is shaped by an environment and by what is already known and believed to be true.

Learning Management System (LMS) - is an application, running on a server accessible through a network that provides a suite of capabilities designed to deliver, track, report on, and administer digital learning content, student progress, and student interactions. (NTG TG IT\&ED)

Method of Instruction - a strategy used for imparting skills, knowledge and attitudes, e.g. interactive lectures, demonstrations and role-play. (NTG TG IT\&ED)

Non-NATO Entity - includes International Organizations (IO), Governmental Organizations (GO) of non-NATO nations, Non-Governmental Organizations (NGO), Non-NATO Multinational forces, Host Nations (when the Host Nation is not a NATO nation), Contractors on operations, exercises and transformational activities as well as Non-NATO countries that do not otherwise meet the definition for "NATO Partner". (MC 458/3)

NATO Education and Training (E\&T) Activity - refers to the delivery and conduct of specific E\&IT solutions (e.g., courses) as well as collective events and activities (e.g., solutions such as Battle Staff Training, a Command Post Exercise, a Live Exercise). E\&T activities do not include the supporting or related management events necessary to define, plan, organize, and coordinate E\&T activities, such as conferences, meetings, working groups and other proceedings not involving the provision of E\&T.

NATO Education and Training (E\&T) Programme - a set of E\&T activities (individual and collective) assembled to satisfy the requirements captured within a discipline.

NATO Partner - refers to Partnership for Peace (PfP), Mediterranean Dialogue (MD), and Istanbul Cooperation Initiative (ICl) countries as well as those Partners across the Globe (PatG) with a partnership programme with NATO. (MC 458/3)

NATO Systems Approach to Training (SAT) - an iterative and interactive sequence of activity leading from the definition of a need for education and individual training through to defining, developing and implementing effective and efficient E\&IT solutions 
to satisfy the need. Note: SAT is an Instructional Systems Design model and is often synonymous with the "ADDIE" model.

Performance Gap - the difference between actual performance and potential/desired performance.

Performance Measurement - is the ongoing monitoring and reporting of programme accomplishments, particularly progress toward pre-established goals. It is typically used as a tool for accountability. (NTG TG IT\&ED)

Performance Objective $(\mathrm{PO})$ - specifies, in precise terms, what an individual must be able to do in terms of job performance and specifies a level of proficiency. A complete PO captures a performance gap and includes a description, in job/function operational terms, of what the individual must do, the conditions under which the performance must be completed, and the standard to be achieved. PO is synonymous with Behavioural Objective.

Performance Requirements - define what an individual will be prepared to do and to what level. Performance requirements are derived from the tasks performed by individuals as part of their principle duties during operations or while occupying specific NFS/NCS positions. Job Descriptions (JDs) capture performance requirements and are essential to define E\&IT solutions.

Performance Statement - a clear, concise and precise statement representing a logical and complete part of the job function which is observable and measurable.

Pilot Course - a trial of an E\&IT solution prior to full implementation.

Post Course Review (PCR) - a structured and systematic programme evaluation process within NATO SAT designed to collect data in order to assess (make judgements concerning) the quality of an E\&IT solution and improve results in the future.

Professional Military Education (PME) - is the systematic instruction of professionals in subjects enhancing their knowledge of the science and art of war. It provides and develops the skills, knowledge, understanding and appreciation of leaders in the nation's armed forces.

Proficiency Level - a scale which defines a degree of competence required in order to perform principle duties and tasks on the job.

\section{Programme - see NATO Education \& Training Programme.}

Programme Evaluation - assesses the merit or value of a programme. For E\&IT, it is a structured and systematic process designed to collect data to assess the quality of a solution. Programme Evaluation is formalized within the Evaluation Phase of the NATO SAT and consists of a Post-Course Review.

Psychomotor Domain - a classification system for learning objectives focused primarily on physical skills addressing coordination, dexterity, manipulation, strength 
and speed. The Psychomotor Domain taxonomy consists of multiple levels ranging from observation and imitation through to mastery and adaptation.

Qualification - is a formal result of judgement and validation process. An authorized institution determines that individual learning output comply with defined standards. (NTG TG IT\&ED)

Quality Assurance (QA) - the application of checks and audits to ensure quality procedures are being carried out. QA focuses on preventing faults, ensuring processes are performed correctly in the first instance. (NTG TG IT\&ED)

Quality Management System (QMS) - a complete set of quality standards, procedures and responsibilities.

Requirements Authority (RA) - an appointment within NATOs Global Programming Governance Structure that reflects responsibility for identifying, collecting and managing the education and training requirements associated with a discipline. The specific role and responsibilities are as follows:

a. Leading the identification of the individual and collective E\&T requirements.

b. Providing input concerning changes to NATO concepts, doctrine, policy and procedures and informing the $\mathrm{DH}$ accordingly.

c. Supporting the harmonization of the individual E\&T requirements with the collective part of the NATO Training Spectrum.

d. De-conflicting E\&T requirements with other RAs where overlap or requirements influence each other.

e. Supporting the Global Programming Development Methodology and the production of the Strategic Training Plan and Training Requirements Analysis.

f. Supporting the Annual Discipline Conference.

g. Annually reviewing E\&T requirements, based on the Lessons Learned process, operational experience and the analysis of emerging threats.

Simulation - the imitation of the operation of a real-world process or system over time. The act of simulating first requires that a model be developed and the model represents the key characteristics or behaviours/functions of the selected physical or abstract system (process). The model represents the system itself, whereas the simulation represents the operation of the system (NTG TG IT\&ED).

Simulator - a training device which captures the significant features of an operational environment to the level of fidelity necessary to maximize the degree of transfer from the training situation to the job.

Skill - a developed aptitude or ability supporting performance. Skills may be described as motor, manual and cognitive/intellectual and are applied according to the 
context. A skill is an organized and coordinated pattern of mental and/or physical activity that is often built up over time through repeated training, practice or other experience.

Skill Analysis - a detailed and systematic study of the skills needed to perform a particular task. It can also refer to the determination of the cues, responses, and decision-making functions involved in performing a skill. (NTG TG IT\&ED)

Standards - the criterion against which performance is measured; identifies a level of proficiency to be attained.

Strategic Training Plan (STP) - a product of the Global Programming - Development Methodology used to capture the strategic picture and formalize education and training needs through a NATO discipline. The STP provides the foundation and necessary justification for education and training through links to Alliance objectives and priorities.

Summative Evaluation - determines the degree to which the learner has achieved Performance Objectives.

Syllabus - a syllabus is, in its simplest form, a written statement of the subjects included in a course of study. In the field of training, syllabuses are constructed in terms of learning objectives that specify the skills, knowledge and attitudes to be acquired by trainees. Also see curriculum.

Synchronous Learning/Training - are events that occur within the same, real time domain with students who are not necessarily in the same location (NTG TG IT\&ED).

Systems Approach to Training (SAT) - see NATO Systems Approach to Training.

Target Audience - the individuals/participants, potentially from within a broader Training Audience, which require specific E\&IT to resolve a performance gap. Also see Training Audience.

Task - a discrete segment of work with a definite beginning and end. A task defines broader duties and is part of a job. Tasks can be produced, compiled, achieved and/or accomplished on their own.

Task Analysis - the systematic process of identifying how a specific task is completed; and a detailed analysis of each of those tasks. Task analysis involves skills analysis.

\section{Teaching Point - see: Content.}

Test - is an event during which a learner is asked to demonstrate an aspect of task performance, skill, knowledge or attitude. Tests which measure the extent to which a task, performance, skill, knowledge or attitude has been learned are deemed achievement tests. (NTG TG IT\&ED)

Test Reliability - the degree to which a test/test item gives consistent results each time it is used. 
Test Validity - the extent to which a test measures what it is designed to measure.

Training Audience - a collective training term referring to the headquarters/ command/participant/ unit identified as the main as well as secondary focus for a training event. Within E\&IT, Target Audience refers to the individual/participant component of the Training Audience.

Training Needs Analysis (TNA) - a series of activities within the Global Programming - Development Methodology which results with a set of E\&T solutions that satisfy a Requirements Package. This defines the objectives required to eliminate gaps and the necessary plans which result in the delivery of E\&T solutions. For E\&IT solutions this requires the application of the NATO SAT.

Training Objective (TO) - within NATO used for Collective Training; it is a mission essential task to be performed, under resource conditions, and defined standards (references and criteria of performance). It describes the staff processes, knowledge, skills or attitudes to be achieved during the conduct of training. Note: in some nations a TO is used within Individual Training and is synonymous with Enabling Objective.

Training Requirements Analysis (TRA) - a process supporting the Global Programming - Development Methodology used to capture NATO education and training requirements. The TRA attempts to match NATO education and training requirements with the available solutions.

Training Requirements Analysis Report (TRA Report) - this is the report documenting the results of a TRA. The TRA Report captures existing education and training solutions, potentially available to the Alliance, and is the tool used to eventually match NATO education and training requirements with the available solutions. The TRA Report also attempts to capture the intended target audiences and identifies preliminary performance objectives in the form of broad performance task statements.

Training Strategy - identifies, in broad terms, an overall approach for delivering a solution to satisfy an education and individual training requirement. Delivery options include residential (traditional) delivery, mobile education and training teams, eLearning/Advanced Distributed Learning or a combination (blended) of approach.

Transfer of Training - the degree to which skills learned in a training device or simulation will affect advanced training or operational performance. It should be noted that high fidelity does not necessarily imply a high degree of transfer of training (NTG TG IT\&ED).

Validation - the confirmation of the capabilities and performance of organizations, individuals, materiel or systems to meet defined standards or criteria, through the provision of objective evidence. 


\section{ADDITIONAL SUPPORT TO NATO EDUCATION AND INDIVIDUAL TRAINING NATO SCHOOL OBERAMMERGAU - COURSE LIST}

1. Introduction. The NATO School Oberammergau (NSO) prepares NATO personnel in their Education and Training roles by providing a series of tailored courses to develop the knowledge, skills and attitudes of educational leaders, instructors, instructional designers and standards/quality assurance personnel. The following courses were developed, based on NATO requirements, to support the implementation of Education and Individual Training (E\&IT) related Bi-SC Directives and, where applicable, may be appropriate for personnel from Education and Training Facilities (ETFs) supporting NATO. The courses break out by area and identify the objectives and intended training audience.

2. M7-135 NATO Global Programming Analysis Course. The target audience is selected NCS/NFS personnel, Department Heads (DHs) and Requirement Authority's (RAs). The aim of this course is to provide participants with the knowledge required to implement or otherwise support the Bi-SC 075-002 Education and Training (E\&T) Directive. This one week course will enable military and civilian personnel in E\&T management positions to support Global Programming and emphasizes the following areas:
a. The Global Programming.
b. Strategic Training Plans.
e. Training Requirements Analysis (TRA).
f. Training Needs Analysis (TNA).
g. Course Accreditation.
h. Supporting Systems and Resources for Global Programming.
i. Quality Assurance (QA).

3. M7-136 NATO Analysis, Design, and Evaluation Course ${ }^{72}$. The target audience is selected NCS/NFS personnel, DHs and ETFs supporting NATO E\&IT. The aim of the course is to educate and train those individuals involved in the design and development of training in a standardized process, enabling them to create effective and efficient training solutions. This one week course will enable military and civilian personnel in positions involved with the definition and delivery of E\&IT to:

a. Translate NATO E\&IT requirements resulting from TRA into NATO E\&IT solutions.

\footnotetext{
${ }^{72}$ Additional training supporting the design, development and evaluation of ADL/e-Learning courseware is also available through NSO.
}

C-1 
b. Develop effective Instructional Materials.

4. M7-137 NATO Quality Assurance Course. The target audience is selected NCS/NFS personnel, DHs and ETFs supporting NATO E\&IT. The aim of this course is to provide participants with the knowledge and skills required to develop and implement a Quality Management System (QMS) at ETFs in order to meet the Quality Standards for NATO ETF institutional accreditation. This one week course will enable military and civilian personnel to do the following:

a. Describe the purpose and framework for QA within NATO Education and Training.

b. Apply the QMS principles, criteria, and standards within their institution.

c. Develop monitoring and reporting tools to support the implementation of a QMS within their Institution.

d. Explain the NATO Quality Standards IAW Bi-SCD 075-007 to institutional leaders and key stakeholders.

e. Develop tools to support the accreditation process of their institution.

5. Instructor Development. NSO recognizes that excellence in instruction does not happen by chance. Instructors are the essential ingredient and NSO has developed two instructional programmes to increase the overall skills and abilities of instructors supporting the delivery of NATO E\&IT. The courses are as follows:

a. M7-83 NATO NCO Instructor Course. The target audience is comprised of instructors selected from the NCS/NFS and ETFs supporting the delivery of NATO E\&IT. The aim of this course is to provide NonCommissioned Officer (NCO) instructors with the skills and knowledge required to effectively instruct on NCO related topics focused in an international setting. This one week course will enable military NCOs in positions involved with the development and implementation of NATO E\&IT to:

(1) Develop and present a formal lesson in accordance with NCO instructor standards.

(2) Produce and present a syndicate lesson from a preselected multinational training catalogue in accordance with Bi-SC NCO Strategy and NCO recommended guidelines.

b. M7-98 NATO Academic Instructor Course. The aim of this course is to apply effective teaching methods and presentation techniques in delivering academic instruction. It will focus on building lesson plans and presenting lessons. This one week course will enable military and civilian personnel, in positions involved with the development and implementation of NATO E\&IT, to develop and present a lesson in accordance with a prepared lesson plan integrating effective instructional techniques. 


\section{QUALITY MANAGEMENT SYSTEM STANDARDS}

Education and Training Facilities which are Institutionally Accredited by NATO are expected to establish, maintain and review their internal processes and procedures to ensure that the following seven standards and guidelines are implemented.

\begin{tabular}{|c|c|}
\hline \multicolumn{2}{|c|}{ 1. Policy and procedures } \\
\hline STANDARD: & \\
\hline & $\begin{array}{l}\text { The Institution has a policy and procedures in place for Quality Management } \\
\text { including clearly defined responsibilities and authority of all involved. The } \\
\text { policy describes the Quality Management System (QMS) and how it involves } \\
\text { the major stakeholders (internal and external) and of how they contribute to } \\
\text { continuous improvement of an institutions main processes. An appropriate } \\
\text { level of internal and external transparency should be guaranteed. }\end{array}$ \\
\hline \multicolumn{2}{|r|}{ en } \\
\hline & $\begin{array}{l}\text { The policy is expected to include: } \\
\text { - the relationship between main activities depending on Education and } \\
\text { Training Facility (ETF) (e.g., relationships and links between teaching, } \\
\text { research, doctrine development, lessons learned); } \\
\text { - the organization of QMS; } \\
\text { - the responsibilities of different departments and individuals for quality } \\
\text { - management; } \\
\text { - } \text { key performance indicators; and }\end{array}$ \\
\hline
\end{tabular}

\begin{tabular}{|l|l|}
\hline 2. Staff/Instructor development \\
\hline STANDARD: & $\begin{array}{l}\text { The institution ensures the staff/Instructors are competent and qualified. Staff } \\
\text { development is a continuous process supported by the institution. }\end{array}$ \\
\hline GUIDELINES: & The Education and Training Facility (ETF) is expected to have: \\
& $\begin{array}{l}\text { - principles, procedures and selection criteria for the recruitment of staff } \\
\text { and external instructors; } \\
\text { procedures and programmes to support the professional development } \\
\text { of staff and instructors (including continuously improving instructor } \\
\text { abilities); level of competency and education and training } \\
\text { - minimum level of and } \\
\text { requirements are included in the job descriptions; } \\
\text { the working conditions of the staff encourage a positive environment. }\end{array}$ \\
\hline
\end{tabular}

D-1 


\begin{tabular}{|l|l|}
\hline 3. Information systems and knowledge management \\
\hline STANDARD: & $\begin{array}{l}\text { The Institution collects, analyses and efficiently uses relevant information for } \\
\text { the effective management and conduct of their training and related activities. }\end{array}$ \\
\hline GUIDELINES: & Information management system is expected to manage: \\
& $\begin{array}{l}\text { - relevant internal and external stakeholders satisfaction/feedback; } \\
\text { - development and version control; }\end{array}$ \\
& $\begin{array}{l}\text { - lesources (courseware); } \\
\text { - learning/teaching resources; }\end{array}$ \\
& - trackiles of students audience; and \\
\hline
\end{tabular}

\begin{tabular}{|c|c|}
\hline \multicolumn{2}{|c|}{ 4. Public information } \\
\hline STANDARD: & \\
\hline & $\begin{array}{l}\text { The Institution publishes and regularly updates objective information, both } \\
\text { qualitative and quantitative about their courses and related activities. }\end{array}$ \\
\hline \multicolumn{2}{|r|}{ 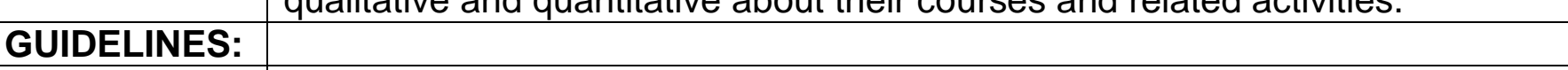 } \\
\hline & $\begin{array}{l}\text { The Education and Training Facility (ETF) is expected to: } \\
\text { - provide and regularly update adequate information about the courses } \\
\text { provided (e.g., course catalogue) on their website and accurately } \\
\text { reflected in Education Training Opportunities Catalogue (ETOC); } \\
\text { - inform main stakeholders and the Community of Interest (Col) about } \\
\text { intended major changes in Course Control Documents (CCDs) and } \\
\text { especially enabling/learning objectives (ELO); and } \\
\text { - develop and maintain a communication network with ETFs and Cols } \\
\text { related to the subjects covered by the CCDs, }\end{array}$ \\
\hline
\end{tabular}




\begin{tabular}{|c|c|}
\hline \multicolumn{2}{|c|}{$\begin{array}{l}\text { 5. Definition and delivery of instruction } \\
\text { STANDARD: }\end{array}$} \\
\hline & \\
\hline & $\begin{array}{l}\text { The Institution has instructions and controls for the analysis, design, } \\
\text { development, implementation and evaluation of Education and Individual } \\
\text { Training (E\&IT) including how the institution plans and schedules courses, } \\
\text { monitors course quality and conducts periodic reviews ensuring the continued } \\
\text { relevance of the E\&IT that is provided. }\end{array}$ \\
\hline \multicolumn{2}{|r|}{ ( ) } \\
\hline & $\begin{array}{l}\text { CCDs, or equivalent, exists for each NATO course and they define the E\&IT } \\
\text { solution. CCDs confirm stakeholder engagement and include: } \\
\text { - the background explaining the need for a course and the fit with NATO } \\
\text { requirements; } \\
\text { - the aim/intent of the course; } \\
\text { - details concerning the intended audience; } \\
\text { - performance objectives which capture the performance gap to be } \\
\text { addressed through E\&IT; } \\
\text { - ELOs which are part of an overall strategy capturing course content } \\
\text { and defining what will be learned, how it will be learned and how long it } \\
\text { will take; } \\
\text { - a reference list supporting the course content; and } \\
\text { - a resource estimate identifying facility, personnel, equipment and } \\
\text { materials essential to conduct a course. } \\
\text { The planned and systemic approach to address E\&IT delivery is documented } \\
\text { including the administration activities within the institution supporting the } \\
\text { development, implementation and evaluation of courses: } \\
\text { - course design takes into account previous training and professional } \\
\text { experience of the intended audience; } \\
\text { - the number of seats for each course is planned in accordance with } \\
\text { NATO and national needs and the capacity and purpose of the } \\
\text { institution; } \\
\text { courseware, including instructional materials, student assessment } \\
\text { instruments and optimum schedules/timetables are in place for each } \\
\text { NATO course; } \\
\text { - appropriate planning and coordination instructions exist to support the } \\
\text { preparation, execution and close out of a course serial/iteration; and } \\
\text { - there are formalized post-course reviews intended monitor quality and } \\
\text { improve E\&IT. }\end{array}$ \\
\hline
\end{tabular}

D-3 


\begin{tabular}{|l|l|}
\hline 6. Student assessment \\
\hline STANDARD: & $\begin{array}{l}\text { Students are assessed using published criteria, regulations and procedures } \\
\text { which are applied consistently and systematically. Students are aware of } \\
\text { what will be expected from them and how their performance will be evaluated. }\end{array}$ \\
\hline GUIDELINES: & $\begin{array}{l}\text { Student assessment procedures are expected to: } \\
\text { - be designed to measure the achievement of the intended learning } \\
\text { - outcomes; }\end{array}$ \\
& $\begin{array}{l}\text { - be appropriate for the purpose (e.g., formative/summative/ } \\
\text { - be based on clear and published criteria; }\end{array}$ \\
& $\begin{array}{l}\text { - where applicable, should not rely on the judgement of a single } \\
\text { - have procedures in place for student appeals; and }\end{array}$ \\
\hline
\end{tabular}

\begin{tabular}{|l|l|}
\hline 7. Learning resources and student support \\
\hline STANDARD: & $\begin{array}{l}\text { The Education and Training Facility (ETF) has appropriate resources } \\
\text { available to support students throughout the learning process. }\end{array}$ \\
\hline GUIDELINES: & $\begin{array}{l}\text { Learning resources and other support mechanisms should be: } \\
\text { - readily accessible to students; }\end{array}$ \\
& $\begin{array}{l}\text { - designed according to student's needs; } \\
\text { - responsive to feedback from those who use them; and }\end{array}$ \\
\hline
\end{tabular}

D-4 


\section{ANNEX E TO \\ Bi-SCD 075-007 \\ DATED 10 SEP 15}

\section{NATO QUALITY STANDARDS}

NATO Quality Standards support NATO Education and Training Facility (ETF) Institutional Accreditation. The Quality Standards validate the education and training mission, including overall leadership and management, of an organization and confirms the relevance of the organization to NATO. To become Institutionally Accredited an ETF must demonstrate a contribution to NATO. NATO Quality Standards address three broad areas and are detailed in the tables that follow.

\section{LEADERSHIP AND MANAGEMENT}

\subsection{General management}

Standards:

1.1.1. Institution has a long term plan based on its mission and vision, which considers NATO priorities and the expectations of major stakeholders.

1.1.2. The Institution has implemented a Quality Management System (QMS) that is supported by relevant documents that are regularly reviewed and remain up to date.

1.1.3. Internal and external communication of the institution is purposeful and managed.

1.1.4. The institution uses information systems that support its management and the coherent performance of its core functions.

\subsection{Personnel management}

Standards:

1.2.1. The Institution has principles and procedures for personnel recruitment and development. They arise from the Institutions objectives and ensure training quality and sustainability.

1.2.2. Personnel satisfaction (including working conditions, flow of information) is monitored and practices to support staff motivation are implemented.

1.2.3. Personnel participate in other NATO activities (working groups, projects).

1.2.4. The faculty and staff have the Education and Training (E\&T) qualifications as per the job descriptions and course control documents.

\subsection{Resources management}

Standards

1.3.1. The Institution has a sustainable budget.

1.3.2. The Institution has defined the principles for budgetary decision making.

1.3.3. The allocation of financial resources of an institution is based on the Institution's actual needs and priorities in accordance with its mission and objectives.

1.3.4. The working conditions of the staff and the learning conditions of students (e.g., library, classrooms, and laboratories) meet the needs arising from the learning objectives, specifics of the institution and the expectations of major stakeholders. 


\section{EDUCATION AND TRAINING}

2.1. Define and deliver Instruction

Standards

2.1.1. Each NATO course is defined and delivered in accordance with principles of Global Programming and the NATO Systems Approach to Training.

2.1.2. Student satisfaction with the quality of instruction and graduate feedback is considered in the development of instruction.

2.1.3. Supervisor's/commander's satisfaction with the performance of graduates is considered in the development of instruction.

2.1.4. Instructor feedback concerning course delivery and quality is considered in the development of instruction.

2.2. Student assessment

Standards

2.2.1. Student progress is monitored and supported throughout the course.

2.2.2. Student assessment supports learning and is in line with learning objectives.

2.2.3. Assessment and graduation criteria are predefined and acknowledged before teaching.

2.2.4. The institution has procedures in place for student appeals.

2.3. Support for training and learning

\section{Standards}

2.3.1. The resource allocation for courses meets the student needs and fits with the learning objectives.

2.3.2. The institution provides students with guidance in support of their studies (as required).

2.3.3. Up to date resources are used to support training.

2.3.4. Student feedback concerning support is taken into account as part of improvement activities. 


\section{CONTRIBUTION TO NATO}

3.1. Support to NATO requirements

Standards

3.1.1. The institution has identified its role in support of NATO.

3.1.2. The institution offers NATO selected/approved courses.

3.1.3. The Institution exploits operational lessons learned to improve training.

3.1.4. The institution's core activities are coherent in support to NATO.

3.2. Support to discipline management.

Standards

3.2.1. The institution contributes to discipline(s) development.

3.2.2. The institution contributes to maintaining NATOs discipline framework.

3.3. Contributions to other NATO associated activities.

\section{Standards}

3.3.1. The institution contributes to the evolvement of NATO in different ways (e.g. doctrine development, R\&D, lessons learned, operations and defence planning). 


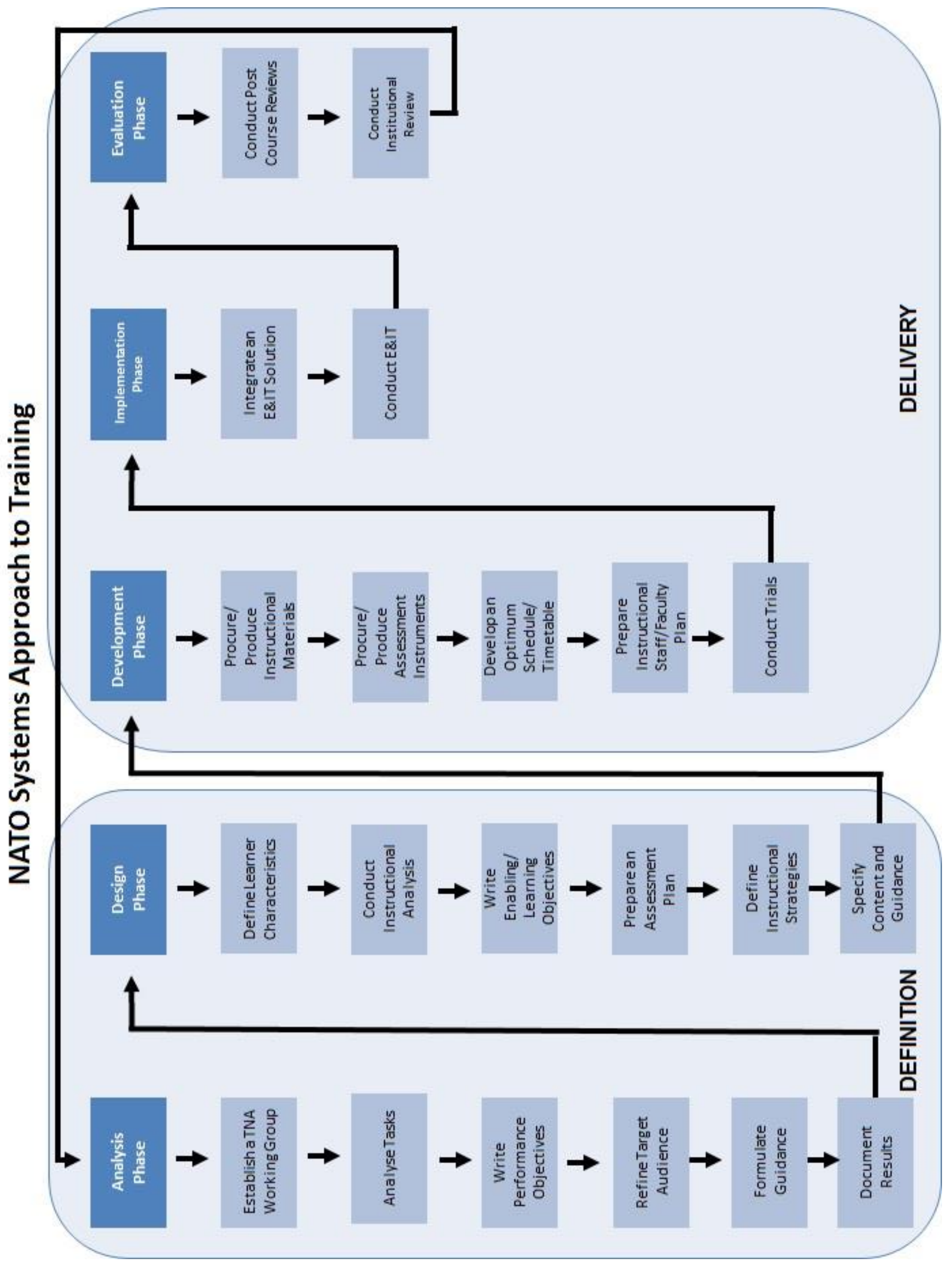

$\mathrm{F}-1$ 


\section{PERFORMANCE PROFICIENCY LEVELS AND KEY WORDS}

1. Basic through to Master. Proficiency levels provide a scale which defines a degree of competence ("expertise") required in order to perform principle duties and tasks on the job within NATO. The duties and tasks are used to capture the performance gap while the proficiency level scale determines the depth of knowledge and skill that an E\&IT solution is intended to target in order to resolve the performance gap ${ }^{73}$. Key action words are used to describe job performance and the action words are categorized based on broad functional areas. The levels of proficiency are based on a modified version of the generic skill descriptions used to augment NATO Occupation Codes. The levels of proficiency and related generic skill descriptors are as follows:
a. Basic Level - Follow.
b. Intermediate Level - Assist.
c. Advance Level - Apply.
d. Expert Level - Enable/Advisor.
e. Master Level - Initiate/Shape/Influence.

2. Institutional Leaders. Enterprise level descriptors, that are indicative of institutional leadership, are not included in the proficiency levels listed above. Institutional leadership positions within NATO are responsible for setting the vision and strategy as well as inspiring and providing overall leadership. Institutional leaders have significant experience and substantial professional military education which prepares them for work within a complex global environment. Institutional leaders will make the critical decisions which shape and position the organization for future success and this will also integrate a long-term view. Key Leader Engagement events, conferences, seminars and related senior level planning forums are frequently conducted within NATO in large part to keep a broad audience aware of evolving issues and their implications. These forums, combined with expert and master level briefs, provide institutional leaders with the essential foundation to make informed decisions and achieve institutional leadership. An exception to this comes in the form of formalized foundation training which is provided to a specific a Training Audience supporting an operational mission and/or exercise.

\footnotetext{
${ }^{73}$ The generic eight skill levels outlined in NATO Occupation Codes - Generic Skill Descriptions have been modified given five levels of proficiency are adequate to identify and define NATO E\&T requirements. The eight levels are outlined in Appendix C to NATO Occupational Area Codes, Version 4.0, published 14 December 2007 by NATO C3 Agency.
} 


\section{Job Performance}

Proficiency Levels

\section{Basic Level (Follow)}

\section{Skill \& Knowledge}

1 The level of proficiency required to successfully perform a routine task or series of task elements (e.g, a step

0 in a sequence of actions) in a structured environment with supervision. Is expected to seek guidance in unexpected conditions. This requires remembering information including facts, terms, concepts, principles as well as the processes and procedures defining job requirements.

Functional Area: Support.

\section{Intermediate Level (Assist)}

\section{Skill \& Knowledge}

2 The level of proficiency required to become functional and successfully perform a series of tasks

2 independently with minimal oversight. Uses discretion in resolving problems and may plan and schedule

0 work within short timeframes. This requires interpreting information, constructing meaning and the

0 comprehension of facts, terms, concepts, and principles as well as the processes and procedures essential to enable understanding and accomplishing job requirements.

Functional Area: Communication, Administrative, Technical and Finance.

\section{Advance Level (Apply)}

\section{Skill \& Knowledge}

The level of proficiency required to interpret direction and guidance and successfully plan and complete

3 tasks independently as well as potentially monitoring the work of others. Uses discretion to resolve

0 increasingly more complex problems. This requires the application of concepts, principles processes and procedures in both non-routine (new) and concrete situations as well as executing, implementing and carrying out processes and procedures to satisfy job requirements.

Functional Area: Communication, Administrative, Technical, Finance, Teaching, Creating and Leadership/ Management.

\section{Expert Level (Enable/Advisor) \\ Skill \& Knowledge}

The level of proficiency required to execute a broad range of complex professional and/or technical work activities leveraging prior education, training and practical experience; this includes maintaining an institutional leaders discipline and/or inter-disciplinary related advice. This level requires setting work objectives and assigning task and the ability to deconstruct and integrate concepts, principles and procedures to support reasoning and as well as the application of a systematic approach to solving nonroutine and ill-defined problems.

Functional Area: Communication, Administrative, Technical, Finance, Teaching, Creating, Research and Leadership/ Management.

\section{Master Level (Initiate, Shape and Influence)}

\section{Skills \& Knowledge}

The level of proficiency required to execute highly complex work activities covering, technical, financial and quality aspects for a functional area. Leverages considerable education, training and extensive practical experience to advise commanders as well as exert significant influence over policy development and contribute to the formulation of strategy and organizational objectives. Decisions made impact the functional area of the enterprise. Able to assess and evaluate risks and understand the implications of new concepts,

technologies and trends. This requires adapting concepts and principles as well as processes and procedures to support critical, asymmetric thinking and reasoning potentially leading research efforts and building knowledge, theory and alternative approaches within a recognized body of knowledge.

Functional Area: Communication, Administrative, Technical, Finance, Teaching, Creating, Research and Leadership/ Management. 


\section{Job Performance - Key Word Areas \& Indicators}

The following key action words are used to describe job task performance. Key word indicators are categorized into nine broad functional areas. Additional functional areas may be created as deemed necessary. Most of the key words provided below are common across multiple proficiency levels; however, some of the functional areas are more applicable to specific proficiency levels. Example: "Support" key words are applicable to the Basic Proficiency Level while other functional areas (e.g., Research) are more applicable to higher levels.

\begin{tabular}{|c|c|c|c|c|c|c|c|c|}
\hline $\begin{array}{l}\text { 음 } \\
\text { 응 } \\
\text { 윽 }\end{array}$ & 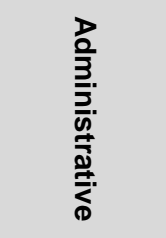 & 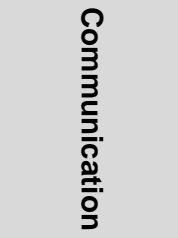 & 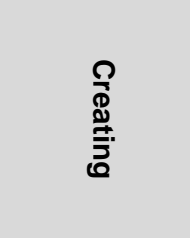 & 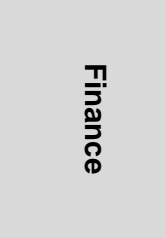 & 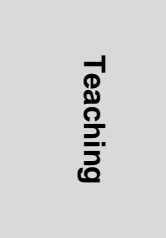 & 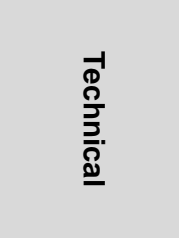 & 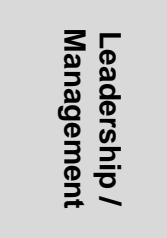 & 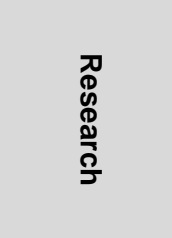 \\
\hline $\begin{array}{l}\text { aid } \\
\text { assist } \\
\text { contribute } \\
\text { help out } \\
\text { observe } \\
\text { support }\end{array}$ & $\begin{array}{l}\text { approve } \\
\text { arrange } \\
\text { catalogue } \\
\text { classify } \\
\text { collect } \\
\text { compile } \\
\text { contract } \\
\text { dispatch } \\
\text { distribute } \\
\text { execute } \\
\text { file } \\
\text { generate } \\
\text { implement } \\
\text { operate } \\
\text { organize } \\
\text { prepare } \\
\text { process } \\
\text { purchase } \\
\text { record } \\
\text { retrieve } \\
\text { screen } \\
\text { specify } \\
\text { staff } \\
\text { systematize } \\
\text { tabulate } \\
\text { transcribe } \\
\text { validate }\end{array}$ & $\begin{array}{l}\text { address } \\
\text { advise } \\
\text { arbitrate } \\
\text { arrange } \\
\text { articulate } \\
\text { author } \\
\text { clarify } \\
\text { collaborate } \\
\text { compose } \\
\text { condense } \\
\text { confer } \\
\text { consult } \\
\text { contact } \\
\text { convey } \\
\text { convince } \\
\text { correspond } \\
\text { counsel } \\
\text { debate } \\
\text { develop } \\
\text { direct } \\
\text { display } \\
\text { draft } \\
\text { edit } \\
\text { enlist } \\
\text { formulate } \\
\text { incorporate } \\
\text { influence } \\
\text { inform } \\
\text { interpret } \\
\text { judge } \\
\text { lecture } \\
\text { market } \\
\text { mediate } \\
\text { moderate } \\
\text { negotiate } \\
\text { persuade } \\
\text { promote } \\
\text { propose } \\
\text { publicize } \\
\text { reconcile } \\
\text { recruit } \\
\text { staff } \\
\text { suggest } \\
\text { translate } \\
\text { synthesize } \\
\text { write }\end{array}$ & $\begin{array}{l}\text { adapt } \\
\text { assemble } \\
\text { build } \\
\text { combine } \\
\text { compose } \\
\text { conceptualize } \\
\text { create } \\
\text { customize } \\
\text { design } \\
\text { develop } \\
\text { devise } \\
\text { direct } \\
\text { establish } \\
\text { fabricate } \\
\text { fashion } \\
\text { illustrate } \\
\text { improve } \\
\text { initiate } \\
\text { institute } \\
\text { integrate } \\
\text { introduce } \\
\text { invent } \\
\text { originate } \\
\text { pioneer } \\
\text { plan } \\
\text { prepare } \\
\text { revitalize } \\
\text { select } \\
\text { shape } \\
\text { solve }\end{array}$ & $\begin{array}{l}\text { administer } \\
\text { adjust } \\
\text { allocate } \\
\text { analyse } \\
\text { appraise } \\
\text { assess } \\
\text { audit } \\
\text { balance } \\
\text { budget } \\
\text { calculate } \\
\text { classify } \\
\text { compile } \\
\text { compute } \\
\text { commit } \\
\text { conserve } \\
\text { contract } \\
\text { correct } \\
\text { determine } \\
\text { develop } \\
\text { estimate } \\
\text { forecast } \\
\text { inspect } \\
\text { manage } \\
\text { market } \\
\text { measure } \\
\text { monitor } \\
\text { plan } \\
\text { predict } \\
\text { project } \\
\text { purchase } \\
\text { quantify } \\
\text { reconcile } \\
\text { reduce } \\
\text { research } \\
\text { verify }\end{array}$ & $\begin{array}{l}\text { adapt } \\
\text { advise } \\
\text { clarify } \\
\text { coach } \\
\text { convey } \\
\text { coordinate } \\
\text { demystify } \\
\text { develop } \\
\text { enable } \\
\text { encourage } \\
\text { evaluate } \\
\text { facilitate } \\
\text { familiarize } \\
\text { guide } \\
\text { inform } \\
\text { instruct } \\
\text { mentor } \\
\text { persuade } \\
\text { stimulate } \\
\text { train }\end{array}$ & $\begin{array}{l}\text { activate } \\
\text { administer } \\
\text { advise } \\
\text { aim } \\
\text { calculate } \\
\text { calibrate } \\
\text { construct } \\
\text { debug } \\
\text { design } \\
\text { devise } \\
\text { diagnose } \\
\text { dismantle } \\
\text { dispose } \\
\text { dissect } \\
\text { dissemble } \\
\text { engineer } \\
\text { engage } \\
\text { estimate } \\
\text { extract } \\
\text { fasten } \\
\text { inspect } \\
\text { install } \\
\text { maintain } \\
\text { manipulate } \\
\text { manufacture } \\
\text { map } \\
\text { measure } \\
\text { mend } \\
\text { mix } \\
\text { monitor } \\
\text { move } \\
\text { navigate } \\
\text { operate } \\
\text { overhaul } \\
\text { plot } \\
\text { predict } \\
\text { programme } \\
\text { propose } \\
\text { rehabilitate } \\
\text { remodel } \\
\text { repair } \\
\text { replace } \\
\text { restore } \\
\text { sight } \\
\text { solve } \\
\text { survey } \\
\text { target } \\
\text { test } \\
\text { verify }\end{array}$ & $\begin{array}{l}\text { activate } \\
\text { administer } \\
\text { advise } \\
\text { allocate } \\
\text { analyse } \\
\text { approve } \\
\text { appraise } \\
\text { assign } \\
\text { authorize } \\
\text { chair } \\
\text { control } \\
\text { coordinate } \\
\text { delegate } \\
\text { develop } \\
\text { direct } \\
\text { enforce } \\
\text { enhance } \\
\text { establish } \\
\text { estimate } \\
\text { evaluate } \\
\text { execute } \\
\text { formulate } \\
\text { guide } \\
\text { improve } \\
\text { implement } \\
\text { initiate } \\
\text { inspire } \\
\text { judge } \\
\text { lead } \\
\text { mentor } \\
\text { modernize } \\
\text { motivate } \\
\text { organize } \\
\text { oversee } \\
\text { plan } \\
\text { preside } \\
\text { prioritize } \\
\text { produce } \\
\text { recommend } \\
\text { resolve } \\
\text { review } \\
\text { schedule } \\
\text { select } \\
\text { spearhead } \\
\text { structure } \\
\text { supervise } \\
\text { transform }\end{array}$ & $\begin{array}{l}\text { analyse } \\
\text { assess } \\
\text { attain } \\
\text { clarify } \\
\text { collect } \\
\text { conduct } \\
\text { critique } \\
\text { diagnose } \\
\text { detect } \\
\text { determine } \\
\text { evaluate } \\
\text { examine } \\
\text { experiment } \\
\text { extract } \\
\text { formulate } \\
\text { identify } \\
\text { inspect } \\
\text { interpret } \\
\text { interview } \\
\text { invent } \\
\text { investigate } \\
\text { locate } \\
\text { measure } \\
\text { organize } \\
\text { research } \\
\text { review } \\
\text { select } \\
\text { solve } \\
\text { study } \\
\text { summarize } \\
\text { survey } \\
\text { systematize } \\
\text { test } \\
\text { verify }\end{array}$ \\
\hline
\end{tabular}




\section{TASK STATEMENT - TRACKING MATRIX}

1. The Task Statement. Tracking Matrix is a locally generated form used to provide an audit trail confirming the source of performance statements used in the development of Performance Objectives. The matrix ensures performance statements remain linked, and accounted for, relative to the E\&IT solutions that are created. Documenting the performance statements provides a DH with an audit trail to the TRA Report and it is helpful in maintaining discipline alignment. NEW performance statements generated by the TNA WG would become a subject for discussion during an Annual Discipline Conference. The matrix is also useful for capturing TRA performance statements which the TNA WG determines do NOT require training.

2. The following is an example how the Performance Statements may be tracked. This example uses sample statements and is NOT complete.

\begin{tabular}{|c|c|c|c|c|c|c|}
\hline \multicolumn{7}{|c|}{ Performance/Task Statement Tracking Matrix } \\
Instructions. Assign a Tacking Number to each performance statement in the TRA Report that is \\
intended to be part of the E\&IT solution. The Tracking Number is generated by the TNA WG. \\
Associate the Tracking Number to the Source Details for this statement from within the TRA Report \\
(meaning identify the line number or paragraph in the TRA Report). Performance statement proficiency \\
is indicated in the TRA Report or otherwise assigned by the TNA WG.
\end{tabular}




\section{TASK ANALYSIS}

The following are example task analysis dependency diagrams. These highlight hierarchical and procedural relationships. Tasks stem from a specific job and duty areas.

\section{Example 1: Maintain Fuels Systems}

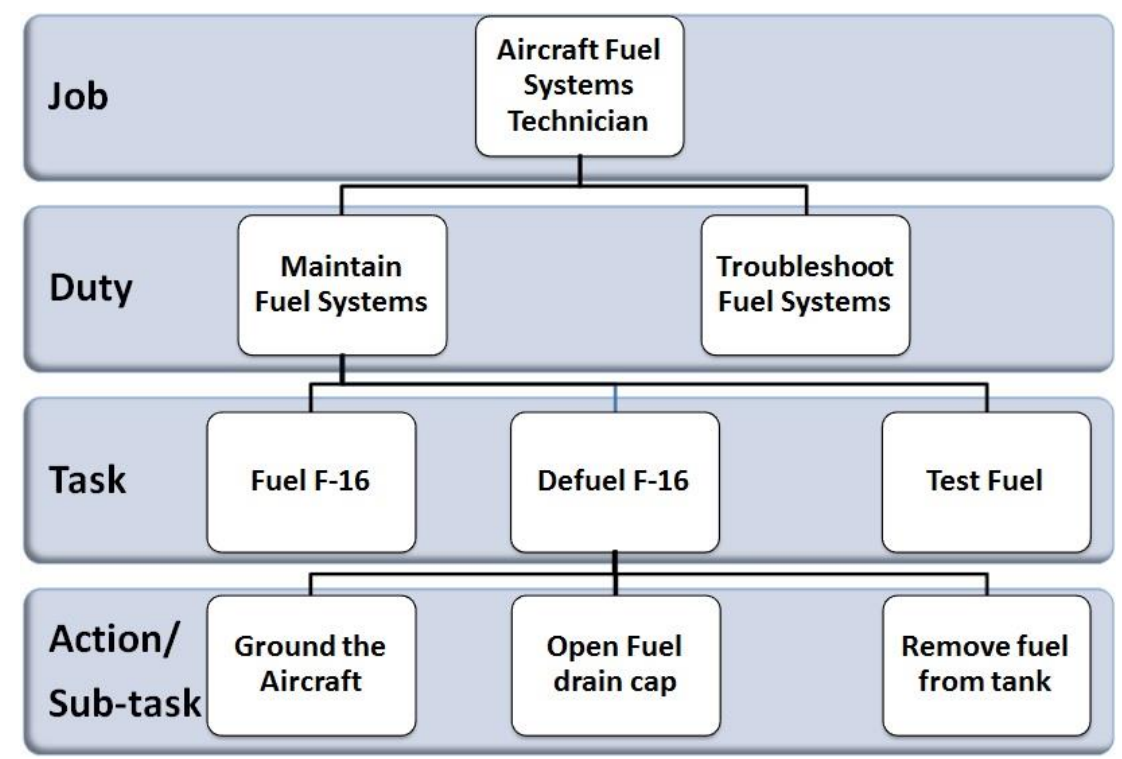

\section{Example 2: Preventative Medicine}

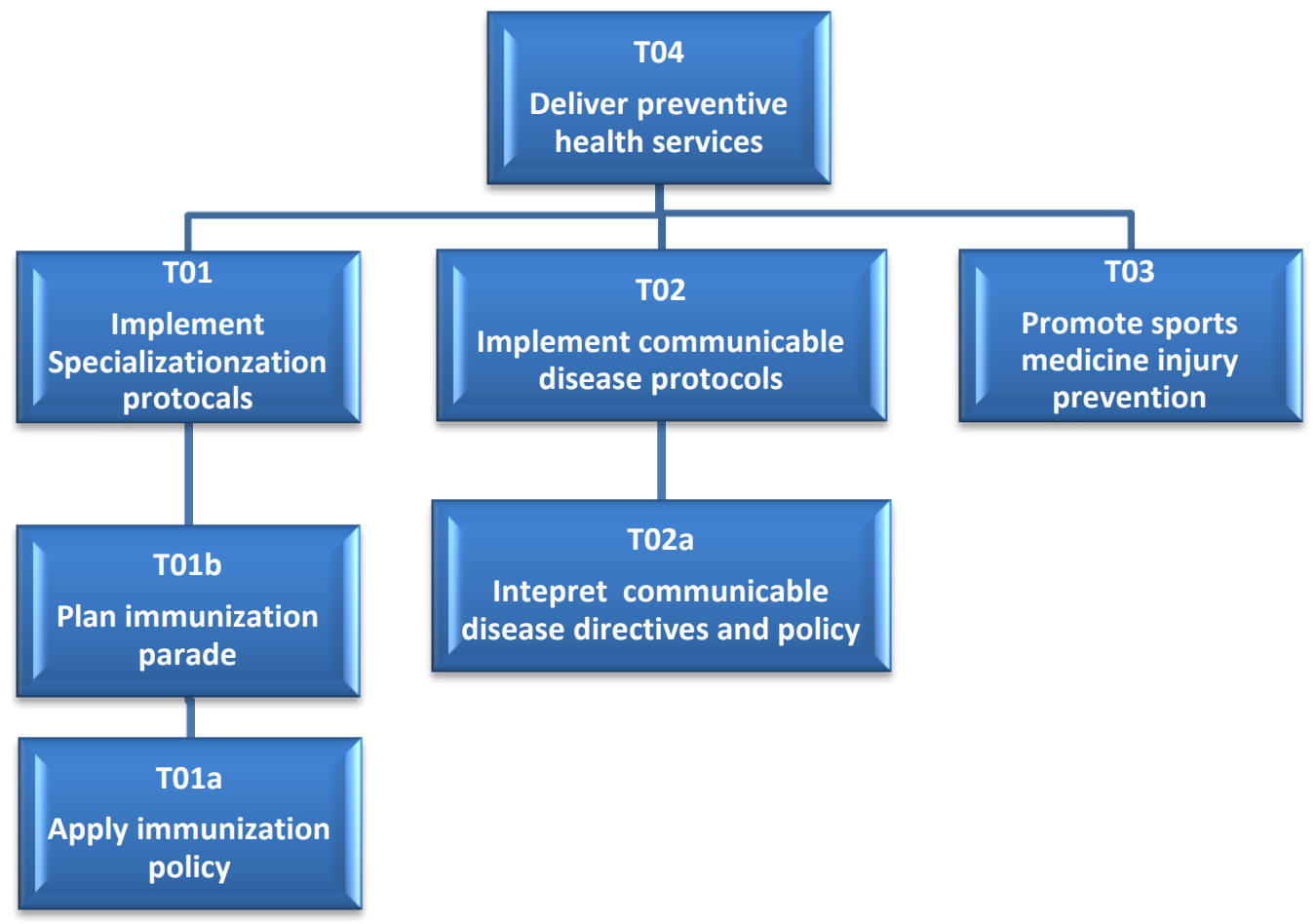

I-1 


\section{PERFORMANCE OBJECTIVES}

\section{INTRODUCTION}

1. POs specify, in precise terms, what an individual must be able to do in terms of job performance and how well. The following will:

a. Describe the three parts to a Performance Objective (PO).

b. Provide guidance to support the development of POs.

c. Include example POs. The example POs provide additional considerations to include in a final product.

2. A PO includes:

a. A performance statement which is a clear, concise and precise statement representing a logical and complete part of the job function (a duty area) which is observable and measurable.

b. Conditions statement which describe the situation, context, in which the performance is accomplished.

c. Standards describe how, and how well, performance must be completed. Standards specify a definite level of achievement and provide the clear and specific criterion defining the required degree of proficiency.

\section{PERFORMANCE STATEMENTS}

3. Performance statements can eliminate the subjective interpretations and ambiguity of what is to be accomplished. The performance statement is the first element of a PO and represents a balance of clarity and brevity while capturing multiple tasks often associated with a duty area. The performance statement is ideally a single sentence with one key (action) word, an object for the action word and any necessary qualifiers. The following conventions apply:

a. Clarity. Represent actual and specific job performance. Also, avoid the use of technical and/or occupational jargon.

b. Brevity. Limit verbosity by not exceeding what is sufficient for follow-on activities.

c. Flexibility. The task should be adaptable enough to meet minor and evolving work criteria. 
d. $\quad$ Limit the Task Statement to One Key (Action) Word or Verb. At times, two action words may seem necessary; however, one of the two action words is often a supporting action. The superior action should be used in the task statement because it signifies the "end". The additional supporting elements will get defined during the development of E\&IT solutions. At this point the focus is job performance:

(1) Example 1: Analyse and Identify = Identify. One must first "Analyse" in order to "Identify," therefore "Analyse" is the supporting action. "Identify" is the superior task.

(2) Example 2: "Assemble and Disassemble". These action words are frequently together in the same task statement. In most cases, the first step in assembling is disassembling. Therefore, the job task is to assemble. Occasionally disassembly is performed independently of assembly and task procedure is inherently separate. In this situation "assemble and disassemble" are two separate and discrete job tasks.

e. Avoid Expressing Ambiguity and Value Judgements. The key is to express what tasks are accomplished on-the-job, not how and/or how well tasks must be completed (e.g., effectively Identify Tactical Intelligence Factors) or degree (e.g., thoroughly Identify Tactical Intelligence Factors). The proficiency of a task completion is stated in operational policy/doctrine manuals and associated training publications.

f. Avoid Expressing how Job Tasks are Achieved. Focus on the outcome of work.

(1) Example. An Intelligence Operator must first "Analyse Tactical Intelligence Data" in order to "Identify Tactical Intelligence Factors." The act of "identification" demonstrates that analysis has occurred. In this situation, "analysis" is the most prominent skill based supporting activity that enables the identification of tactical intelligence factors. The most significant means to the outcome of a task (such as analysis) are almost always skill and/or applied knowledge based supporting activities (e.g. operating machines and tools, analysing sources of information, methods employed, steps of a procedure, and cognitive and/or psychomotor skills). These activities support and/or enable the completion of a genuine job task.

4. Constructing performance statements involves the application of principles described previously. Table $\mathrm{J}-1$ reviews examples and provides further guidance to consider when developing performance statements.

\begin{tabular}{|c|l|}
\hline \multicolumn{2}{|c|}{ Performance Statements } \\
\hline Example & \multicolumn{1}{c|}{ Comment } \\
\hline $\begin{array}{c}\text { Obtain a venepuncture blood } \\
\text { specimen }\end{array}$ & $\begin{array}{l}\text { Good example: } \\
\text { - Identifies the task being done with one action word - } \\
\text { Obtain. }\end{array}$ \\
& $\begin{array}{l}\text { Identifies the object (what) is being acted upon - } \mathbf{a} \\
\text { blood specimen. }\end{array}$ \\
\hline
\end{tabular}




\begin{tabular}{|c|c|}
\hline \multicolumn{2}{|c|}{ Performance Statements } \\
\hline Example & Comment \\
\hline & $\begin{array}{l}\text { - Qualifies the action. When necessary, uses a qualifier } \\
\text { to distinguish a means, methodology or approach - } \\
\text { venepuncture. } \\
\text { Note: qualifiers are only necessary when there are } \\
\text { alternative means, method or approach for conducting the } \\
\text { action. }\end{array}$ \\
\hline $\begin{array}{c}\text { Plan, organize and control } \\
\text { travel expenses }\end{array}$ & $\begin{array}{l}\text { More than one key (action) word - a performance } \\
\text { statement is not intended to be a list of sub-tasks. } \\
\text { Revision: Control travel expenses }\end{array}$ \\
\hline $\begin{array}{l}\text { Understand the laws of armed } \\
\text { conflict }\end{array}$ & $\begin{array}{l}\text { Focus on job performance action words not the enabling } \\
\text { supporting elements (knowledge). Knowledge } \\
\text { requirements may be reflected in the Standard; however, } \\
\text { knowledge elements are often better left to defining/writing } \\
\text { the Enabling/Learning Objectives during the Design } \\
\text { Phase. } \\
\text { Suggestion: When constructing performance statements } \\
\text { focus on the outcome - "Why" is the knowledge required; } \\
\text { understanding the laws of armed conflict is required in } \\
\text { order to? } \\
\text { Revised: Advise Commanders on the laws of armed } \\
\text { conflict". } \\
\text { * Note: Context is important and in some situations a } \\
\text { performance statement which is "knowledge based" } \\
\text { maybe better reflected in the standard. Example: "Apply } \\
\text { the laws of armed conflict" is not an ideal performance } \\
\text { statement given "Why" is the knowledge required is still } \\
\text { not clear. A clear understanding of the Target Audience is } \\
\text { also essential in order to correctly describe desire } \\
\text { performance }\end{array}$ \\
\hline $\begin{array}{l}\text { The student will learn forklift } \\
\text { operations by studying the } \\
\text { operator's manual }\end{array}$ & $\begin{array}{l}\text { This is not a performance statement. This refers to a } \\
\text { learning activity not a performance outcome to be } \\
\text { achieved as a result of E\&IT. Observing the student } \\
\text { reading provides no measure of whether learning has } \\
\text { occurred and there is no clear result or product from the } \\
\text { specified action. } \\
\text { Revised: } \\
\text { - Load trailers (given a forklift) } \\
\text { - Operate a forklift (move pallets and cargo, } \\
\quad \text { maintain situational awareness, adhere to safety } \\
\text { procedure outlines in reference X) } \\
\text { * Note: Desired performance must be placed into the } \\
\text { proper context hence the conditions and standard } \\
\text { statements become important and in many situations } \\
\text { provide qualifiers for the performance statement. }\end{array}$ \\
\hline
\end{tabular}

Table J-1 Performance Statement - Guidance 


\section{CONDITION STATEMENTS}

5. Conditions reflect the work situation as accurately as possible, but include only those factors that influence job performance. Conditions address what is normally provided as well as what might otherwise not be unavailable. An example is as follows:
a. Tools and equipment.
b. Job aids, reference manual and specific material.
c. Supervision.
d. Assistance.
e. Environment (day, night, temperature extremes).

f. Special physical, psychological demands (confined work space, noise).

\section{STANDARDS STATEMENTS}

6. Standards reflect the product, process or combination of both which describe how and how well the task(s) must be satisfied. Standards are based on actual job requirements and included specific criterion which are either based in doctrine or references and reflect the performance outcome to be judged. The measure generally addresses as following:

a. Speed. The speed of performing a task can have a critical effect on the outcome of a mission: a rapid response can contribute to the success of a mission but too slow a response may spell disaster. In other settings, work must be done quickly in order to avoid backlogs and to promote overall unit effectiveness. Standards of speed must reflect operational requirements as in the following examples:

(1) Rescue hitch must be tied within 3 minutes or.

(2) Rate of typing is 45 words per minute.

b. Soundness of Judgement. If the judgement or decision required in performing a task is such that successful performance will be seriously affected by a wrong decision, it must be shown as a measure in the standard. For example, "patient is referred to medical officer when seriousness of ailment is beyond the medical assistant's own authorized scope of care". If the end product is the decision itself, then the standard must directly measure the adequacy of the member's analytical or decision-making ability.

c. Measures of Accuracy. Accuracy measures are often used as a means for describing a desired level of proficiency (tunes a radio to achieve a signal strength within $5 \%$ of maximum range) or physical dimensions of a finished product as well as a maximum error rate.

d. Completeness. This can describe the steps to be followed in a process as well as their specific sequence. 


\section{EXAMPLE - PERFORMANCE OBJECTIVES}

7. The following are Example POs. POs are included within Part 2 of the Course Control Document II - Course Proposal. Additional paragraphs may be included to further amplify the requirements described within the first three paragraphs of the PO. Note: Each PO should include the proficiency level indicator.

\section{PERFORMANCE OBJECTIVE - EXAMPLE 1: CBRN WARNING AND REPORTING SPECIALIST}

\section{Performance Objective 001}

1. Performance Statement: Predict nuclear hazard fallout.

2. Conditions:

a. Given:

(1) Map scale 1:250,000

(2) ATP-45(E) - Warning and Reporting Hazard Prediction CBRN Incident Operators Manual

(3) Weather information including a wind message and forecast

3. Standard: Interpret the intelligence provided and select an appropriate course of action in order to produce a simplified estimate of the yield within an accuracy of $10 \%$ by interpreting the Basic Wind Message and constructing a wind vector plot.

4. Proficiency Level: 400 


\section{PERFORMANCE OBJECTIVE - EXAMPLE 2: COOK}

\section{Performance Objective 002}

1. Performance Statement: Prepare Breakfast Meal Items

2. Conditions:

a. Given:

(1) References, recipes and written instructions;

(2) Food supplies;

(3) Equipped cooking establishment and materials;

(4) Portion Size standards;

(5) Personal protective equipment;

(6) Food Services clothing;

(7) Cooking establishment; and

(8) Minimal supervision.

3. Standard: Adhering to the principles of teamwork, cost awareness, economy of resources, hygiene, sanitation, safety and security procedures and environmental regulations, the Cook shall prepare the breakfast meal items by:

a. $\quad$ Adhering to food safety regulations in accordance with (IAW) Reference $P$ 269 chap 7 (Hygiene and Sanitation);

b. Preparing Breakfast IAW P 269 with specific attention to:

(1) recipe fundamentals;

(2) ten principles of cooking; and

(3) proper weights, measures and conversion within an accuracy of $5 \%$.

c. Preparing food and beverage breakfast items from raw ingredients IAW Reference P 269 or commercial mixes as per instructions, to include;

(1) hot and cold cereals;

(2) eggs (any style);

(3) pancakes;

(4) French toast;

(5) Preparing Crepes and Cooking Crepes;

(6) starches (beans, potatoes);

(7) vegetables;

(8) fruits; and

(9) Breakfast meat product.

4. Proficiency Level: 300

5. Reference. Publication (P) 269 - Food Preparation and the Professional Chef, (2011) Culinary Institute of America 
PERFORMANCE OBJECTIVE - EXAMPLE 3: EMERGENCY FIRST AID

\section{Performance Objective 003}

1. Performance Statement. Administer First Aid.

2. Conditions:

a. Given:

casualty, and emergency first aid kit.

b. Denied: references; and

c. Environment: Under any condition.

3. Standard. In accordance with casualty directive, administer First Aid to include:

a. Initiating emergency scene management within five seconds of discovering a casualty and applying first aid protocols as the situation dictates and as determined through the conduct of

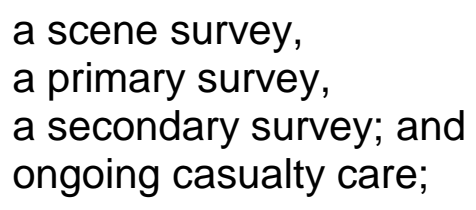

b. treating shock, unconsciousness and fainting;

c. applying direct and indirect methods of adult artificial respiration;

d. initiating adult choking procedures;

e. treating severe bleeding;

f. applying single rescuer adult CPR;

g. conducting child and infant resuscitation;

h. applying proper care for injuries to:
(1)
bones, joints and muscles, the head and eyes, spinal and pelvic areas, and chest area;

i. Dressing wounds, to include: penetrating injuries, and burns; and

j. stabilising diabetic emergencies, seizures and convulsions, asthmatic attack and allergic reactions. 
4. Proficiency Level: 300

5. References. A list of publications and manuals applicable to this PO.

6. TRA Cross Reference. A list of the TRA performance statement numbers which were captured during the task analysis and which are used here to provide an audit trail to the TRA statements.

7. Limitations. Additional considerations which may affect the development of the E\&IT solution, including student assessment considerations. Example: The ETF providing this training does not have the resources to test the "any condition" requirement stated in para $2 \mathrm{c}$. Actual performance will be in a classroom setting with full light and low light to simulate different degrees of difficulty.

8. Other Remarks. Additional considerations. 


\section{COURSE CONTROL DOCUMENT I - CONTROL FORM}

The Control Form is a coversheet to a Course Proposal. This is the basis of agreement for moving forward and formalizing an E\&IT solution within a specific ETF. The coversheet is specific to a course and along with the Course Proposal initiates a course within the NATO Education Training Opportunities Catalogue (ETOC). The Control Form identifies the specific stakeholders concerned with managing a discipline and the definition and delivery of E\&IT solutions. When applicable the supporting area (a sub-category within a discipline) is identified. Areas are captured within the ETOC. The sign offs may include an External Course OPR, should the ETF require expert support which is external to the ETF. The Control Form may also include various sign offs internal to the ETF. The Control Form may be adapted to meet the needs of the originator (the ETF) with additional sign offs. All NATO selected and approved E\&IT solutions, including those which are already developed and in place, require a Control Form. An example Control Form is enclosed. Technical support is available at: eitephelp@act.nato.int. 


\begin{tabular}{|c|c|c|c|c|c|}
\hline \multicolumn{6}{|c|}{ COURSE CONTROL DOCUMENT I - CONTROL FORM } \\
\hline & \multirow{2}{*}{$\begin{array}{l}\text { New Course } \\
\text { Revision }\end{array}$} & \multicolumn{4}{|c|}{ COURSE TITLE } \\
\hline & & Brief Descriptic & & & \\
\hline \multicolumn{3}{|c|}{ Discipline } & Area (if applicable) & \multicolumn{2}{|c|}{$\begin{array}{l}\text { ETOC Course Code (if } \\
\text { applicable) }\end{array}$} \\
\hline \# & \multicolumn{2}{|c|}{ Activity } & Unit Name & Acknowledgement & Date \\
\hline 1 & \multicolumn{2}{|c|}{$\begin{array}{l}\text { ETF Officer of Primary Responsibility } \\
\text { (OPR): Responsible for the E\&IT } \\
\text { solution within the ETF. } \\
\text { Enclose: } \\
\text { CCD II- Course Proposal (or an } \\
\text { equivalent). }\end{array}$} & ETF & $\begin{array}{l}\text { Signature: } \\
\text { Name: } \\
\text { Rank: } \\
\text { Position: }\end{array}$ & $D D / M M / Y Y$ \\
\hline 2 & \multicolumn{2}{|c|}{$\begin{array}{l}\text { ETF Command - Endorsement. ETF } \\
\text { leadership intent to support NATO } \\
\text { and implement a proposed or } \\
\text { modified E\&IT solution. }\end{array}$} & ETF & $\begin{array}{l}\text { Signature: } \\
\text { Name: } \\
\text { Rank: } \\
\text { Position: }\end{array}$ & $D D / M M / Y Y$ \\
\hline 3 & \multicolumn{2}{|c|}{$\begin{array}{l}\text { External Course OPR. This } \\
\text { endorsement is ONLY included when } \\
\text { the ETF responsible for the SAT } \\
\text { Delivery Stage requires support from } \\
\text { the NCS during the Implementation } \\
\text { Phase. }\end{array}$} & RA Representative & $\begin{array}{l}\text { Signature: } \\
\text { Name: } \\
\text { Rank: } \\
\text { Position: }\end{array}$ & $D D / M M / Y Y$ \\
\hline 4 & \multicolumn{2}{|c|}{$\begin{array}{l}\text { Department Head. Acknowledges the } \\
\text { proposed E\&IT solution is in } \\
\text { alignment with the discipline TRA } \\
\text { Report. The new E\&IT solution will be } \\
\text { activated as "Listed" within the ETOC } \\
\text { until CCD III is uploaded. } \\
\text { Note: The DH is responsible and } \\
\text { accountable for ensuring CCD I is } \\
\text { produced; however, this is completed } \\
\text { in close coordination with an ETF. }\end{array}$} & DH & $\begin{array}{l}\text { Signature: } \\
\text { Name: } \\
\text { Rank: } \\
\text { Position: }\end{array}$ & $x^{2}$ \\
\hline
\end{tabular}




\section{COURSE CONTROL DOCUMENT - II: COURSE PROPOSAL}

The Course Proposal provides the foundation for an E\&IT solution and includes enough detail to identify where and how the solution fits within the discipline landscape. The Course Proposal, along with the coversheet (Course Control Document $-\mathrm{I}$ ) is entered into the NATO Education Training Opportunities Catalogue (ETOC) by the responsible Education and Training Facility (ETF) to initiate a course.

\section{COURSE CONTROL DOCUMENT II - COURSE PROPOSAL}

COURSE TITLE: CODE:

\section{PART-1: COURSE REQUIREMENT}

\section{a. Requirement:}

The rationale (need) for the creation or otherwise modification of a course. This addresses the initial tasking to address a performance gap along with the background and history which served as the basis for creating a course.

\section{b. Aim:}

Provides the overall intent of the E\&IT.

\section{c. Security Classification:}

Identifies the security clearance required for the course.

\section{d. Target Audience:}

A brief description confirming the intended audience specifying who is eligible to enrol on the course. The details further identify the rank level, language proficiency and other assumed prerequisites.
(1) Rank Level.
(2) Language Proficiency.

\section{e. Training Strategy:}

A brief description concerning how the E\&IT requirement will likely be resolved including an estimate of the duration for a course or other alternative intervention.

\section{f. Estimated Number of Students per year:}

An estimate of the demand from the NCS, NFS, NATO Nations, Partners and others that may potentially require this course on an annual basis. The $R A$ is expected to capture the potential NCS/NFS demand while MPD should capture partner nation demand.

\section{g. Depth of Knowledge:}

An estimate of the depth of knowledge to be achieved through the course. This is the extrapolated from the highest proficiency level assigned to the Performance Objectives. 
COURSE CONTROL DOCUMENT II - COURSE PROPOSAL

COURSE TITLE:

CODE:

\section{PART- 2: PERFORMANCE OBJECTIVES (POs)}

Details each of the intended outcomes to be addressed through an E\&IT solution, includes a performance statement (essential task), the conditions and prescribed standard to be achieved.

PO 1:

1. Performance Statement. A clear, concise and precise statement representing a logical and complete part of the job function, which is observable and measurable.

2. Conditions: Conditions provide context and describe the situation, under which the performance must be completed.

3. Standards. The Standards describe how and how well performance must be completed.

4. Proficiency Level. Specifies a level (100-500) which broadly defines and captures the degree of competence or "expertise" to be achieved on the job.

PO 2:

1. Performance Statement. A clear, concise and precise statement representing a logical and complete part of the job function, which is observable and measurable.

2. Conditions: Conditions provide context and describe the situation, under which the performance must be completed.

3. Standards. The Standards describe how and how well performance must be completed.

4. Proficiency Level. Specifies a level (100-500) which broadly defines and captures the degree of competence or "expertise" to be achieved on the job. 


\title{
LEARNING DOMAINS
}

\author{
ANNEX M TO \\ Bi-SCD 075-007 \\ DATED 10 SEP 15
}

\section{LEVELS OF LEARNING}

1. Learning domains are classification schemes developed by educational theorists to support the development of instruction and guide student evaluation ${ }^{74}$. The initial work in this area was published in the 1950's and has continued to evolve ${ }^{75}$. There are three specific domains and within each there is a hierarchy, commonly referred to as a taxonomy, which reflects the progressive levels of learning. The learning of the lower levels enables progress into the higher levels of the taxonomy. The learning domains are aligned with the knowledge, skill and attitudinal elements that define a performance gap. The three domains are as follows:

a. Cognitive Domain (the Knowledge Elements). The cognitive domain addresses mental skills and intellectual abilities that progress from remembering and the recall or recognition of specific facts through to evaluating and creating new knowledge. The cognitive domain involves the processing of information (storing, recalling and interpreting) and its subsequent application or use. The cognitive domain aligns with the knowledge elements supporting tasks. The knowledge elements include the theoretical and practical understanding of subject matter required to effectively accomplish a step, task, or series of tasks.

b. Psychomotor Domain (the skills elements). The psychomotor domain addresses coordination, dexterity, manipulation, strength, speed as well as actions which demonstrate fine motor skills, including the use of precision instruments or tools. The levels within the psychomotor domain reflect a progression from observation and imitation through to mastery and adapting of learned skills. The psychomotor domain is aligned with physical skills and addresses the performance of tasks. Skills-based learning consists of an organized and coordinated pattern of mental and/or physical activity that becomes more precise through repetition and practice.

c. Affective Domain (the attitude elements). The affective domain addresses emotions and in particular beliefs, feelings and convictions which underlie behaviour and motivates action. The affective domain is aligned with attitude and, in general, relates to a pre-disposition to behave in certain ways. Attitude is believed to be developed over time and is shaped by an environment and experiences. Outcomes within the affective domain tend to be the most difficult to articulate. The learning within the affective domain is often integrated with events which support the cognitive and psychomotor domain.

\footnotetext{
${ }^{74} \mathrm{~A}$ complete list of references which are the basis for the learning domains are provided at the end of this section.

${ }^{75}$ More recent research has resulted in the development of alternative versions of the Psychomotor Domain as well as subtle adjustments to the classification levels within the Cognitive Domain.
} 


\section{Cognitive Domain}

\section{Levels}

\section{Knowledge/Remember:}

The ability to recall of facts, terms, concepts, principles and the procedures previously learned material.

\section{Comprehension/Understand:}

The ability to interpret information, construct meaning and understand facts, terms, concepts, principles and procedures.

\section{Examples and Key Words}

Examples:

\section{- Recite a policy,}

- List safety rules.

Key Words: arrange, define, duplicate, identify, label, list, mark, match, name, order, recall, recite, reproduce, recognize, reproduce, select, state.

\section{Examples:}

- Summarize the principles of war.

- Explain debugging a computer system.

Key Words: allocate, arrange, categorize, classify, convert, , distinguish, estimate, extend, explain, extrapolate, group, illustrate, infer, interpret, label, match, paraphrase, predict, reiterate, report, restate, review, reword, rewrite, select, separate, summarize, theorize, translate.

\section{Examples:}

- Calculate the sonar range.

- Construct a job interview guide.

\section{Application:}

3 The ability to use concepts, principles and procedures in both new and concrete situations

\section{Analysis:}

The ability to deconstruct concepts, principles and procedures to support

4 analytical thinking and reasoning skills; includes the examination of information, making inferences and finding evidence to support generalizations.

\section{Synthesis/Build:}

The ability to rearrange, adapt and integrate ideas. Putting elements/ parts together to form new patterns or

5 structures. The emphasis is creating and building knowledge based on new ideas and creative thinking, including developing new/unique structures, systems, models and approaches and creating new meaning,

\section{Evaluation/Assess:}

The ability to make judgements about the value of ideas or materials this includes critical thinking and assessing viability
Key Words: apply, associate, administer, apply, calculate, change, classify, compute, compare, conduct, contrast, control, construct, discover, examine, execute, employ, establish, examine, illustrate, identify, implement, initiate, interpret, manipulate, modify, operate, perform, predict, prepare, produce, relate, respond, show, solve.

\section{Examples:}

- Breakdown a financial balance sheet

- Troubleshoot a piece of equipment

Key Words: analyse, breakdown, catalogue, compare, condense, contrast, deconstruct, derive, design, determine, diagram, differentiate, discriminate, distinguish, divide, examine, experiment, explain, extrapolate, graph, infer, interpret, modify, measure, outline, plan, plot, predict, produce, project, quantify, resolve, revise, relate, separate, summarize, search, solve, test, troubleshoot.

\section{Examples:}

\section{- Formulate an Op Order \\ - Compile a business plan}

Key Words: analyse, appraise, arrange, assemble, build, calculate, categorize, collect, combine, compare, compile, compose, construct, create, design derive, develop, devise, encrypt, estimate, evaluate, format, formulate generate, measure, modify, originate, outline, organize, plan, produce, propose, rearrange, reconstruct, reframe, relate, reorganize, revise, rewrite, route, summarize, write.

\section{Examples:}

- Select the most effective solution

- Defend a proposal

Key Words: appraise, assess, compare, conclude, contrast, criticise, critique, decide, defend, describe, diagnose, discriminate, evaluates, explain, interpret, judge, justify, rank, recommend, relate, summarize, support, validate. 


\section{Psychomotor Domain $^{76}$}

\section{Domain Level}

\section{Perception:}

1 The ability to use sensory cues to guide motor activity.

\section{Examples and Key Words}

Key Words: describe, detect differentiate, distinguish, identify, isolate, recognize, relate, select, sketch

\section{Set/ Readiness:}

Readiness to act includes mental, physical, and

2 emotional pre-requisites. These three sets are dispositions that predetermine a person's response to different situations (sometimes called mindsets)

\section{Guided Response/Imitation}

3 The early stages in learning a skill that includes imitation and potentially trial and error. Adequacy of performance is achieved by practicing.

\section{Mechanism/Manipulation:}

This is the intermediate stage in learning a complex

4 physical or mental skill. Learned responses have become habitual and the movements can be performed with some confidence and proficiency

Key Words: adhere, display, explain, state.

Key Words: adhere, arrange, assemble, build, construct, copy, dismantle, display, dissect, fasten, fix, follow, grind, heat, imitate, manipulate, measure, mend, prepare, react, repeat, replicate reproduce, responds, trace, try.

Key Words: assemble, build, calibrate, construct, dismantle, fasten, grind, heat, manipulate, measure, mend, mix, organize, shape, sketch.

Key Words: assemble, build, calibrate, complete, construct, control, demonstrate, dismantle, display, dissect, execute fasten, fix, grind, heat, manipulate, measure,

\section{Complex Overt Response/Precision:}

5 Performing a skill with a high degree of precision Performance involves complex action. mend, mix, organize, perfect, sketch, show.

NOTE: The Key Words are the same as Mechanism, but will have qualifying adverbs or adjectives that indicate that the performance is quicker, better, more accurate,

\section{Adaptation/Articulation:}

6 Skills are well developed and can be modified and combined to adapt and integrate to satisfy a nonstandard tasks and situations.

Key Words: Adapt, adjust, alter, arrange, assault, combine, composes, construct, coordinate, create, design, develop, estimate, formulate, integrate, invent, modify, rearrange, reorganize, revises, solve, troubleshoot,

\section{Origination/Naturalization:}

Creating new approaches to fit a particular situation 7 or specific problem. Learning outcomes emphasize creativity based upon highly developed skills which are second-nature and natural, without needing to think much about it.

Key Words: arrange, build, combine, compose, construct, create, design, initiate, make, originate.

76 The Psychomotor Domain, as presented here, is a hybrid of the models proposed by Simpson (1972) and Dave (1970). Details are provided in the reference list at the end of this section, 


\section{Affective Domain}

\section{Domain Level}

Receiving (Perception):

1

Aware of an attitude, behaviour, or value but not yet ready to act on the situation.

\section{Responding (Interpreting):}

Active participation on the part of the learners.

2 Attends and reacts to a particular phenomenon. Learning outcomes may emphasize compliance in responding, willingness to respond, or satisfaction in responding (motivation).

\section{Valuing:}

The worth or value a person attaches to a particular object, phenomenon, or behaviour. This ranges

3 from simple acceptance to the more complex state of commitment. Valuing is based on the internalisation of a set of specified values, while clues to these values are expressed in the learner's overt behaviour and are often identifiable.

\section{Organization:}

Internalisation of values and beliefs. Organizes values into priorities by contrasting different values, resolving conflicts between them, and creating a unique value system. The emphasis is on comparing, relating, and synthesising values.

\section{Internalising Values:}

Has a value system that controls their behaviour. The behaviour is pervasive, consistent, predictable, and most importantly, characteristic of the learner. Instructional objectives are concerned with the student's general patterns of adjustment (personal, social, emotional).

\section{Examples and Key Words}

Examples: Listen to others opinions

Key Words: Accept, ask, choose, describe, follow, give, hold, identify, locate, name, point to, select, sit, erects, reply, use.

\section{Examples: Participates in discussions.}

Key Words: Answer, assist, aid, complete, comply conform, cooperate, discuss, examine, greet, help, label, obey, perform, practice, present, read, recite, report, respond, select, tell, write

Examples: Propose plans to social improvement and follows through with commitment. Informs management on matters that one feels strongly about.

Key Words: Accept, complete, defend, demonstrate, devote, differentiate, explain, follow, form, initiate, invite, join, justify, propose, pursue, read, report, seek, select, share, study, work.

\section{Examples: Recognizes the need for balance between} freedom and responsible behaviour.

Key Words: Adhere, alter, arrange, codify, combine, compare, complete, defend, discriminate, display, explain, formulate, generalize, identify, integrate, modify, order, organize, prepare, relate.

\section{Examples:}

Cooperates in group activities (displays teamwork). Displays a professional commitment to ethical practice on a daily basis.

Key Words: Act, discriminate, display, influence, internalize, listen, modify, perform, practice, propose, qualifies, question, revise, serve, solve, verify. 


\section{References}

2. The following references were used and adapted in order to produce the learning domain taxonomies.

\section{a. Cognitive Domain}

Bloom, B.S. (Ed.). Engelhart, M.D., Furst, E.J., Hill, W.H., Krathwohl, D.R. (1956).

Taxonomy of Educational Objectives, Handbook I: The Cognitive Domain. New York:

David McKay Co Inc.

Anderson, L.W., \& Krathwohl (Eds.). (2001). A Taxonomy for Learning, Teaching, and Assessing: A Revision of Bloom's Taxonomy of Educational Objectives. New York: Longman.

\section{b. Psychomotor Domain}

Simpson E.J. (1972). The Classification of Educational Objectives in the Psychomotor Domain. Washington, DC: Gryphon House.

Dave, R.H. (1970). Psychomotor levels in Developing and Writing Behavioural Objectives, pp.20-21. R.J. Armstrong, ed. Tucson, Arizona: Educational Innovators Press.

\section{c. Affective Domain}

Krathwohl, D.R., Bloom, B.S., Masia, B.B. (1973). Taxonomy of Educational Objectives, the Classification of Educational Goals. Handbook II: Affective Domain. New York: David McKay Co., Inc 


\section{ENABLING/LEARNING OBJECTIVES - EXAMPLE}

\section{COURSE CONTROL DOCUMENT III - PROGRAMME OF CLASSES}

Code:

\section{Title: Geo-Spatial Intelligence Analyst}

PO 12: Interpret Object-Oriented GPS data files.

ELO 012.01:

1. Performance: Describe general geodesy principles

2. Conditions: Given:
a. Orders;
b. ADP and ancillary equipment;
c. Current software and GIS extensions; and
d. GPS data sets.

3. Standards: Explain general geodesy by:
a. Identifying the basic terms and concepts for geodesy;
b. Explaining the earth's dimensions;
c. Describing positioning techniques; and
d. Explaining projections.

4. Assessment: 30 question multiple choice theory test.

5. Instructional Strategy:

\begin{tabular}{|c|c|c|c|}
\hline Content & \multicolumn{2}{|c|}{ Method \& Time } & References \\
\hline Identify geodesy terms and concepts & Lecture & $50 \mathrm{~min}$ & A: Chap 1, Page 5-7 \\
\hline TP1 Introduce the concept of geodesy & & & \\
\hline TP2 Define of Geodesy; & & & \\
\hline $\begin{array}{l}\text { TP3 Explain Pythagoras theory and the use to } \\
\text { measure the circumference of the earth }\end{array}$ & & & \\
\hline $\begin{array}{l}\text { TP4 Eratosthenes theory used to measure the } \\
\text { circumference of the earth. }\end{array}$ & & & \\
\hline Explain the earth's dimensions & Lecture & $100 \mathrm{~min}$ & A: Chap 2, Page 29-35 \\
\hline TP1 Explain the shape of the earth; & & & \\
\hline TP2 Explain Measurement Parameters & & & \\
\hline TP3 Define Ellipsoids, Geoids and Spheroids. & & & \\
\hline Describe horizontal positioning techniques & Lecture & $100 \mathrm{~min}$ & A: Chap 4, Page 49-71 \\
\hline $\begin{array}{l}\text { TP } 1 \text { Outline horizontal and vertical Positioning on the } \\
\text { Earth's surface; }\end{array}$ & & & \\
\hline TP2 2D and 3D Cartesian Coordinate System & & & \\
\hline TP3 Types of Horizontal Positioning; & & & \\
\hline
\end{tabular}




\begin{tabular}{|c|c|c|c|}
\hline \multirow{2}{*}{$\begin{array}{l}\text { Content } \\
\text { TP4 Polar coordinates, Azimuth, and Bearing } \\
\text { Direction Coordinates; }\end{array}$} & \multicolumn{2}{|c|}{ Method \& Time } & References \\
\hline & & & \\
\hline TP5 True, Grid, and Magnetic North; & & & \\
\hline TP6 Curvilinear Coordinate System & & & \\
\hline TP7 Time (hours-min-sec) & & & \\
\hline TP8 Triangulation, Trilateration, and Traversing; and. & & & \\
\hline TP9 Explain the earth's dimensions & & & \\
\hline Describe vertical positioning & Lecture & $100 \mathrm{~min}$ & A: Chap 5, Page 36-45 \\
\hline TP1 Explain Vertical Positioning on the earth's surface & & & \\
\hline TP2 Identify 4 Types of Vertical Positioning & & & \\
\hline $\begin{array}{l}\text { TP3 Describe precise levelling, trigonometric } \\
\text { measurement, barometric and echo sounding }\end{array}$ & & & \\
\hline TP4 Outline Trigonometric Height Measurement & & & \\
\hline TP5 2D and 3D Cartesian Coordinate System & & & \\
\hline Explain projections & Lecture & $100 \mathrm{~min}$ & A: Chap 4, Page 49-71 \\
\hline $\begin{array}{l}\text { TP1 Identify projection characteristics: area, shape, } \\
\text { direction, scale; }\end{array}$ & & & \\
\hline $\begin{array}{l}\text { TP2 Differentiate projection characteristics: area, } \\
\text { shape, direction, scale; }\end{array}$ & & & \\
\hline $\begin{array}{l}\text { TP3 Identify types of projections azimuthal, conic, } \\
\text { cylindrical; }\end{array}$ & & & \\
\hline $\begin{array}{l}\text { TP4 Differentiate projection characteristics: azimuthal, } \\
\text { conic, cylindrical; }\end{array}$ & & & \\
\hline $\begin{array}{l}\text { TP5 Explain Point of Light Origin (orthographic, } \\
\text { stereographic, sinusoidal, mercator, globular). }\end{array}$ & & & \\
\hline Geodesy Test & Test & $70 \min$ & \\
\hline Geodesy Debrief & Debrief & $30 \min$ & \\
\hline Total Time: & & $550 \mathrm{~min}$ & \\
\hline
\end{tabular}

\section{Depth of Knowledge: $\mathbf{2 0 0}$}

7. References: A. Kaula, M. (2000). Theory of Satellite Geodesy: Applications of Satellites To Geodesy.

8. Limitations:

9. Resources:
a. White board;
b. Globe; and
c. Projection System
d. Student Handout - Geodesy Backgrounder - Handout 


\section{ANNEX O TO \\ Bi-SCD 075-007 \\ DATED 10 SEP 15}

\section{DEPTH OF KNOWLEDGE - PERFORMANCE PROFICIENCY MATRIX}

1. Depth of Knowledge (DoK) refers to the level of learning to be achieved as a result of an E\&IT solution. DoK is an inclusive term addressing both the Cognitive Domain (Knowledge elements) and the Psychomotor Domain (skill elements) ${ }^{77}$. The DoK - level of learning is based on job proficiency skill and knowledge requirements and the enclosed matrix aligns job performance proficiency levels with DoK levels of learning.

2. The matrix is a tool that supports the design and development of E\&IT solutions. The matrix is also useful for providing a preliminary assessment of the fit between an existing E\&IT solution and a NATO E\&IT requirement. During the design and development of E\&IT solutions the DoK matrix is used to:

a. Develop Enabling/Learning Objectives (ELOs) at the appropriate level of learning and in alignment with Performance Objectives (POs).

b. Identify and select instructional methods.

c. Guide student assessment and preparing an assessment plan.

77 Affective Domain - attitudinal elements are integrated with cognitive and psychomotor learning and as result are part of the criteria and behavioural traits captured within the standards of the applicable ELOs.

O-1 


\begin{tabular}{|c|c|c|c|c|}
\hline \multirow{2}{*}{\multicolumn{2}{|c|}{$\begin{array}{c}\text { Job Performance Outcomes } \\
\text { Job/Function } \\
\text { Proficiency Level }\end{array}$}} & \multicolumn{3}{|c|}{ Enabling/Learning Outcomes } \\
\hline & & \multicolumn{2}{|r|}{$\begin{array}{l}\text { Levels of Learning } \\
\text { - Depth of Knowledge(and skill) Descriptors- }\end{array}$} & $\begin{array}{c}\text { Learning } \\
\text { Key Word Indicators }\end{array}$ \\
\hline \multirow[t]{2}{*}{100} & \multirow[t]{2}{*}{$\begin{array}{l}\text { Basic Level - (Follow) } \\
\text { Skill \& Knowledge } \\
\text { The level of proficiency required to successfully perform a } \\
\text { routine task or series of task elements (e.g, a step in a } \\
\text { sequence of actions) in a structured environment with } \\
\text { supervision. Is expected to seek guidance in unexpected } \\
\text { conditions. This requires remembering information } \\
\text { including facts, terms, concepts, principles as well as the } \\
\text { processes and procedures defining job requirements. }\end{array}$} & \multirow[t]{2}{*}{100} & $\begin{array}{l}\text { Psychomotor: } \\
\text { Perceptions, Readiness \& Guided Response } \\
\text { This involves the readiness to act, observing and } \\
\text { imitating prescribed and defined actions and } \\
\text { processes. Includes the use of sensory cues and } \\
\text { establishing the mental, physical, and emotional } \\
\text { prerequisites to skills development. }\end{array}$ & $\begin{array}{l}\text { adhere adhere, arrange, assemble, } \\
\text { dismantle, detect, display, fasten, } \\
\text { follow, grind, heat, identify, imitate, } \\
\text { measure, mend, prepare, recognize, } \\
\text { repeat, replicate, reproduce, responds, } \\
\text { select, sketch, trace, }\end{array}$ \\
\hline & & & $\begin{array}{l}\text { Cognitive: } \\
\text { Remembering explicit knowledge } \\
\text { Enable an individual to recall elements and details of } \\
\text { structure or process and recognize or identify specific } \\
\text { information. }\end{array}$ & $\begin{array}{l}\text { arrange, define, duplicate, identify, } \\
\text { label, list, mark, match, name, order, } \\
\text { recall, recite, reproduce, recognize, } \\
\text { reproduce, select, state. }\end{array}$ \\
\hline \multirow{2}{*}{200} & \multirow{2}{*}{$\begin{array}{l}\text { Intermediate Level (Assist) } \\
\text { Skill \& Knowledge } \\
\text { The level of proficiency required to become functional and } \\
\text { successfully perform a series of tasks independently with } \\
\text { minimal oversight. Uses discretion in resolving problems } \\
\text { and may plan and schedule work within short timeframes. } \\
\text { This requires interpreting information, constructing meaning } \\
\text { and the comprehension of facts, terms, concepts, and } \\
\text { principles as well as the processes and procedures } \\
\text { essential to enable understanding and accomplishing job } \\
\text { requirements. }\end{array}$} & \multirow{2}{*}{200} & $\begin{array}{l}\text { Psychomotor: } \\
\text { Mechanism/Manipulation } \\
\text { The intermediate stage in learning a complex skill. } \\
\text { Learned responses achieve functional proficiency and } \\
\text { become habitual and can be performed with some } \\
\text { confidence and proficiency. }\end{array}$ & $\begin{array}{l}\text { assemble, build, calibrate, construct, } \\
\text { dismantle, fasten, grind, heat, } \\
\text { manipulate, measure, mend, mix, } \\
\text { organize, shape, sketch. }\end{array}$ \\
\hline & & & $\begin{array}{l}\text { Cognitive: } \\
\text { Comprehending/Understanding: Enable an } \\
\text { individual to interpret information; construct meaning } \\
\text { and comprehend facts, terms, concepts, principles and } \\
\text { procedures. }\end{array}$ & $\begin{array}{l}\text { arrange, categorize, classify, convert, } \\
\text { distinguish, estimate, explain, } \\
\text { extrapolate, group, illustrate, label, } \\
\text { match, paraphrase, predict, reiterate, } \\
\text { restate, reword, rewrite, report, select, } \\
\text { separate, summarize, translate. }\end{array}$ \\
\hline
\end{tabular}




\begin{tabular}{|c|c|c|c|c|}
\hline \multicolumn{2}{|r|}{ Job Performance Outcomes } & \multicolumn{3}{|c|}{ Enabling/Learning Outcomes } \\
\hline \multicolumn{2}{|r|}{$\begin{array}{c}\text { Job/Function } \\
\text { Proficiency Level }\end{array}$} & \multicolumn{2}{|r|}{$\begin{array}{c}\text { Levels of Learning } \\
\text { - Depth of Knowledge(and skill) Descriptors- }\end{array}$} & \multirow{2}{*}{\begin{tabular}{l}
\multicolumn{1}{c}{ Learning } \\
\multicolumn{1}{c}{ Key Word Indicators } \\
assemble, build, calibrate, construct, \\
control, dismantle, display, dissect, \\
execute fasten, fix, grind, heat, \\
manipulate, measure, mend, mix, \\
organize, perfect, sketch.
\end{tabular}} \\
\hline \multirow{2}{*}{300} & \multirow{2}{*}{$\begin{array}{l}\text { Advance Level (Apply) } \\
\text { Skill \& Knowledge } \\
\text { The level of proficiency required to interpret direction and } \\
\text { guidance and successfully plan and complete tasks } \\
\text { independently as well as potentially monitoring the work of } \\
\text { others. Uses discretion to resolve increasingly complex } \\
\text { problems. This requires the application of concepts, } \\
\text { principles processes and procedures in both non-routine, } \\
\text { new, and concrete situations as well as executing, } \\
\text { implementing and carrying out processes and procedures } \\
\text { to satisfy job requirements. }\end{array}$} & \multirow{2}{*}{300} & $\begin{array}{l}\text { Psychomotor: } \\
\text { Complex response/Precision } \\
\text { Performing skills with a high degree of precision. } \\
\text { Performance involves complex action. }\end{array}$ & \\
\hline & & & $\begin{array}{l}\text { Cognitive: } \\
\text { Applying } \\
\text { Enable an individual to use concepts, principles and } \\
\text { procedures in both new and concrete situations - put } \\
\text { theory into practice. }\end{array}$ & $\begin{array}{l}\text { administer, apply, calculate, change, } \\
\text { compute, construct, examine, execute, } \\
\text { employ, identify, implement, } \\
\text { manipulate, modify, operate, perform, } \\
\text { predict, prepare, produce, relate, } \\
\text { respond, show, solve. }\end{array}$ \\
\hline \multirow[b]{2}{*}{400} & \multirow{2}{*}{$\begin{array}{l}\text { Expert Level (Enable/Advisor) } \\
\text { Skill \& Knowledge } \\
\text { The level of proficiency required executing a broad range of } \\
\text { complex professional and/or technical work activities } \\
\text { leveraging prior education, training and practical } \\
\text { experience; this includes maintaining an awareness of } \\
\text { developing trends within the wider occupational field, } \\
\text { analytical thinking and providing institutional leaders } \\
\text { discipline and/or inter-disciplinary related advice. This level } \\
\text { requires setting work objectives and assigning task and the } \\
\text { ability to deconstruct and integrate concepts, principles and } \\
\text { procedures to support reasoning and as well as the } \\
\text { application of a systematic approach to solving non-routine } \\
\text { and ill-defined problems. }\end{array}$} & \multirow[b]{2}{*}{400} & $\begin{array}{l}\text { Psychomotor: } \\
\text { Adaptation } \\
\text { Skills are well developed and can be modified and } \\
\text { combined to adapt and integrate to satisfy a non- } \\
\text { standard tasks and situations. }\end{array}$ & $\begin{array}{l}\text { adapt, adjust, alter, arrange, assault, } \\
\text { assess, combine, composes, construct, } \\
\text { coordinate, create, create, design, } \\
\text { develop, estimate, formulate, integrate, } \\
\text { invent, modify, master, manage, } \\
\text { rearrange, reorganize, revises, specify, } \\
\text { solve, troubleshoot, varies. }\end{array}$ \\
\hline & & & $\begin{array}{l}\text { Cognitive: } \\
\text { Analysing } \\
\text { Enable an individual to deconstruct concepts, } \\
\text { principles and procedures to support analytical thinking } \\
\text { and reasoning; includes the examination of information, } \\
\text { making inferences and finding evidence to support } \\
\text { generalizations. }\end{array}$ & $\begin{array}{l}\text { analyse, break down, compare, } \\
\text { condense, contrast, deconstruct, } \\
\text { design, diagram, differentiate, } \\
\text { discriminate, distinguish, divide, } \\
\text { experiment, extrapolate, graph, infer, } \\
\text { interpret, modify, measure, plan, plot, } \\
\text { predict, produce, project, quantify, } \\
\text { resolve, revise, search, solve, test, } \\
\text { troubleshoot. }\end{array}$ \\
\hline
\end{tabular}

\section{O-3}

NATO UNCLASSIFIED 


\begin{tabular}{|c|c|c|c|c|}
\hline \multicolumn{2}{|r|}{ Job Performance Outcomes } & \multicolumn{3}{|c|}{ Enabling/Learning Outcomes } \\
\hline \multicolumn{2}{|r|}{$\begin{array}{c}\text { Job/Function } \\
\text { Proficiency Level }\end{array}$} & \multicolumn{2}{|r|}{$\begin{array}{c}\text { Levels of Learning } \\
\text { - Depth of Knowledge(and skill) Descriptors- }\end{array}$} & \multirow{2}{*}{\begin{tabular}{l}
\multicolumn{1}{c}{ Learning } \\
\multicolumn{1}{c}{ Key Word Indicators } \\
arrange, build, combine, compose, \\
construct, create, design, initiate, make, \\
originate.
\end{tabular}} \\
\hline \multirow[b]{2}{*}{500} & \multirow{2}{*}{$\begin{array}{l}\text { Master Level (Initiate, Shape and Influence) } \\
\text { Skills \& Knowledge } \\
\text { The level of proficiency required to execute highly complex } \\
\text { work activities covering, technical, financial and quality } \\
\text { aspects for a functional area. Leverages considerable } \\
\text { education, training and extensive practical experience to } \\
\text { advise commanders as well as exert significant influence } \\
\text { over policy development and contribute to the formulation } \\
\text { of strategy and organizational objectives. Decisions made } \\
\text { impact the functional area of the enterprise. Able to assess } \\
\text { and evaluate risks and understand the implications of new } \\
\text { concepts, technologies and trends. This requires adapting } \\
\text { concepts and principles as well as processes and } \\
\text { procedures to support critical, asymmetric thinking and } \\
\text { reasoning potentially leading research efforts and building } \\
\text { knowledge, theory and alternative approaches within a } \\
\text { recognized body of knowledge. }\end{array}$} & & $\begin{array}{l}\text { Psychomotor: } \\
\text { Originate } \\
\text { Creating new approaches to resolve problems and } \\
\text { challenging situations. Learning outcomes emphasize } \\
\text { creativity based upon highly developed skills which are } \\
\text { second-nature and natural, without needing to think } \\
\text { much about it. }\end{array}$ & \\
\hline & & 500 & $\begin{array}{l}\text { Cognitive: } \\
\text { Assessing/Building/Creating } \\
\text { Adapting and integrating concepts, principles and } \\
\text { procedures to create and build knowledge, theory and } \\
\text { alternative approaches. Enables higher order thinking } \\
\text { and reasoning and includes the examination of } \\
\text { information, making inferences and formulating } \\
\text { solutions. }\end{array}$ & $\begin{array}{l}\text { appraise, assemble, assess, build, } \\
\text { categorize, combine, compile, } \\
\text { compose, conclude, construct, contrast, } \\
\text { create, critique, defend, design, derive } \\
\text { develop, devise, diagnose, discriminate, } \\
\text { encrypt, estimate, evaluate, formulate } \\
\text { generate, hypothesize, integrate, } \\
\text { interpret, invent, investigate, judge, } \\
\text { justify, measure, modify, outline, } \\
\text { originate, organize, plan, predict, } \\
\text { propose, rank, rearrange, recommend, } \\
\text { reconstruct, reframe, revise, rewrite, } \\
\text { summarize, validate, war game, write. }\end{array}$ \\
\hline
\end{tabular}




\section{ANNEX P TO \\ Bi-SCD 075-007 \\ DATED 10 SEP 15}

\section{METHODS OF INSTRUCTION}

1. The following tables describe suggested methods of instruction in terms of their definition, application and suggested techniques for instructors. A summary concerning the use of coaching is also provided at the conclusion of the Annex. The methods of instruction are as follows:
a. Behaviour Modelling.
b. Case Study.
c. Demonstration and Performance.
d. Field Trip.
e. Gaming.
f. Guided Discussion.
g. Interactive Lecture.
h. Panel Discussion.
i. Peer Learning.
j. Problem-based Learning (Small Group - Syndicate Work).
k. Role Play.
I. Self-Study.
m. Simulation (including In-basket Exercise, Serious Gaming).
n. Study Assignment.
o. Tutorial. 


\begin{tabular}{|c|c|}
\hline \multicolumn{2}{|c|}{ Behaviour Modelling } \\
\hline Definition & $\begin{array}{l}\text { Behaviour modelling is a form of demonstration and it generally captured as part of the } \\
\text { Demonstration/Performance method. Behaviour modelling is used during a } \\
\text { demonstration to achieve attitudinal elements including the development of interpersonal } \\
\text { skills. This method allows the learner to see the desired behaviours or skills first hand. } \\
\text { Learners acquire new behaviours by observing live or video models and then rehearsing } \\
\text { (practicing) the behaviours. Behaviour modelling is usually employed with smaller } \\
\text { groups, as each learner must rehearse the behaviour as part of the learning process. }\end{array}$ \\
\hline Application & $\begin{array}{l}\text { The instructor introduces the lesson by describing the what, why, when and where of the } \\
\text { topic. The instructor describes the skill in question and then models both effective and } \\
\text { ineffective behaviours verifying that learners have clearly understood the procedures, } \\
\text { before moving on. Next, the instructor provides learners with a video or live } \\
\text { presentation that sets the job context and models effective and ineffective behaviour in } \\
\text { that setting. } \\
\text { Following the modelling session, the instructor discusses the behaviour and what } \\
\text { learners should do during their practice session. Learners discuss and practice modelling } \\
\text { effective behaviour on their own or with a partner. Then each learner demonstrates the } \\
\text { behaviour while the instructor and the remainder of the class observes. The instructor } \\
\text { provides feedback to the learners and coaches them on their performance. } \\
\text { Learners reflect on the feedback and repeat the exercise. This process continues until } \\
\text { learners master the behaviour. Ideally, learners should be videotaped so that they can } \\
\text { observe their behaviour and reflect on their performance and the instructor feedback. } \\
\text { Instructors should have learners try the behaviour as soon as possible in the lesson. } \\
\text { Learners must be provided adequate time to practice to allow them to master the } \\
\text { behaviour. }\end{array}$ \\
\hline Techniques & $\begin{array}{l}\text { Instructors must be able to demonstrate effective and ineffective behaviours to employ } \\
\text { this method even when a supporting video is used. It is critical that the correct } \\
\text { behaviours are accurately modelled; otherwise learners may become confused and } \\
\text { discouraged. } \\
\text { Instructors employing the behaviour modelling method should be able to provide detailed } \\
\text { feedback to the learner on his or her performance. Correct behaviours should be } \\
\text { positively reinforced, and areas requiring improvement identified. }\end{array}$ \\
\hline
\end{tabular}




\begin{tabular}{|c|c|}
\hline \multicolumn{2}{|l|}{ Case Study } \\
\hline Definition & $\begin{array}{l}\text { In the case study method the instructor provides learners with the opportunity to deal } \\
\text { with a simulated, real life situation in the classroom. Learners respond to the scenario } \\
\text { related to the target performance, by examining the facts and incidents of the case, to } \\
\text { critically analyse data and develop solutions. }\end{array}$ \\
\hline Application & 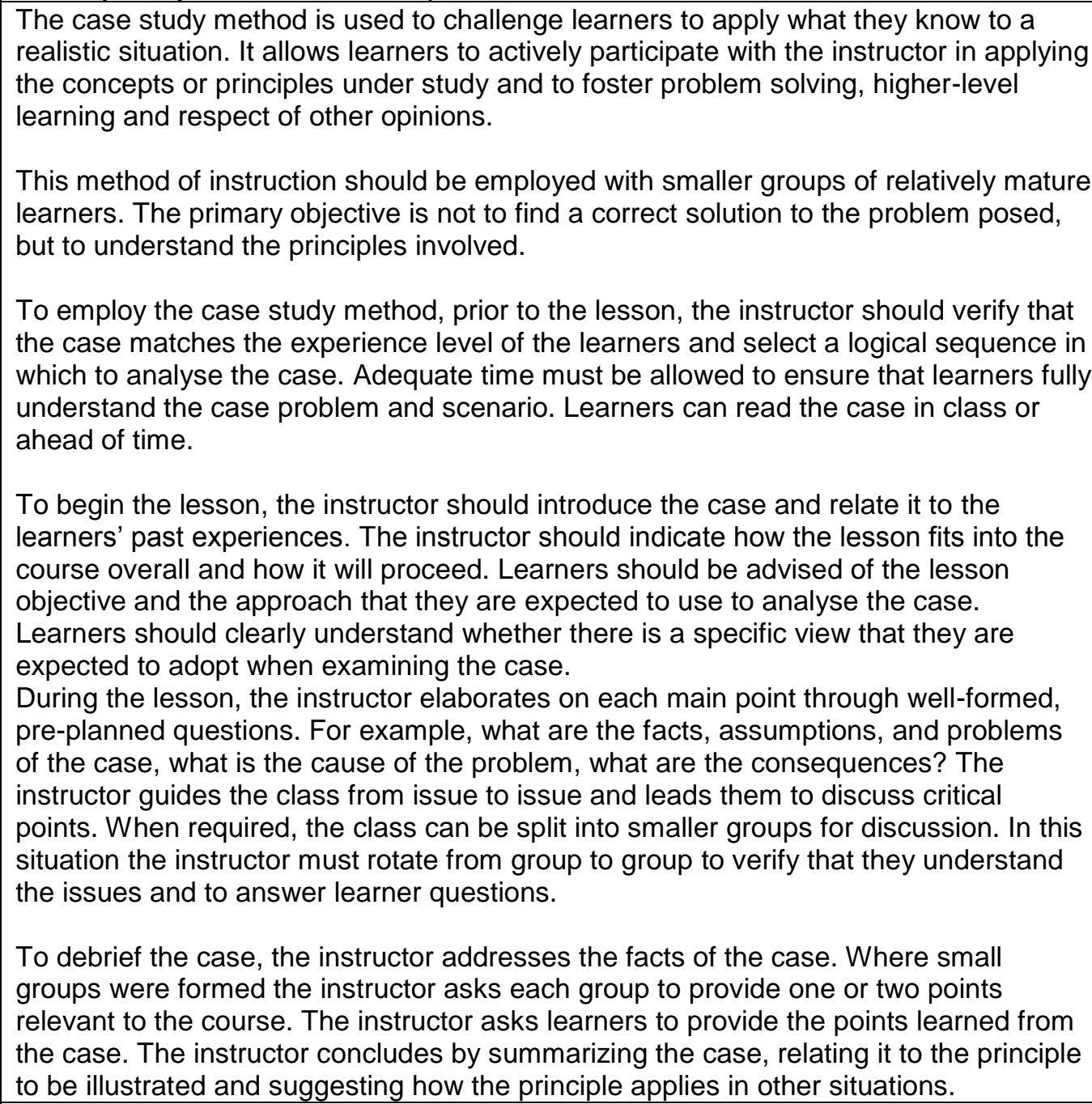 \\
\hline Techniques & $\begin{array}{l}\text { There are a number of techniques the instructor can use to facilitate analysis of the } \\
\text { case study. They include: } \\
\text { - monitor learners who are not participating and try to draw them into the } \\
\text { discussion, starting with closed questions and then asking for an opinion or } \\
\text { comment on an issue. } \\
\text { ask stimulating questions when needed to promote thinking or guide the } \\
\text { discussion, e.g., What is the importance of that fact? Do we need to look at } \\
\text { additional facts or information? Is there another way of looking at it? } \\
\text { - ask learners to respond to a question instead of responding yourself, when } \\
\text { possible. } \\
\text { record learners' points on a chalk board (also give each group a flipchart for } \\
\text { group work). } \\
\text { - summarize the discussion to assist learners to refocus and progress when } \\
\text { necessary. }\end{array}$ \\
\hline
\end{tabular}




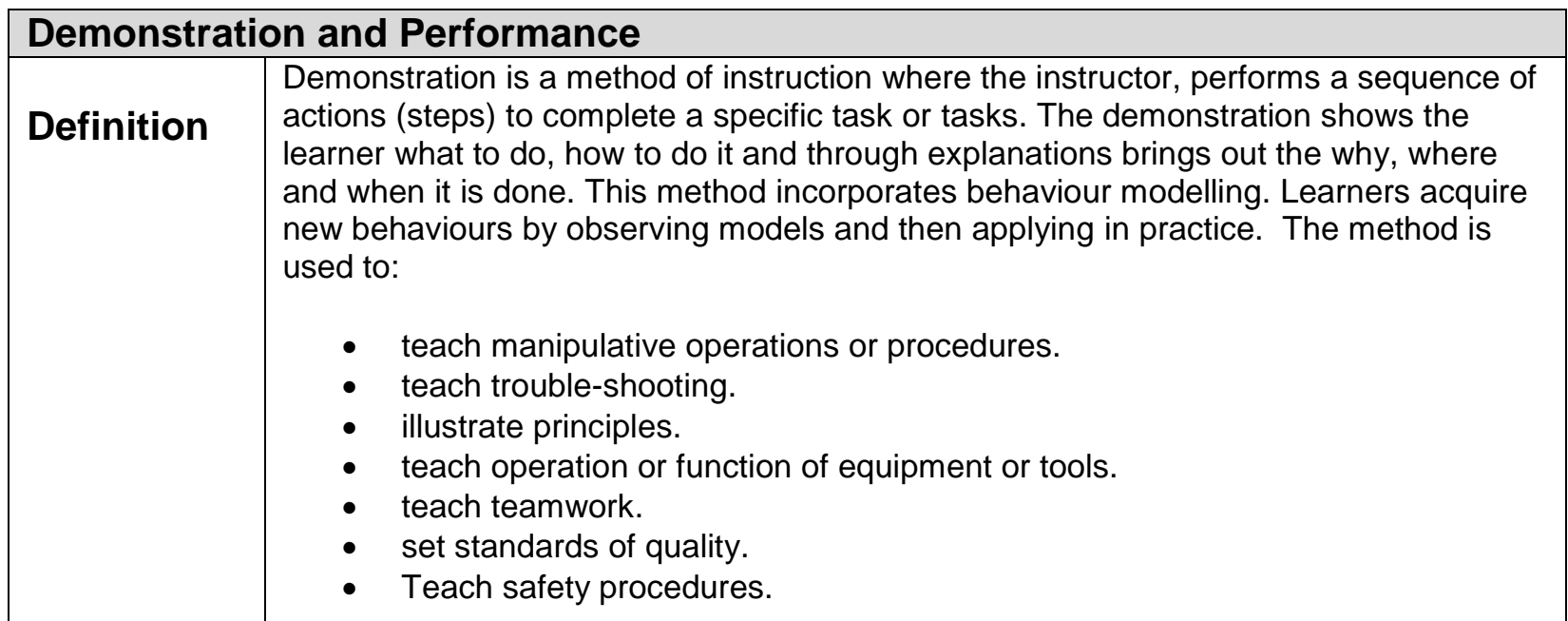

Performance. Performance is a method in which the course member learns by doing, i.e., is required to perform under controlled conditions the operation, skill or movement being taught. An instructor assumes the role of coach. It is used to:

- teach manipulative operations or procedures.

- teach operation or function of equipment.

- teach team skills.

- Teach safety procedures.

Application In practice, the Demonstration and Performance methods are used together when teaching skills. Learners observe the performance of the target task and rehearse it under controlled conditions.

Techniques highly skilled in the procedures to be demonstrated. Learners must be shown the correct procedures. Providing an effective demonstration requires careful planning. Prior to the lesson, the instructor ensures that the task has been broken down into small sequential steps. If necessary, the instructor should rehearse the lesson prior to delivery to ensure the procedures are accurate and clear. The instructor also prepares all materials in advance and organizes the class so all can see.

The instructor begins by introducing the lesson, identifying what learners will be able to do at the end, where this skill can be applied and why it is important to learn. During the lesson, the instructor explains each step and then demonstrates each step reiterating the critical components. In larger groups it may be helpful to provide a hand-out outlining the steps for learners to follow. Learners practice the task step by step under supervision. The instructor provides assistance or re-demonstrates as necessary. The instructor may also pose questions to the learners throughout the demonstration to ensure they understand the steps. Practice under supervision continues until the learner masters the skill. Mastery may require practice beyond class time depending on the complexity of the task and the level of the learner.

Allowing learners to practice as early as possible and positively reinforcing everything learners do correctly enhances learning. The Demonstration and Performance method can also be used to support an explanation of a theory or concept (e.g., physics heavier objects fall faster than lighter objects). 


\begin{tabular}{|l|l|}
\hline Field Trip & $\begin{array}{l}\text { The field trip is a planned learning experience in which learners observe "real life" } \\
\text { operations that illustrate what was discussed or learned in the classroom. It is realistic } \\
\text { and brings relevance to instruction. The field trip is used to: }\end{array}$ \\
\hline Definition & $\begin{array}{l}\text { - } \quad \text { reinforce and clarify classroom learning. } \\
\text { inject variety into the training situation. } \\
\text { in the classroom. }\end{array}$ \\
\hline Application & $\begin{array}{l}\text { The field trip requires careful planning to ensure it enhances classroom learning. Prior } \\
\text { to the trip, the exact operation or equipment that learners will observe must be } \\
\text { specified. Details such as transportation, safety or security considerations and whether } \\
\text { members of the field unit will be available to demonstrate the use of equipment should } \\
\text { be pre-arranged. }\end{array}$ \\
\hline Techniques & $\begin{array}{l}\text { If learners will be allowed to manipulate equipment, appropriate procedures should be } \\
\text { pre-arranged and presented to the learners. During the presentation, learners can } \\
\text { rotate through the demonstration, while others observe or look at other materials. } \\
\text { Learners may be grouped and given access to equipment if careful supervision is not } \\
\text { warranted or if additional personnel are available to supervise them on the job site. } \\
\text { Planning the field trip will ensure instructional goals are achieved and that control of } \\
\text { the learning situation are maintained. } \\
\text { The Field Trip can be valuable to enhance motivation, demonstrate the relevance of } \\
\text { material being taught and facilitate transfer to the workplace. }\end{array}$ \\
\hline
\end{tabular}

\begin{tabular}{|l|l|}
\hline Gaming & $\begin{array}{l}\text { Gaming is a method employed to allow learners to practice behaviours under the } \\
\text { conditions of the game. Games include conflict, rules and in some cases teams and } \\
\text { this leads to competition: "winners" and "losers". Games are motivating for learners } \\
\text { and can transfer well to the job but can have negative implications. }\end{array}$ \\
\hline Definition \\
$\begin{array}{l}\text { Games are used with one or more individuals to practice skills associated with a social } \\
\text { system or human interaction. The game must instruct some type of skill such as } \\
\text { applying strategies or principles. Normally steps or procedures are repeated allowing } \\
\text { learners to develop skills. }\end{array}$ \\
\hline Application & $\begin{array}{l}\text { Before employing this method the instructor must explain the game and rules. During } \\
\text { the game instructors should ensure that the game is played in the manner expected. }\end{array}$ \\
\hline Techniques & $\begin{array}{l}\text { Games can inject variety into the classroom but it is critical that the game support } \\
\text { learning of course material, for example, games allowing learners to practice } \\
\text { language, recall terms, recognize equipment parts, and use strategies in games of } \\
\text { tactics. }\end{array}$ \\
\hline
\end{tabular}




\begin{tabular}{|c|c|}
\hline \multicolumn{2}{|c|}{ Guided Discussion } \\
\hline Definition & $\begin{array}{l}\text { Guided Discussion is a method in which learners are guided in steps to reach } \\
\text { instructional objectives by drawing out their opinions, knowledge, experience and } \\
\text { capabilities and by building on these to explore and develop new material. Learners } \\
\text { discuss issues to expand their knowledge of the subject. It is used to: } \\
\text { - develop imaginative solutions to problems (e.g., through brainstorming). } \\
\text { - } \text { stimulate thinking and interest and secure learner participation. } \\
\text { - } \text { supplement reflection. } \\
\text { - determine how well learners understand concepts and principles. } \\
\text { - } \text { clarify or review points. } \\
\text { - } \text { } \text { Fostermine learner progtitudinal change. }\end{array}$ \\
\hline Application & $\begin{array}{l}\text { This method of instruction is employed with a small group of } 4-12 \text { persons normally } \\
\text { seated in a circular or horseshoe fashion to facilitate discussion. Reading material } \\
\text { should be provided to learners in advance so that learners are familiar with the } \\
\text { concepts that will be discussed. }\end{array}$ \\
\hline Techniques & $\begin{array}{l}\text { To conduct a guided discussion, an instructor should introduce the topic and scenario, } \\
\text { outline the main discussion points, state the what, where and why of the lesson and } \\
\text { create an open environment. } \\
\text { During the body of the lesson the instructor poses open lead-off questions to guide the } \\
\text { discussion towards the aim. Conducting a guided discussion requires skills in order to } \\
\text { recognize digression and tactfully redirect discussion using rephrased questions, } \\
\text { comments or summaries. Encouragement of learner discussion is essential by inviting } \\
\text { members to talk, using follow-on questions and resolving conflict. } \\
\text { The instructor concludes the lesson by reviewing all the main points contributed by } \\
\text { both the learner and instructor and relating points back to the lesson aim. } \\
\text { The guided discussion is relevant and meaningful to the learner if it is designed to } \\
\text { meet their needs. It stimulates thinking and can result in higher levels of retention due } \\
\text { to extensive learner participation. }\end{array}$ \\
\hline
\end{tabular}




\begin{tabular}{|c|c|}
\hline \multicolumn{2}{|c|}{ Interactive Lecture } \\
\hline Definition & $\begin{array}{l}\text { The interactive lecture is a formal or semi-formal presentation in which the instructor } \\
\text { presents a series of events, facts, principles, etc. and learners listen and participate by } \\
\text { asking or responding to questions and commenting. It is efficient and standardized. It } \\
\text { is used to: } \\
\text { - } \quad \text { orient learners and generate interest. } \\
\text { - introduce a subject or give an overview. } \\
\text { - } \quad \text { present basic or background material. } \\
\text { - introduce a demonstration, discussion or performance. } \\
\text { - } \quad \text { Review, clarify, emphasize or summarize. }\end{array}$ \\
\hline Application & $\begin{array}{l}\text { The interactive lecture can be employed with groups as large as forty. However, the } \\
\text { larger the group the more difficult to build in lecture interactivity. Prior to the lesson, } \\
\text { the instructor considers issues that could arise and prepares examples and } \\
\text { explanations to deal with them. The instructor practices lecture delivery and prepares } \\
\text { material. }\end{array}$ \\
\hline Techniques & $\begin{array}{l}\text { During the lecture, the instructor pays attention to learner feedback such as facial } \\
\text { expressions, body language and alertness. If learners appear unsure it is best to deal } \\
\text { with the problem before moving forward by asking if anyone has questions or posing } \\
\text { questions to the class. Learner involvement can be promoted by: providing an outline } \\
\text { of the lecture's main points; citing relevant comparisons, reasons, examples, statistics } \\
\text { and testimonials (CREST); mixing surprising or interesting points with dryer material to } \\
\text { stimulate learners; identifying problems the material is relevant to; and incorporating } \\
\text { other methods after } 20 \text { minutes of lecture such as a video. Discussion or hand-out } \\
\text { completion can improve learner attention during the second part of the lecture. The } \\
\text { instructor concludes by summarizing key points and re-motivating learners. }\end{array}$ \\
\hline \multicolumn{2}{|c|}{ Panel Discussion } \\
\hline Definition & $\begin{array}{l}\text { A panel discussion is designed to provide an opportunity for a group to hear several } \\
\text { (3-5) people knowledgeable about a specific issue or topic, present information and } \\
\text { discuss their views. A panel discussion may help the audience further clarify and } \\
\text { evaluate their positions regarding the specific issues or topics being discussed and } \\
\text { increase their understanding of the positions of others. Panel discussions offer insight } \\
\text { and potential lessons learned and may also be used to provide differing perspectives } \\
\text { on a topic or issue. }\end{array}$ \\
\hline Application & $\begin{array}{l}\text { The moderator introduces a topic/issue which stems from specific desired learning } \\
\text { outcomes and the members of the panel present their views and opinions regarding } \\
\text { the issue or topic for a set amount of time. The panel should be aware of the intent of } \\
\text { the session in order to provide time to prepare. } \\
\text { The panel discusses the issue or topic with each other by asking questions or reacting } \\
\text { to the views and opinions of other panel members. A specific amount of time should } \\
\text { be established. As necessary the moderator directs the discussion and presents } \\
\text { questions. } \\
\text { The moderator closes the discussion and provides a summary of main points } \\
\text { discussed. } \\
\text { The moderator opens for questions from observers before moving on to the next topic } \\
\text { or issue. } \\
\text { Panel discussions are well suited to online forums, video-teleconferences and } \\
\text { teleconferences. Often this is the best way to attract leading experts. }\end{array}$ \\
\hline Techniques & $\begin{array}{l}\text { The moderator is critical to the success of the panel. The moderator controls the } \\
\text { discussions, ensuring the objectives are being achieved: } \\
\text { - Clearly state the objective at the outset as part of the introduction. It reminds }\end{array}$ \\
\hline
\end{tabular}




\begin{tabular}{|c|c|}
\hline & $\begin{array}{l}\text { the panellists why they are there and informs participants of the intended } \\
\text { outcome. } \\
\text { - The moderator introduces the panellists. Keep it focused on the background } \\
\text { relevant to the issue. The intent is to inform the audience so they can form } \\
\text { appropriate questions. } \\
\text { - Moderators are not panellists, the answers and discussions should flow } \\
\text { among the participants and include opportunities for engagement with the } \\
\text { audience. } \\
\text { Let the panellists talk to each other; however, ensure the discussion and } \\
\text { debate is addressing the intended outcomes. } \\
\text { Ideally the discussions can move online forums at a later date providing the } \\
\text { opportunity for participants to interact further with the members of the panel. }\end{array}$ \\
\hline \multicolumn{2}{|c|}{ Peer Learning } \\
\hline Definition & $\begin{array}{l}\text { During peer learning, structured materials are provided to learners who then teach } \\
\text { their peers. This method is motivational and is used to facilitate: } \\
\text { - team building. } \\
\text { - } \quad \text { recall of facts. } \\
\text { comprehension of concepts. }\end{array}$ \\
\hline Application & $\begin{array}{l}\text { Peer learning results in increased learning and retention rates for both learners } \\
\text { receiving and providing instruction. Those acting as learners benefit from the individual } \\
\text { instruction and those acting as instructors benefit from preparing and developing } \\
\text { instruction. }\end{array}$ \\
\hline Techniques & $\begin{array}{l}\text { Peer learning can consist of advanced learners assisting individual learners, learners } \\
\text { leading group discussions and learners having the opportunity to play both the learner } \\
\text { and the instructor. It is most valuable to have learners play both roles if possible. } \\
\text { Instructors should pair stronger and slower learners allowing the stronger learner to } \\
\text { instruct or coach skills first. Then they can switch allowing both to have the benefit of } \\
\text { extra practice and providing instruction. Peer learning increases learner participation } \\
\text { and motivation. The quality of instruction must be assured. }\end{array}$ \\
\hline
\end{tabular}

\begin{tabular}{|l|l|}
\hline Problem-based Learning (Small Group - Syndicate) \\
\hline Definition & $\begin{array}{l}\text { Problem-based learning is a method that facilitates the learning of principles and } \\
\text { concepts by having learners work on solving a problem drawn from the work } \\
\text { environment. It is often used to develop critical thinking skills and problem solving. }\end{array}$ \\
\hline Application & $\begin{array}{l}\text { This method is usually conducted with small groups of } 5 \text { to } 7 \text { learners or with pre- } \\
\text { established teams. Instructors prepare carefully constructed problems that will serve } \\
\text { as the learning stimulus. Problems must be as realistic as possible so that learners } \\
\text { can relate it to their work. }\end{array}$ \\
\hline Techniques & $\begin{array}{l}\text { During the lesson, learners analyse the problem and work towards solving it. } \\
\text { Instructors facilitate learning by posing questions to get learners thinking and talking } \\
\text { (e.g., What are the clues, facts and any guesses about the problem and the causes? } \\
\text { What other information is needed?). The instructor should ensure that all learners } \\
\text { participate, because discussion is key to learning, but they should try not to influence } \\
\text { decisions. Instructors may also challenge learners thinking by questioning learners } \\
\text { without leading them to the correct answer (e.g., What does this mean? What are the } \\
\text { implications?). } \\
\text { Instructors using this method must be experienced in facilitating learning and coaching } \\
\text { learners. Instructors should refer to the coaching section in this manual for detailed } \\
\text { information on the coaching process. }\end{array}$ \\
\hline
\end{tabular}




\begin{tabular}{|l|l|}
\hline Role Play & $\begin{array}{l}\text { In this method, learners play defined roles in a scenario designed to reflect the } \\
\text { conditions of the target performance. It allows learners to: }\end{array}$ \\
\hline Definition & $\quad$ learn through practicing what they will have to do on the job. \\
& $\begin{array}{l}\text { - } \quad \text { learn by imitating others' behaviour. } \\
\text { Role-playing exercises are methods of interaction in which learners play out and } \\
\text { practice realistic behaviours by assuming specific roles and circumstances. They are } \\
\text { used to represent a social system or interpersonal process in miniature so that the } \\
\text { learner can practice making the responses to various situations that are similar to } \\
\text { those he or she will encounter on the job. Role play is often used for language training, } \\
\text { attitudinal objectives and to develop human interaction skills. It is realistic and } \\
\text { promotes cooperative learning. }\end{array}$ \\
$\begin{array}{l}\text { The instructor begins the lesson by clearly explaining the objective of the lesson (what, } \\
\text { where, when and why). It is critical to explain that role-playing is a learning process } \\
\text { and learners are not expected to play their roles perfectly from the start. This will help } \\
\text { to put learners at ease. } \\
\text { The instructor must clearly explain each role the learners will play. This is followed by } \\
\text { a demonstration of the role-play either on video or through a live performance by } \\
\text { instructional staff. Learners are paired or grouped together and the role-plays are } \\
\text { cycled through. The instructor does not interfere during the role-play unless learners } \\
\text { require cues or assistance, or a safety issue arises. }\end{array}$ \\
\hline Techniques \\
$\begin{array}{l}\text { Following each role-play, the instructor debriefs the learner on his or her performance. } \\
\text { Correct behaviours should be positively reinforced, and areas requiring improvement } \\
\text { identified. Ideally, the role-play will have been videotaped so that learners can watch } \\
\text { their performance and reflect on it and the constructive feedback provided by the } \\
\text { instructor to improve performance. }\end{array}$ \\
$\begin{array}{l}\text { Instructors should be able to accurately demonstrate the skills being acquired during } \\
\text { the role-play to assist learners if necessary. Instructors employing role-play should be } \\
\text { able to coach learners and provide them with detailed feedback on their performance. }\end{array}$ \\
\hline
\end{tabular}

\begin{tabular}{|c|c|}
\hline & \\
\hline Definition & $\begin{array}{l}\text { Self-study is a method of self-instruction using printed and/or audio-visual or } \\
\text { computer-based media, often presented through Advanced Distributed Learning } \\
\text { (ADL)/e-Learning or programmed instructional packages (PIPs) to be completed prior } \\
\text { to, during, or following a course. Learners receive instructional materials containing } \\
\text { built in feedback and work through them independently. It is used to: } \\
\text { - provide remedial or make-up instruction for late arrivals, absentees or } \\
\text { transients. } \\
\text { - } \quad \text { maintain previously learned skills which are not performed frequently enough. } \\
\text { - } \quad \text { provide common knowledge and skill background for learners prior to onset of } \\
\text { - pourse. } \\
\text { - permide review and practice of knowledge and skills. } \\
\text { Self-study can provide staff with needed time to prepare for instruction while learners } \\
\text { complete individual activities. However, this method does require considerable lead- } \\
\text { time to prepare material especially if they are technology-based. }\end{array}$ \\
\hline Application & $\begin{array}{l}\text { Prior to the self-study session, the instructor should confirm that required materials } \\
\text { and resources are available and prepare any additional hand-outs or instructions. }\end{array}$ \\
\hline
\end{tabular}


\begin{tabular}{|l|l|}
\hline Techniques & $\begin{array}{l}\text { The instructor must provide clear direction to the learner on what they have to do and } \\
\text { allow them the opportunity to pose questions or raise concerns. Depending on the } \\
\text { complexity of the activities and the maturity of the learners, an instructor should check } \\
\text { in with learners to ensure they are progressing and provide assistance as necessary. } \\
\text { Some self-study materials enable learners to skip material they already know and } \\
\text { progress at their own pace. }\end{array}$ \\
\hline
\end{tabular}

\begin{tabular}{|c|c|}
\hline \multicolumn{2}{|c|}{ Simulation (including In-basket Exercise, Serious Gaming) } \\
\hline \multirow[t]{3}{*}{ Definition } & $\begin{array}{l}\text { Simulations are used to provide instruction of complex skills using a dynamic } \\
\text { representation of a system or the actual equipment and the job environment. A } \\
\text { simulator is an apparatus built to run the simulation. Simulations are context specific } \\
\text { and realistic and facilitate transfer of learning to the job and do not necessarily require } \\
\text { simulators to create the environment. Role players are often used in parallel as part of } \\
\text { the method to create the require context. }\end{array}$ \\
\hline & $\begin{array}{l}\text { Simulation provides learners with situated learning and practice. The simulation may } \\
\text { not exactly duplicate actual physical skills but should effectively duplicate conceptual } \\
\text { tasks. Instructors should employ simulations so that learners learn how a system or } \\
\text { device works while avoiding danger or other limitations of the real environment (e.g., } \\
\text { access to equipment, weather, and operations). }\end{array}$ \\
\hline & $\begin{array}{l}\text { Complex skills must be progressively developed. Instructors should provide learners } \\
\text { with simple scenarios or problems at the beginning and gradually build up to more } \\
\text { complex situations as the learners' skills advance. Instructors may be able to stop } \\
\text { simulations to provide direction or explanations and slow down or speed up the } \\
\text { process to facilitate learning. It is through specific, constructive feedback and coaching } \\
\text { from instructors that learners' skill will develop. }\end{array}$ \\
\hline Application & $\begin{array}{l}\text { Simulations can be developed in a variety of forms. For example, the in-basket } \\
\text { exercise is a type of simulation in which learners respond to a variety of } \\
\text { memorandums, directives, and messages that recreate a job specific scenario. } \\
\text { Interruptions, emergencies, and random events are usually factored into the exercise. } \\
\text { The in-basket method is effective for developing decision-making and prioritizing skills. } \\
\text { War gamming is an example of serious games. Serious games are not a simulation } \\
\text { alone. It may be a simulation combined with elements of game-play. Serious games } \\
\text { have evolved significantly as a means of computer generated environments, micro- } \\
\text { worlds and role plays. }\end{array}$ \\
\hline Techniques & $\begin{array}{l}\text { Instructors must provide coaching, guidance and constructive feedback to learners on } \\
\text { their performance during simulation. Instructors are referred to the section titled } \\
\text { Coaching in this manual for detailed guidance on the coaching process that should be } \\
\text { employed to enhance learning during a simulation. }\end{array}$ \\
\hline
\end{tabular}

\begin{tabular}{|c|c|}
\hline \multicolumn{2}{|c|}{ Study Assignment } \\
\hline Definition & $\begin{array}{l}\text { Study assignment entails the assignment of the study of books, periodicals, manuals } \\
\text { or hand-outs, and/or the review of audio-visual materials; the completion of a project } \\
\text { or research paper, or prescribes problems and exercises for the practice of a skill. It } \\
\text { can: } \\
\text { - orient learners to a topic prior to classroom or laboratory work. } \\
\text { - } \quad \text { pet the stage for a lecture, demonstration or discussion. } \\
\text { - experience through differentiated assignments. } \\
\text { - provide for the review of material covered in class or to give practice. } \\
\text { - provide enriching material. }\end{array}$ \\
\hline Application & $\begin{array}{l}\text { Providing learners with study assignments facilitates learning by covering concepts in } \\
\text { greater detail and by allowing instructors to assess individual learner progress. Study } \\
\text { assignments are helpful to all learners and especially those experiencing difficulty. }\end{array}$ \\
\hline Techniques & $\begin{array}{l}\text { Study assignments require instructor preparation time in advance for development of } \\
\text { materials and instructions. To ensure out of class assignments are effective the } \\
\text { instructor must provide clear direction, verify that work is completed and provide } \\
\text { detailed feedback to the learner. }\end{array}$ \\
\hline
\end{tabular}




\begin{tabular}{|l|l|}
\hline Tutorial & $\begin{array}{l}\text { Tutorial is a method of instruction in which an instructor works directly with an } \\
\text { individual to ensure the successful completion of activities. It may be customized to } \\
\text { meet the learner's needs. It is used to: }\end{array}$ \\
Definition & $\begin{array}{l}\text { teach highly complex skills and operations, or operations involving danger or } \\
\text { expensive equipment - within this context this is closely aligned with } \\
\text { coaching. } \\
\text { provide individualized often remedial assistance/instruction. }\end{array}$ \\
\hline $\begin{array}{l}\text { The tutorial is a highly motivating method of instruction as it provides one on one } \\
\text { individualized instruction. There is much more time for one-on-one interaction as the } \\
\text { learner absorbs the material. }\end{array}$ & $\begin{array}{l}\text { During the tutorial the instructor is able to adapt to the learner and use instructional } \\
\text { strategies that will meet the learner's needs. For example, some learners respond } \\
\text { more quickly to visual representation and diagrams than written text. Others may catch } \\
\text { on quicker by discussing how something works to fully understand it. Often a tutorial } \\
\text { will involve several strategies depending on the complexity of the topic and the needs } \\
\text { of the learner and will focus on the areas of difficulty. }\end{array}$ \\
\hline Application & $\begin{array}{l}\text { Tutorials are ideal for providing remedial help or instructing complicated or dangerous } \\
\text { procedures and techniques are described as part of coaching. This method of } \\
\text { instruction does require extensive time to conduct depending on the number of } \\
\text { learners. }\end{array}$ \\
\hline Techniques & $\begin{array}{l}\text { To effectively use the tutorial method instructors should be able to determine any } \\
\text { difficulties that the learner is experiencing and respond to them. Instructors should be } \\
\text { able to recognize whether the learner responds better to hands on experiences, } \\
\text { discussions, visual or text materials and use this to provide them with the appropriate } \\
\text { learning experience if they are experiencing difficulty. Knowledge of a variety of } \\
\text { instructional methods and strategies will assist the instructor using the tutorial method. } \\
\text { because it is implemented in the unit versus the training establishment or } \\
\text { learning centre. }\end{array}$ \\
\hline
\end{tabular}

\begin{tabular}{|l|l|}
\hline Coaching & \multicolumn{2}{|l|}{$\begin{array}{l}\text { Coaching consists of aspects of the performance and demonstration method of } \\
\text { instruction but is more learner centred and developmental. The instructor's role as a } \\
\text { coach is to draw the learner's attention to critical elements of the task execution. The } \\
\text { instructor, based on his or her knowledge of the individual learner, asks the learner } \\
\text { questions which will lead them to take the next appropriate step in the procedure or } \\
\text { take a different direction altogether. This is especially important when learners lose } \\
\text { their train of thought or focus. The instructor must assist the learner to get back on } \\
\text { track and continue with the task. Questions to the learner to assess his or her thinking } \\
\text { and situational awareness under these conditions should be clear, concise and require } \\
\text { short responses so that the flow of the task or operation is not disrupted. Instructors } \\
\text { must be constantly monitoring the learners' performance to determine what they are } \\
\text { doing correctly, as well as areas requiring improvement and how to correct them. The } \\
\text { coaching sessions require a thorough debrief to complete the experiential learning } \\
\text { cycle. }\end{array}$} \\
\hline Application & $\begin{array}{l}\text { Simulators. Simulators are employed for the development of complex skills such as } \\
\text { piloting aircraft, ships, submarines and operating combat vehicles. The coaching } \\
\text { method is employed to assist learners to develop skills in simulators. Coaching in this } \\
\text { context is situated in the environment and is normally one to one or one to small } \\
\text { group. }\end{array}$ \\
\hline Techniques & $\begin{array}{l}\text { Coaching is typically one-on-one or small group and the instructor role can be } \\
\text { conducted in three stages consisting of briefing, monitoring and debriefing. } \\
\text { BRIEFING }\end{array}$ \\
\hline
\end{tabular}


- The learner should initially be put at ease and advised of the aim of the simulation session and any relevant background. This step serves to engage the appropriate mental model of the task under development.

- The instructor should then explain and demonstrate each component of the task emphasizing the critical elements. Large tasks should be broken down into smaller tasks so that it can be taught in smaller chunks. Exactly what is being done at each component of the task should be demonstrated and described as well as why it is performed that way. Questions from the learner are encouraged to ensure they understand what to do.

- Immediately prior to the simulation session the instructor reviews the main points of the task and confirms that the learner is ready.

\section{MONITORING}

- This stage consists of performance and observation, preferably using a standard checklist. The learner performs the task while the instructor closely monitors to see that it is carried out correctly and to note corrections the learner must make. The learner should be allowed to carry out the task. The instructor must keep track of what the learner is doing and use brief questions to assess his or her thinking or keywords to cue or help the learner to proceed to the next component.

\section{DEBRIEFING}

- Before providing feedback, the instructor examines the learner's performance to determine what was done properly and what areas are weak, and to determine why the problem is occurring. Then the instructor can provide precise constructive feedback on strengths and the weaknesses, and also advise the learner how to correct the problems using explanation and demonstration. It is preferable to focus on correcting two to three major problems in each run rather than every minor error because too much feedback will overwhelm and de-motivate the learner.

- The debrief must be a positive learning experience, so the instructor should put the learner at ease and present a positive, supportive attitude. The instructor should begin by summarizing the learner's overall performance.

- Instructors should take the time to address the components of the task that were performed well in order to reinforce the correct behaviour, instil confidence and motivate the learner. As the session continues the instructor identifies and analyses two to three problem areas providing clear explanations of what was done incorrectly. The instructor should encourage the learner to participate in analysing his or her performance of the task by posing guiding questions. The instructor provides guidance on how to correct deficiencies and suggestions to improve performance.

- The instructor concludes by summarizing strong points, reconfirming what will be done to correct the two to three major problems addressed and by re-motivating the learner. 


\section{ANNEX Q TO \\ Bi-SCD 075-007 \\ DATED 10 SEP 15}

\section{METHOD SELECTION MATRIX}

1. The following method selection matrix identifies methods based on the classification of an ELO (Cognitive versus Psychomotor) and the intended level of learning to be achieved, as indicated by Depth of Knowledge (DoK) and skill key word indicators. The following considerations should also be factored into method selection:

a. What will interest, engage and motivate students?

b. Does the target audience have prior learning (knowledge, skill and/or experiences) which could be leveraged?

c. Are there operational scenarios, lessons learned, incident reports or stories which could be leveraged and used to promote higher levels of learning through more active engagement? This, in turn, could influence decisions to use specific imagery and video. 


\begin{tabular}{|c|c|c|c|c|}
\hline \multicolumn{5}{|c|}{ Method Selection } \\
\hline & Type of Learning & $\begin{array}{c}\text { Depth of Knowledge (and skill) } \\
\text { Key Word Indicators }\end{array}$ & \multicolumn{2}{|c|}{ Method of Instruction } \\
\hline \multirow{2}{*}{$\begin{array}{l}1 \\
0 \\
0\end{array}$} & $\begin{array}{l}\text { Psychomotor } \\
\text { Perceptions, Readiness } \\
\text { \& Guided Response }\end{array}$ & $\begin{array}{l}\text { adhere, arrange, assemble, dismantle, detect, } \\
\text { display, fasten, follow, grind, heat, identify, } \\
\text { imitate, measure, mend, prepare, recognize, } \\
\text { repeat, replicate, reproduce, responds, select, } \\
\text { sketch, trace, }\end{array}$ & $\begin{array}{l}\text { - Demonstration / } \\
\text { performance }\end{array}$ & - Role play \\
\hline & $\begin{array}{c}\text { Cognitive } \\
\text { Remembering explicit } \\
\text { knowledge }\end{array}$ & $\begin{array}{l}\text { arrange, define, duplicate, identify, label, list, } \\
\text { mark, match, name, order, recall, recite, } \\
\text { reproduce, recognize, reproduce, select, state. }\end{array}$ & $\begin{array}{l}\text { - Lecture } \\
\text { - Self-Study }\end{array}$ & - Tutorial \\
\hline \multirow{2}{*}{$\begin{array}{l}2 \\
0 \\
0\end{array}$} & $\begin{array}{c}\text { Psychomotor } \\
\text { Mechanism/Manipulation }\end{array}$ & $\begin{array}{l}\text { assemble, build, calibrate, construct, dismantle, } \\
\text { fasten, grind, heat, manipulate, measure, mend, } \\
\text { mix, organize, shape, sketch. }\end{array}$ & $\begin{array}{l}\text { - Demonstration / } \\
\text { performance } \\
\text { - Role play }\end{array}$ & $\begin{array}{l}\text { - Simulation } \\
\text { - OJT }\end{array}$ \\
\hline & $\begin{array}{l}\text { Cognitive } \\
\text { Comprehending/ } \\
\text { Understanding }\end{array}$ & $\begin{array}{l}\text { arrange, categorize, classify, convert, } \\
\text { distinguish, estimate, explain, extrapolate, group, } \\
\text { illustrate, label, match, paraphrase, predict, } \\
\text { reiterate, restate, reword, rewrite, report, select, } \\
\text { separate, summarize, translate. }\end{array}$ & $\begin{array}{l}\text { - Lecture } \\
\text { - Self-Study } \\
\text { - Tutorial }\end{array}$ & $\begin{array}{l}\text { - Field trip } \\
\text { - Small } \\
\text { Group } \\
\text { - Gaming }\end{array}$ \\
\hline \multirow[b]{2}{*}{$\begin{array}{l}3 \\
0 \\
0\end{array}$} & $\begin{array}{l}\text { Psychomotor } \\
\text { Complex } \\
\text { response/Precision }\end{array}$ & $\begin{array}{l}\text { assemble, build, calibrate, construct, control, } \\
\text { dismantle, display, dissect, execute fasten, fix, } \\
\text { grind, heat, manipulate, measure, mend, mix, } \\
\text { organize, perfect, sketch. }\end{array}$ & $\begin{array}{l}\text { - Demonstration/ } \\
\text { Performance } \\
\text { - Gaming }\end{array}$ & $\begin{array}{l}\text { - Simulation } \\
\text { - Role play } \\
\text { - OJT }\end{array}$ \\
\hline & $\begin{array}{l}\text { Cognitive } \\
\text { Applying }\end{array}$ & $\begin{array}{l}\text { administer, apply, calculate, change, compute, } \\
\text { construct, examine, execute, employ, identify, } \\
\text { implement, manipulate, modify, operate, perform, } \\
\text { predict, prepare, produce, relate, respond, show, } \\
\text { solve. }\end{array}$ & $\begin{array}{l}\text { - Lecture } \\
\text { - Guided } \\
\text { Discussion } \\
\text { - Study } \\
\text { assignment } \\
\text { - Self-study } \\
\text { - Gaming }\end{array}$ & $\begin{array}{l}\text { - Simulation } \\
\text { - Panel } \\
\text { Discussion } \\
\text { - Peer } \\
\text { learning } \\
\text { - Small } \\
\quad \text { Group } \\
\text { - Role play } \\
\text { - Case study } \\
\end{array}$ \\
\hline \multirow[b]{2}{*}{$\begin{array}{l}4 \\
0 \\
0\end{array}$} & $\begin{array}{l}\text { Psychomotor } \\
\text { Adaptation }\end{array}$ & $\begin{array}{l}\text { adapt, adjust, alter, arrange, assault, combine, } \\
\text { composes, construct, coordinate, create, design, } \\
\text { develop, estimate, formulate, integrate, invent, } \\
\text { modify, rearrange, reorganize, revises, solve, } \\
\text { troubleshoot, }\end{array}$ & $\begin{array}{l}\text { - Performance } \\
\text { - Gaming }\end{array}$ & $\begin{array}{l}\text { - Role play } \\
\text { - Simulation } \\
\text { - OJT }\end{array}$ \\
\hline & $\begin{array}{l}\text { Cognitive } \\
\text { Analysing }\end{array}$ & $\begin{array}{l}\text { analyse, break down, compare, condense, } \\
\text { contrast, deconstruct, design, diagram, } \\
\text { differentiate, discriminate, distinguish, divide, } \\
\text { experiment, extrapolate, graph, infer, interpret, } \\
\text { modify, measure, plan, plot, predict, produce, } \\
\text { project, quantify, resolve, revise, search, solve, } \\
\text { test, troubleshoot. }\end{array}$ & $\begin{array}{l}\text { - Lecture } \\
\text { - Guided } \\
\text { Discussion } \\
\text { - Self-study } \\
\text { - Gaming } \\
\text { - Peer learning }\end{array}$ & $\begin{array}{l}\text { - Panel } \\
\text { Discussion } \\
\text { - Small } \\
\text { Group } \\
\text { - Simulation } \\
\text { - Role play } \\
\text { - Case study }\end{array}$ \\
\hline \multirow[b]{2}{*}{$\begin{array}{l}5 \\
0 \\
0\end{array}$} & $\begin{array}{l}\text { Psychomotor } \\
\text { Originate }\end{array}$ & $\begin{array}{l}\text { arrange, build, combine, compose, construct, } \\
\text { create, design, initiate, make, originate. }\end{array}$ & $\begin{array}{l}\text { - Performance } \\
\text { - Gaming }\end{array}$ & $\begin{array}{l}\text { - Simulation } \\
\text { - Role play }\end{array}$ \\
\hline & $\begin{array}{c}\text { Cognitive } \\
\text { Assessing/Building/ } \\
\text { Creating: }\end{array}$ & $\begin{array}{l}\text { appraise, assemble, assess, build, categorize, } \\
\text { combine, compile, compose, conclude, } \\
\text { construct, contrast, create, critique, defend, } \\
\text { design, derive develop, devise, diagnose, } \\
\text { discriminate, encrypt, estimate, evaluate, } \\
\text { formulate generate, hypothesize, integrate, } \\
\text { interpret, invent, investigate, judge, justify, } \\
\text { measure, modify, outline, originate, organize, } \\
\text { plan, predict, propose, rank, rearrange, } \\
\text { recommend, reconstruct, reframe, revise, } \\
\text { rewrite, summarize, validate, war game, write. }\end{array}$ & $\begin{array}{l}\text { - Self-Study } \\
\text { - Gaming } \\
\text { - Simulation } \\
\text { - Role play } \\
\text { - Case study }\end{array}$ & $\begin{array}{l}\text { - Peer } \\
\text { learning } \\
\text { - Panel } \\
\text { Discussion } \\
\text { - Small } \\
\text { Group } \\
\text { - Field Trip }\end{array}$ \\
\hline
\end{tabular}




\section{COURSE CONTROL DOCUMENT (CCD) III - PROGRAMME OF CLASSES}

1. The Programme of Classes is the final course control document developed to define an NATO E\&IT solution ${ }^{78}$. The ETF generates the Programme of Classes. This CCD includes the ELO and provides the details supporting the overall instructional strategy including the final structure of the content, the instructional method as well as the time allocated to complete the ELO. CCD III also includes student assessment details.

2. The CCD III - Programme of Classes is uploaded to the ETOC by the ETF and subsequently verified with the $\mathrm{DH}$ as an appropriate solution to meet the previously identified POs in CCD II. Example formats for CCD III are enclosed. The format for CCD III may be adapted by ETFs as required. ETOC technical support is available at: eitephelp@act.nato.int.

\footnotetext{
${ }^{78}$ Course Control Documents (CCD) are the output products for the NATO SAT Definition Stage. The CCD define a NATO E\&IT solution. ETFs may use other forms and formats to describe their respective plan to satisfy an E\&IT requirement. The alternative formats include: Training Plan, Programme of Learning, Course Curriculum, Programme of Instruction as well as Course Syllabus. The essential elements to be addressed are outlined in Chapters 5 and 6.
} 
Course Control Document - III: Programme of Classes

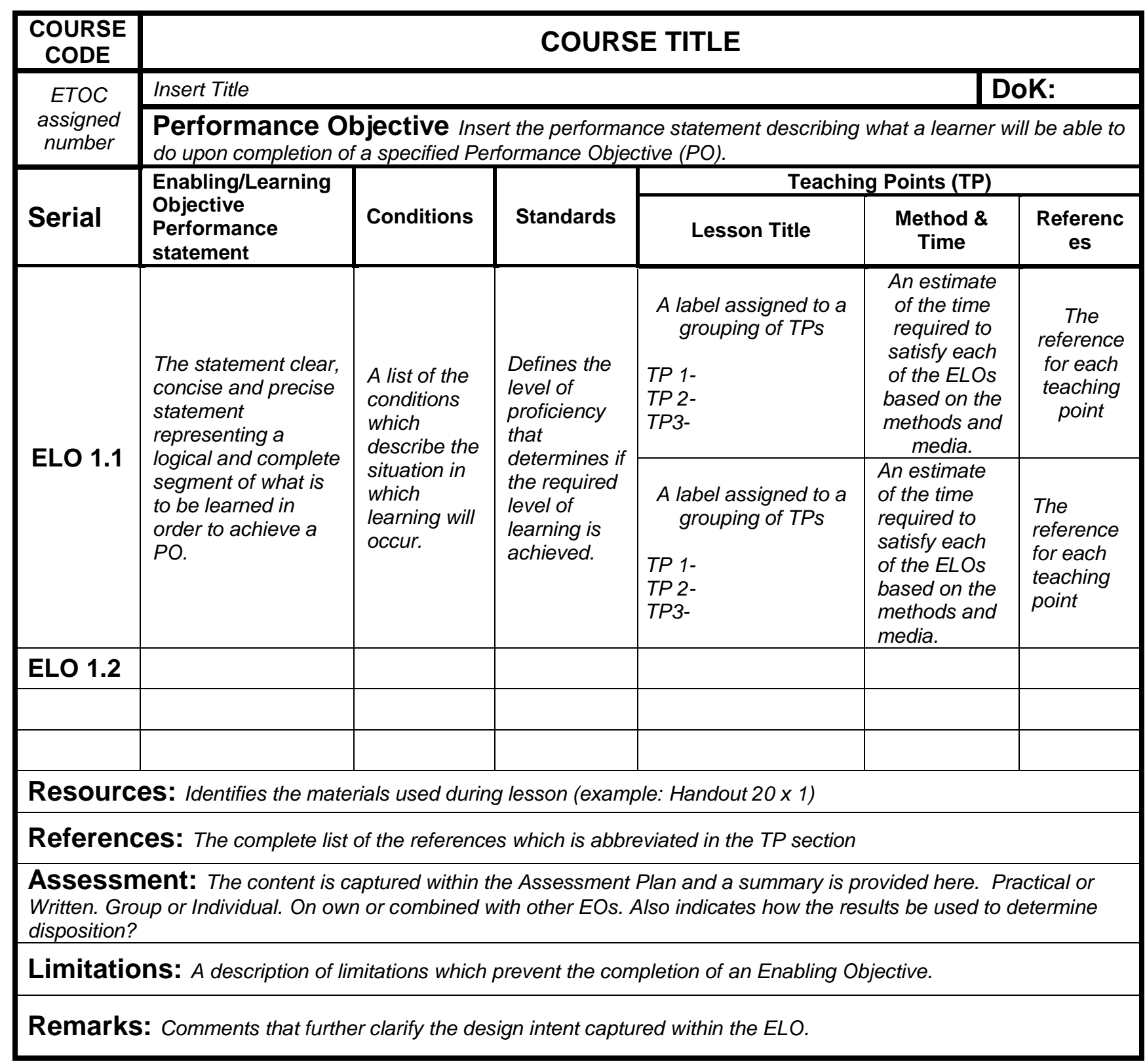


Control Document - III: Programme of Classes

\begin{tabular}{|c|c|c|c|c|c|c|}
\hline \multirow[t]{2}{*}{$\begin{array}{c}\text { COURSE } \\
\text { CODE }\end{array}$} & \multicolumn{6}{|c|}{ COURSE TITLE } \\
\hline & \multicolumn{6}{|c|}{ Performance Objective } \\
\hline \multirow[b]{2}{*}{ Serial } & \multirow{2}{*}{$\begin{array}{l}\text { Enabling/Learning } \\
\text { Objective } \\
\text { Performance } \\
\text { statement } \\
\end{array}$} & \multirow[b]{2}{*}{ Conditions } & \multirow[b]{2}{*}{ Standards } & \multicolumn{3}{|c|}{ Teaching Points (TP) } \\
\hline & & & & Lesson Title & Method \& Time & References \\
\hline \multicolumn{7}{|l|}{ ELO 1.1} \\
\hline \multicolumn{7}{|l|}{ ELO 1.2} \\
\hline \multicolumn{7}{|l|}{ ELO 1.3 } \\
\hline \multicolumn{7}{|l|}{ ELO 1.4} \\
\hline \multicolumn{7}{|c|}{ Resources: } \\
\hline \multicolumn{7}{|c|}{ References: } \\
\hline \multicolumn{7}{|c|}{ Assessment: } \\
\hline \multicolumn{7}{|c|}{ Limitations: } \\
\hline Remarks & & & & & & \\
\hline
\end{tabular}




\section{\begin{tabular}{|l|l|}
\hline \multicolumn{2}{|c|}{ COURSE CONTROL DOCUMENT III - PROGRAMME OF CLASSES } \\
\hline \hline Code: & Title: \\
\hline \hline
\end{tabular}}

PO 1: Insert the performance statement describing what a learner will be able to do upon completion of a specified Performance Objective (PO).

\section{ELO 1.1:}

1. Performance: The statement clear, concise and precise statement representing a logical and complete segment of what is to be learned in order to achieve a PO.

2. Conditions: $A$ list of the conditions which describe the situation in which learning will occur.

3. Standards: Defines the level of proficiency that determines if the required level of learning is achieved.

4. Assessment: The content is captured within the Assessment Plan and a summary is provided here. Practical or Written. Group or Individual. On own or combined with other EOs. Also indicates how the results be used to determine disposition?

\section{Instructional Strategy:}

\begin{tabular}{|c|c|c|c|}
\hline Content & Metho & Time & References \\
\hline $\begin{array}{l}\text { a. Lesson Title: A label assigned the 1st grouping of } \\
\text { teaching points (TPS) }\end{array}$ & $\begin{array}{l}\text { Identify } \\
\text { methods }\end{array}$ & $\begin{array}{c}\text { An } \\
\text { estimate } \\
\text { of the time }\end{array}$ & $\begin{array}{l}\text { Links content to } \\
\quad \text { a source }\end{array}$ \\
\hline TP 1 & & & \\
\hline TP2 & & & \\
\hline TP3 & & & \\
\hline TP4 & & & \\
\hline TP5 & & & \\
\hline $\begin{array}{l}\text { b. Lesson Title: } A \text { label assigned to a } 2^{\text {nd }} \text { grouping of } \\
\text { TPs }\end{array}$ & & & \\
\hline TP 1 & & & \\
\hline TP2 & & & \\
\hline TP3 & & & \\
\hline $\begin{array}{l}\text { C. Lesson Title: } A \text { label assigned to a 3rd grouping of } \\
\text { TPS }\end{array}$ & & & \\
\hline TP 1 & & & \\
\hline TP2 & & & \\
\hline Total Time: & & & \\
\hline
\end{tabular}

6. Depth of Knowledge: Specifies a level (100-500) which identifies the level of learning.

7. Limitations: A description of limitations which prevent the completion of Enabling/Learning Objective.

8. Resources: Comments that further clarify the design intent captured within the Enabling/Learning Objective. 


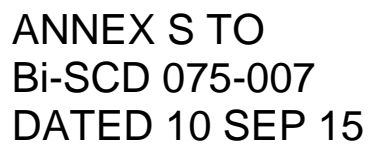

\section{COURSE MONITORING}

Course Monitoring is an additional element supporting the Post Course Review - Internal Evaluation. Course Monitoring concentrates on the delivery of instruction and gathers observation data. The focus is on the performance of individual instructors (Instructional Effectiveness) and assesses many elements that may affect course quality including a confirmation of the alignment of the objectives with what is delivered, appropriateness of the instructional methods, quality of instructional materials, time allocation. Observations for improving student evaluation may also be included. Course Monitoring also provides an opportunity to verify that instructors have the prerequisite qualifications and training is satisfied. An example observation sheet to support Course Monitoring is provided below.

Lesson Observation Checklist

\begin{tabular}{|l|l|l|l|}
\hline Monitor Name & Start Time: & \\
\hline Date of Audit: & End Time: & \\
\hline Course Number: & Instructor/Facilitator: & \\
\hline Lesson Title: & & \\
\hline
\end{tabular}

\begin{tabular}{|l|l|l|l|}
\hline $\begin{array}{l}\text { Supporting Documentation } \\
\text { Lesson Plan for the period of instruction } \\
\text { was available. }\end{array}$ & & & \\
\hline $\begin{array}{l}\text { Written guidance to students for } \\
\text { syndicate work was provided. }\end{array}$ & & & \\
\hline $\begin{array}{l}\text { The lesson title is clearly identified in } \\
\text { Course Critique. }\end{array}$ & & & \\
\hline $\begin{array}{l}\text { The Lesson is clearly identified in the } \\
\text { Course Schedule. }\end{array}$ & & & \\
\hline
\end{tabular}

\begin{tabular}{|c|c|c|c|c|}
\hline Lesson Alignment & Yes & Some & No & N/A \\
\hline \multicolumn{5}{|l|}{ The aim of the Lesson is clearly stated. } \\
\hline \multicolumn{5}{|l|}{$\begin{array}{l}\text { The teaching points presented align with } \\
\text { the LO stated in the CCD III. }\end{array}$} \\
\hline \multicolumn{5}{|l|}{$\begin{array}{l}\text { The references for the lesson are stated } \\
\text { and are consistent with the CCD III. }\end{array}$} \\
\hline \multicolumn{5}{|l|}{$\begin{array}{l}\text { The timing for the lesson is consistent } \\
\text { with the CCD III and the Course Schedule. }\end{array}$} \\
\hline \multicolumn{5}{|l|}{$\begin{array}{l}\text { The syndicate work was aligned with the } \\
\text { objectives outlined in the CCD III. }\end{array}$} \\
\hline \multicolumn{5}{|l|}{$\begin{array}{l}\text { The instructional strategy used was } \\
\text { aligned with the instructional strategy } \\
\text { listed in the CCD III. }\end{array}$} \\
\hline \multicolumn{5}{|l|}{$\begin{array}{l}\text { The DOK was consistent with the level } \\
\text { identified in the CCD III. }\end{array}$} \\
\hline $\begin{array}{l}\text { The assessment strategy is consistent } \\
\text { with the CCD III. }\end{array}$ & & & & \\
\hline
\end{tabular}




\begin{tabular}{|c|c|c|c|c|}
\hline Instructional Effectiveness & Yes & Some & No & N/A \\
\hline $\begin{array}{l}\text { The training facility was adequately } \\
\text { prepared to deliver instruction. }\end{array}$ & & & & \\
\hline $\begin{array}{l}\text { Supporting materials were readily } \\
\text { available. }\end{array}$ & & & & \\
\hline $\begin{array}{l}\text { The facilitator gained and maintained the } \\
\text { attention of the class. }\end{array}$ & & & & \\
\hline $\begin{array}{l}\text { The facilitator established the relevance } \\
\text { of what was being presented to the } \\
\text { students. }\end{array}$ & & & & \\
\hline $\begin{array}{l}\text { The teaching points were presented in a } \\
\text { logical sequence. }\end{array}$ & & & & \\
\hline $\begin{array}{l}\text { The facilitator provided relative verbal } \\
\text { support (examples / explanations / } \\
\text { statistics). }\end{array}$ & & & & \\
\hline $\begin{array}{l}\text { The visual aids used were clear and } \\
\text { supported the teaching points. }\end{array}$ & & & & \\
\hline $\begin{array}{l}\text { Media used during the lesson were of } \\
\text { appropriate number, duration and quality. }\end{array}$ & & & & \\
\hline $\begin{array}{l}\text { The facilitator engaged the students } \\
\text { during the lesson using effective } \\
\text { questioning techniques. }\end{array}$ & & & & \\
\hline $\begin{array}{l}\text { The facilitator emphasized important } \\
\text { points / issues. }\end{array}$ & & & & \\
\hline $\begin{array}{l}\text { The facilitator periodically checked for } \\
\text { student understanding. }\end{array}$ & & & & \\
\hline $\begin{array}{l}\text { The facilitator provided a summary of the } \\
\text { main teaching points at the end of the } \\
\text { lesson. }\end{array}$ & & & & \\
\hline
\end{tabular}

\begin{tabular}{|l|l|l|l|}
\hline $\begin{array}{l}\text { Student Assessment } \\
\text { Assessment details / test Instructions } \\
\text { provided to the student. }\end{array}$ & & & \\
\hline $\begin{array}{l}\text { The assessment is at the proper DOK for } \\
\text { the course. }\end{array}$ & & & \\
\hline $\begin{array}{l}\text { An answer key or assessment checklist } \\
\text { for syndicate presentations is available. }\end{array}$ & & & \\
\hline $\begin{array}{l}\text { The assessment is aligned with the } \\
\text { course lesson objectives and CCD III. }\end{array}$ & & & \\
\hline $\begin{array}{l}\text { The DOK being assessed is consistent } \\
\text { with the LO(s) in the CCD III. }\end{array}$ & & & \\
\hline $\begin{array}{l}\text { The content assessed aligns with the } \\
\text { content presented during the course. }\end{array}$ & & & \\
\hline $\begin{array}{l}\text { Students are provided with the results of } \\
\text { the assessment as well as facilitator } \\
\text { feedback. }\end{array}$ & & & \\
\hline
\end{tabular}

Other Comments and Best Practice Observations 


\section{ANNEX T TO \\ Bi-SCD 075-007 \\ DATED 10 SEP 15}

\section{TEST ITEM ANALYSIS}

1. Through the quantifying of data (systematically assigning numbers to data) statistical analysis can be performed so that relationships and trends can be identified and interpreted. A trend is a pattern or prevailing theme. Trends can reveal strengths and weaknesses within a course. For test items, item analysis is used to quantify data so that test items of questionable quality can be identified as well as indicate areas where individuals have not mastered objective(s). In the case of surveys, observations and other forms feedback the data is quantified and interpreted through descriptive statistics. The use of statistical software applications can make the process of data interpretation an easier task. Data must be interpreted to identify the problems so that recommendations can be made and solutions generated. Item analysis provides information about the reliability and validity of test items. Item analysis can be performed in terms of the following:
a. Test Item Difficulty.
b. Test Item Discrimination.

\section{TEST ITEM DIFFICULTY}

2. The frequency of students answering a test item correctly determines the level of difficulty. For example, if 45 of 50 students answer an item correctly, then the level of difficulty is low (.90) since 90 percent were able to answer correctly. However, if 10 out of 50 students answer correctly, then the level of difficulty is high (.20). The possible range for the Difficulty Index is 0 to 1 ; the closer to 0 the more difficult the item. The difficulty index is the proportion of students who answer a test item correctly and is it calculated in the example below.

Example:
Difficulty Index (p). The proportion of students who answer a test item correctly.
\[ \begin{array}{c}\mathbf{p}=\quad \begin{array}{c}\text { Number of students selecting correct answer } \\ \text { Total number of students attempting the test item }\end{array} \\ \mathbf{p}=\frac{45}{50}=.90\end{array} \]

3. When Difficulty Index or "p" level is less than about .25, the item is considered relatively difficult. When the Difficulty Index is above .75 the item is considered relatively easy. A Difficulty Index above .75 on its own does is not problematic, nor is a result of 1 . Tests should appear to have a low level of difficulty given the intent this indicates higher levels of proficiency. Item difficulty should be considered along with test item discrimination when assessing the effectiveness of a test item. 


\section{TEST ITEM DISCRIMINATION}

4. Test item discrimination is an index of an item's effectiveness at discriminating those who appear to have learned content better from those who have not. It is the degree to which students with high overall scores on a particular test get a test item correct. The item discrimination index is referred to as a point bi-serial correlation coefficient. Its possible range is -1.00 to 1.00 . A strong positive correlation (.3) suggests that students who get any one question correct also have a relatively high score on the overall test. Any positive value is an indication of a positive correlation and this is generally acceptable.

\section{Example:}

Discrimination Index (D). The Measure of the extent to which a test item discriminates or differentiates between students who perform well on the overall test and those who do not perform well on the overall test.

$D=$ Number who got item correct in an upper group - Number with item correct in lower group Total number of students in both groups

$$
\mathrm{D}=\frac{7-3}{20}=.2
$$

Note: D does not require the total population completing a test to be included in the calculation. Depending on the size of the group a representative same is satisfactory. Example: Use $50 \%$ of the total population comprised of the top $25 \%$ and the bottom $25 \%$.

\section{INTERPRETING RESULTS}

5. $\quad$ Test items which consistently result with a higher level of difficulty (e.g., $p=.25$ ) and a corresponding positive discrimination index (e.g., $\mathrm{D}=.25$ ) indicate a quality test item. It is also acceptable to have a low level of difficultly (e.g., $p=.90$ ) and discrimination near zero (meaning no discrimination) and still have a desirable and quality test item. The intent is to determine if the test item itself is measuring what it should. When the level of difficulty is higher (e.g., $p=.25$ ) and there is any negative discrimination (e.g., $p=-.25$ ) the item should be reviewed if there is a trend. If this result is an outlier and occurs during a single application (one course of several), this is an indication there may have been issue with course execution and monitoring of the next event is recommended. 